Aus der Abteilung Mund-, Kiefer- und Gesichtschirurgie

(Prof. Dr.med. Dr.med.dent. H. Schliephake)

im Zentrum Zahn-, Mund- und Kieferheilkunde

der Medizinischen Fakultät der Universität Göttingen

\title{
Vergleich der Dekontaminationswirkung von Dioden- und Er:YAG-Laserlicht sowie chemischen Desinfektionslösungen auf Titanoberflächen mit oralen Biofilmen
}

Eine in-vitro-Studie ex vivo

\author{
Inaugural - Dissertation \\ zur Erlangung des Doktorgrades für Zahnheilkunde \\ der Medizinischen Fakultät \\ der Georg - August - Universität zu Göttingen
}

vorgelegt von

Johanna Katharina Eiffert

aus Göttingen

Göttingen 2011 
Dekan: Prof. Dr. med. C. Frömmel

I Berichterstatterin: Priv.-Doz. Dr.med.dent. S. Sennhenn-Kirchner

II Berichterstatter/in: Prof. Dr. med. Borg-von-Zepelin

III Berichterstatter/in: Prof. Dr. rer. nat. Virsik-Köpp

Tag der mündlichen Prüfung: 23.01.2012 


\section{Inhaltsverzeichnis}

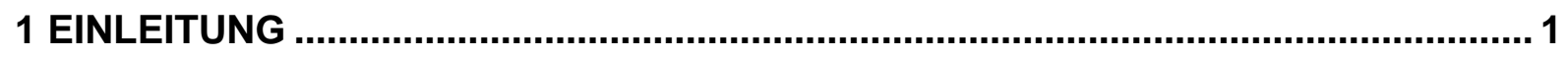

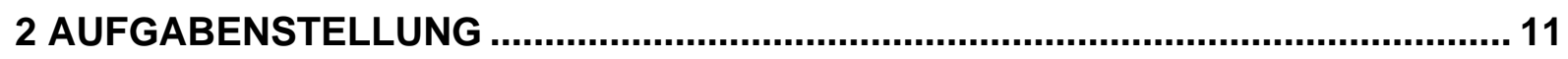

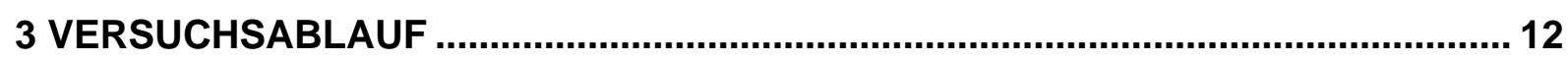

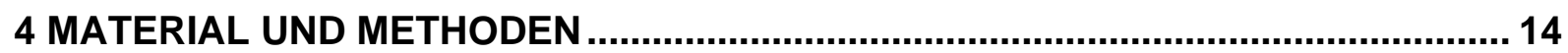

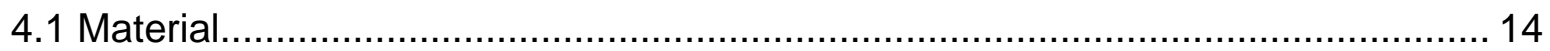

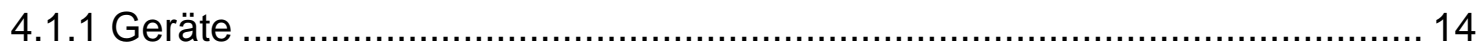

4.1.2 Verbrauchsmaterialien und Zubehör.................................................... 14

4.1.3 Puffer und Nährlösungen ........................................................................ 15

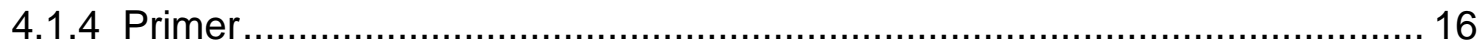

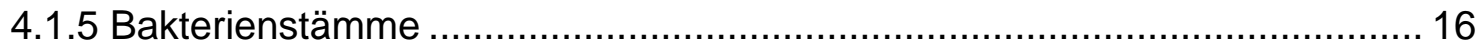

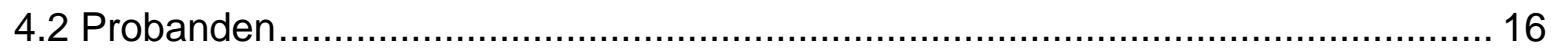

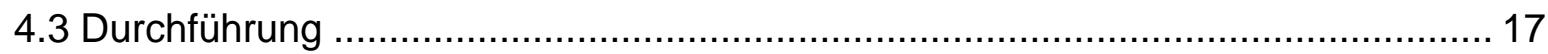

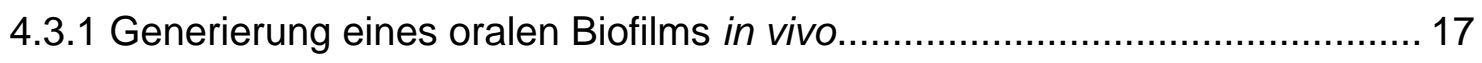

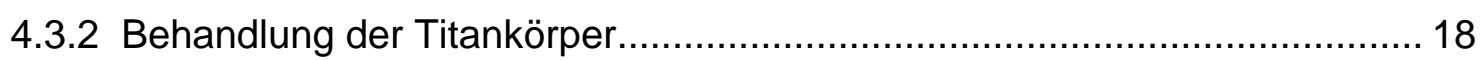

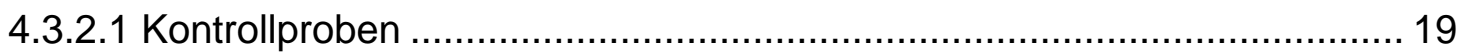

4.3.2.2 Behandlung mit Lasern............................................................... 19

4.3.2.3 Behandlungen mit Spüllösungen................................................... 20

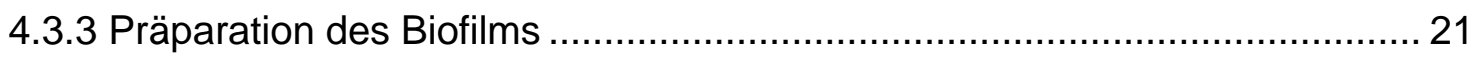

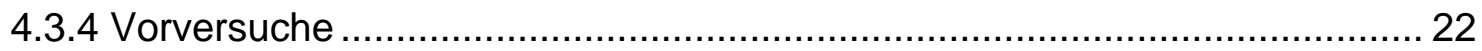

4.3.4.1 Ermittlungen geeigneter Kulturbedingungen und Verdünnungsstufen..... 23

4.3.4.2 Typisierung von drei Bakterienspezies im Biofilm .................................. 23

4.3.4.3 Auswirkungen der Behandlungen auf die bakterielle DNA...................... 23

4.3.5 Mikrobiologisch kulturelle Untersuchung …………............................. 24

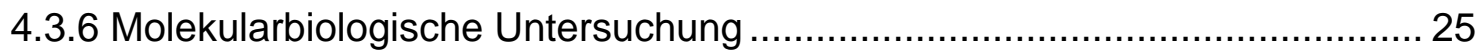

4.3.6.1 Isolierung und Reinigung bakterieller DNA...................................... 26

4.3.6.2 Oligonukleotide und PCR-Durchführung ……….................................. 28

4.3.6.3 Vermeidung von Kontaminationen .................................................... 30

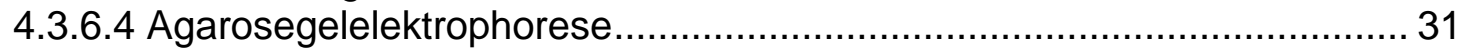

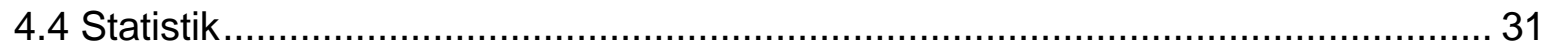

5 ERGEBNISSE

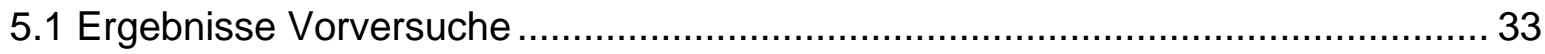

5.1.1 Ermittlung geeigneter Kulturbedingungen und Verdünnungsstufen .............. 33

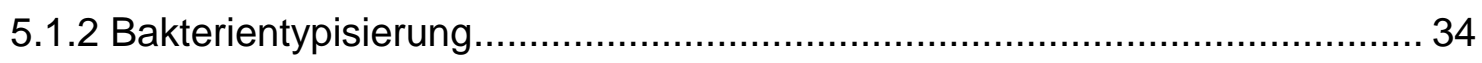

5.1.3 Auswirkungen der Behandlung auf die bakterielle DNA ...............................35 
5.2 Kulturelle Untersuchung nach Behandlung der Titanhülsen............................. 37

5.2.1 Dekontamination mit dem Diodenlaser ............................................... 37

5.2.2 Dekontamination mit dem Erbium:YAG-Laser ...................................... 38

5.2.3 Dekontamination mit Chlorhexidindigluconat........................................ 40

5.2.4 Dekontamination mit Octenidindihydrochlorid/2-Phenoxyethanol ................ 41

5.2.5 Vergleich der Wirksamkeit der Dekontaminationsverfahren auf Grundlage der Kulturergebnisse ......................................................................... 42

5.3 Molekularbiologische Untersuchung nach Behandlung der Titankörper ........... 46

5.3.1 Untersuchung von Fusobacterium nucleatum ....................................... 48

5.3.2 Untersuchung von Eikenella corrodens ................................................ 50

5.3.3 Ergebnisse der Untersuchung von Prevotella intermedia.......................... 53

5.3.4 Vergleich der Resultate unabhängig von der Bakterienspezies ................. 55

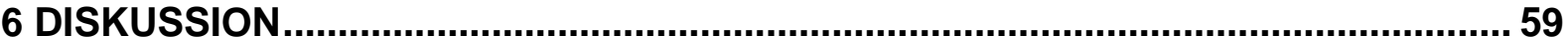

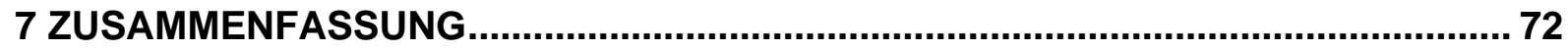

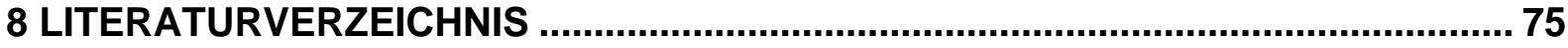




\section{Abkürzungen}

Abb.

Abbildung

Anti

Antikörper

ATCC

Bakterienstammsammlung: (engl.)

American Typeculture Collection

$\mathrm{BHI}$

Nährmedium: (engl.) Brain Heart Infusion

$\mathrm{CHX}$

Chlorhexidin

Cp

$\Delta$

Anstiegspunkt: (engl.) crossing point

DNA

DTT
EDTA
engl.

DTT
EDTA
engl.

Differenz

Desoxyribonukleinsäure: (engl.)

desoxyribonucleic acid

Dithiothreitol

engl.

Ethylendiamintetraacetat

$\mathrm{Er}$

$\lambda$

$\mu$

$\min$

M

$\mathrm{Nd}$

$\mathrm{nm}$

p

PBS

englisch

Erbium

Lambda; Einheit für Wellenlängen

Mikro $\left(10^{-6}\right)$

Minute

molar

Neodym

Nanometer

Piko $\left(10^{-12}\right)$

phosphatgepufferte Kochsalzlösung: (engl.)

phosphate buffered saline

PCR

Polymerase-Kettenreaktion: (engl.) polymerase chain reaction

rpm

Umdrehungszahl: (engl.) rounds per minute

RT

Raumtemperatur

RTF

Transportmedium: (engl.) reduced transport

fluid

sec

Sekunde

Tab.

Tabelle

TBE

Tris/Borat/EDTA 
$\mathrm{Tm}$

UMG

UV

UK

W

$\mathrm{w} / \mathrm{v}$

YAG
Schmelzpunkt: (engl.) Temperature of melting

Universitätsmedizin Göttingen

Ultraviolett

Unterkiefer

Watt

Gewicht pro Volumen

Yttrium-Aluminium-Granat 


\section{Einleitung}

\section{Zahnärztliche Implantologie}

Implantate nehmen in der prothetischen Zahnheilkunde bei der Versorgung von Einzelzahnlücken, teilbezahnten oder zahnlosen Kiefern einen immer größeren Raum ein und Implantationen können mittlerweile in vielen Zahnkliniken und in spezialisierten Praxen als Routineeingriff bezeichnet werden. Die ständige Weiterentwicklung der eingesetzten Materialien und der zahnärztlichen Techniken führen zu einer zunehmenden Verweildauer der Implantate im Kiefer (Berglundh et al. 2002). Die Lebensdauer eines Implantats hängt von einer Vielzahl von Faktoren ab.

Postimplantologische pathologische Befunde an Implantaten werden abhängig vom Zeitpunkt des Auftretens und abhängig von der Ursache mit den Begriffen früh/spät und als nicht-infektiös/infektiös charakterisiert (Leonhardt et al. 1999).

Implantatlockerungen und Verluste treten vor allem direkt in der Einheilphase auf (Hultin et al. 2002). Die Einheilung kann durch reduzierte Qualität des Knochenlagers, intraoperative bakterielle Kontamination, systemische Erkrankungen und Medikamente sowie durch andere begleitende Entzündungsreaktionen gefährdet werden.

Die Lebensdauer für bereits osseointegrierte Implantate kann durch okklusale Überlastung und/oder Plaque-induzierte periimplantäre Infektionen kompromittiert werden (Quirynen et al. 2002a). Über einen Zeitraum von fünf Jahren kommt es bei bis zu 14\% der Patienten zu einem Implantatverlust, der auf eine Periimplantitis zurückgeführt wird (Leonhardt et al. 2002, Leonhardt et al. 2003, Norowski und Bumgardner 2009). Hier wirken sich vorbestehende Parodontitis, Vorerkrankungen wie Diabetes, Gewohnheiten des Patienten wie mangelhafte Mundhygiene und Rauchen, aber auch Stress nachteilig aus (Genco et al. 1998, Leonhardt et al. 2003).

\section{Periimplantäre Infektionen}

Der Fachbegriff „Periimplantitis“ wurde in den 80er Jahren eingeführt, um einen destruktiven entzündlichen Prozess zu beschreiben, der Weich- und Hartgewebe um osseointegrierte Implantate einbezieht und periimplantär zu Taschenbildung und Knochenverlust führt (Mombelli 2002) .

Wie die Gingivitis als erste Entzündungsreaktion der Weichgewebe und die Parodontitis als destruktiver Abbauprozess des Zahnhalteapparates und des parodontalen Knochens definiert wird, entsteht um Implantate die Mukositis, die ohne Behandlung zu einer Periimplantitis führt, welche immer mit einem periimplantären Knochenverlust 
vergesellschaftet ist (Lang et al. 2000). Kausal verantwortlich für eine Periimplantits sind Mikroorganismen der Mundhöhle. Sie lagern sich auf dem Weichgewebe um den Hals des Zahnimplantates ab und können in die Implantat-Abutment Verbindung eindringen. Besiedeln parodontopathogene Keime die Implantatoberfläche ungestört für längere Zeit, können ihre Bestandteile und Stoffwechselprodukte eine Entzündung des periimplantären Gewebes auslösen, die sich dann nach apikal ausbreiten kann (Sanchez-Garces und Gay-Escoda 2004).

Eine positive Korrelation zwischen guter Mundhygiene und langer Haltbarkeit von Implantaten wurde beschrieben (Lindquist et al. 1996). In diesem Kontext findet man eine klare Assoziation zwischen einer Biofilmbildung auf der Implantatoberfläche und begleitender Entzündung im periimplantären Weichgewebe (Hultin et al. 2002, Shibli et al. 2003).

Untersuchungen haben gezeigt, dass auf den Titanoberflächen die gleichen Bakterienspezies gefunden werden wie in den Plaques benachbarter natürlicher Zähne (Quirynen et al 2002b, De Boever AL und De Boever JA 2006), und dass Mikroorganismen, die für die chronische Parodontitis verantwortlich gemacht werden, auch bei Periimplantitis nachzuweisen sind (Mombelli 2002).

Für eine ungenügende ossäre Integration nach einem Zeitraum von länger als einem Jahr wird als Hauptursache eine Periimplantitis angeschuldigt (Hultin et al. 2002). In Metaanalysen findet sich in bis zu 50\% eine Periimplantitis als Ursache. Angaben über die Häufigkeit einer Implantat begleitenden Mukositis in der Literatur variieren deutlich zwischen 1-44\% (Leonhardt et al. 1999, Roos-Jansaker et al. 2006). Diese weite Spanne wird durch uneinheitliche Definitionen und Bedingungen in den einzelnen Studien erklärt.

\section{Bedeutung des Biofilms}

Ein oraler Biofilm entsteht auf der Grundlage eines ca. 0,1-1 $\mu$ messenden Pellikels, das sich auch bei guter Mundhygiene innerhalb kurzer Zeit auf der gereinigten Zahnoberfläche ablagert. Es besteht aus einer unstrukturierten Ansammlung von Proteinen, Lipiden, Speichel und Sulkusflüssigkeit (Hellwig et al. 1999). Wird eine Implantatoberfläche aus Titan dem intraoralen Milieu ausgesetzt, wird diese ebenso von dieser Schicht überzogen (Mombelli und Decaillet 2011).

An das semipermeable Pellikel lagern sich selektiv Mikroorganismen des Speichels an. Die Adhäsion erfolgt hierbei durch van-der-Waals-Kräfte, elektrostatische Kräfte, aber auch durch spezifische Bindungsmoleküle, die sogenannten Adhäsine. Wird die Plaqueschicht nicht entfernt, nimmt ihr Durchmesser in der Folge durch Zellteilung und 
Akkumulation weiterer Keime aus dem Speichel zu. Der Biofilm, der sich zunächst flächig ausgebreitet hat, wächst dreidimensional.

Die zahlreichen Bakterien, die zunächst aus der oralen Standortflora stammen, sind in einer schleimigen extrazellulären Matrix aus Wasser und polymeren Molekülen eingeschlossen, die von den Bakterien ausgeschieden werden (Kolenbrander 2000, Marsh 2004). Die verbindenden Strukturen sind bakteriellen Ursprungs, z.B. Exopolysaccharide wie Glucosamin, oder wirtsspezifisch, z.B. Fibronektin oder Albumin. Wird der Biofilm nicht entfernt, reift er und die Bakterienarten verändern sich. Sind zunächst als Erstbesiedler vor allem gram-positive, aerobe Kokken und Aktinomyzeten anzutreffen (Hellwig et al. 1999, Shibli et al. 2003, Li et al. 2004), entstehen durch das Wachstum des Biofilms im Laufe der Zeit jedoch immer mehr sauerstoffarme Nischen. In diesen kommt es im weiteren Verlauf vermehrt zur Anlagerung gram-negativer, fakultativ und strikt anaerober Bakterien, welche nach etwa neun Tagen überwiegen Durch den Biofilm sind die Bakterien nun vor äußeren Einflüssen, wie der Antwort des Immunsystems, Temperatur und pH-Wert-Schwankungen sowie vor Bakteriziden stärker geschützt als im planktonischen Zustand (Kolenbrander 2000).

Bisher wurden mehr als 500 Bakterienarten in oralen Biofilmen nachgewiesen. Die Zahl wird sich durch den Einsatz moderner molekularbiologischer Methoden, die auf Gensequenzen fokussieren, noch weiter erhöhen, da viele Mikroorganismen nicht mit konventionellen Methoden kultiviert werden können. Auf harten Oberflächen liegen in der Matrix mehrere Bakterienschichten übereinander und können eine Dicke von mehreren 100 Mikrometern erreichen. Im Gegensatz dazu findet man auf gesundem Weichgewebe in der Regel nur eine einfache bakterielle Zellschicht (Kolenbrander 2000, Kolenbrander et al. 2010).

Die Zusammensetzung der Bakterienpopulation im Biofilm ist uneinheitlich. Die Einflussgrößen sind sehr komplex und u.a. abhängig von individuellen Patientenparametern und der intraoralen Lokalisation.

Es besteht eine metabolische Kooperation, da selbst strikt anaerob wachsende Mikroorganismen sich neben aeroben oder fakultativ anaeroben Bakterien behaupten können, die den lokalen Sauerstoff verbrauchen (Bradshaw et al. 1996, Bradshaw et al. 1998).

Es ist sogar so, dass für eine solche Besiedlung mit Anaerobiern immer die vorherige Besiedlung mit Kokken obligat ist, da die einen ohne die anderen nicht überleben können (Bradshaw et al. 1996). 
Aktuelle Untersuchungen verdeutlichen zunehmend die Bildung funktioneller Gemeinschaften von Mikroorganismen, die mit entsprechenden klinischen Bildern assoziiert sind (Socransky et al. 1998). Mit Parodontitis werden z.B. Treponema denticola, Eikenella corrodens, Porphyromonas gingivalis, Bacterioides forsythus, Fusobakterien und Peptostreptokokken in Verbindung gebracht, während Veillonella parvula, Actinomyces odontolyticus, Streptococcus intermedius, Streptococcus sanguis eher bei Gesunden nachgewiesen werden (Socransky et al. 1998). Das Verständnis zur Wechselwirkung bzw. der Kommunikation zwischen verschiedenen Mikroorganismen im Verbund mit Wirtsfaktoren ist Gegenstand der aktuellen Forschung (Papapanou et al. 2009, Kolenbrander et al. 2010). Es wird davon ausgegangen, dass sie durch ein primitives Kommunikationssystem, auch „quorum sensing“ genannt, genetische Informationen austauschen können, da sich Bakterien im Biofilm in ihrem Phänotyp und ihrem genetischen Expressionsmuster von den speziesidentischen Mikroorganismen außerhalb des Verbundes unterscheiden (Marsh 2004).

Die Pathogenese der Entzündungsreaktion, die letztlich zum Implantatverlust führen kann, wird durch mikrobielle Faktoren, in deren Folge es zu Interaktionen des Abwehrsystems und anderen Zellen des Wirtes kommt, ergänzt. Das Zusammenspiel von direkter Wirkung des Mikroorganismus, der Abwehrreaktion und ggf. daraus resultierenden schädlichen Folgen z.B. durch verstärkte Aktivierung von T-Zellen mit einer überschießenden Sekretion von Entzündungsmediatoren ist entscheidend für den Verlauf der Inflammation (Shetty 2006). Neutrophile Granulozyten gehören zu den effizientesten Abwehrzellen gegenüber bakteriellen Infektionen, gleichzeitig können sie durch Bildung von Sauerstoffradikalen oder von proteolytischen Enzymen für Gewebeschädigungen verantwortlich sein (Gustafsson und Asman 1996).

Das Verständnis der komplexen Vorgänge ist durch neue molekularbiologische Techniken deutlich verbessert worden. So wurde kürzlich durch RNA-Untersuchungen mit sog. Microarray-Methoden gezeigt, dass die Genexpression im humanen gingivalen Gewebe von der Kolonisation definierter Bakterien (Papapanou et al. 2009) abhängt.

Die Empfindlichkeit gegenüber antimikrobiellen Substanzen ist im Biofilm reduziert (Norowski und Bumgardner 2009). Als Ursachen werden herabgesetzte Teilungsraten der Mikroorganismen und geringere Antibiotikakonzentrationen am Wirkort durch Inaktivierung der Substanzen und schlechtere Penetration beschrieben (Gilbert et al. 1997, Stewart 2002). In dem Zusammenhang scheint auch das Alter des Biofilms eine Rolle zu spielen. So ist die minimale Hemmkonzentration von Chlorhexidindigluconat gegenüber Streptococcus sanguis in $72 \mathrm{~h}$ alten Plaques signifikant höher als in $24 \mathrm{~h}$ alten 
(Millward und Wilson 1989). Studien haben außerdem gezeigt, dass für die Abtötung von Bakterien in Biofilmen eine Überdosierung notwendig ist (Wilson 1996, Socransky und Haffajee 2002)

Die Erkenntnisse zur Bildung von Biofilmen auf dentalen Implantaten und deren pathogenetische Auswirkungen belegen die Bedeutung für die Entstehung einer Mukositis oder Periimplantitis bis hin zum Implantatverlust (Riley et al. 2005, RoosJansaker et al. 2006).

Biofilmkontrolle

Für die klinische Praxis folgt somit, dass eine Biofilmbildung auf dem Implantat möglichst eingeschränkt werden sollte. Hat sich bereits ein Biofilm auf einer Implantatoberfläche etabliert, sollte diese dekontaminiert werden (Sbordone und Bortolaia 2003).

Die Eradikation der pathogenen Mikroorganismen von der Implantatoberfläche, die meist aus Titan besteht, gilt damit zweifellos als erfolgversprechendste Maßnahme zur Prophylaxe oder Therapie der Periimplantitis (Mombelli und Lang 1998, Leonhardt et al. 1999, Riley et al. 2005).

Es bieten sich verschiedene Verfahren an, die auch die besonderen Eigenschaften von Titan berücksichtigen. Titan hat sich aufgrund seiner hervorragenden Biokompatibilität als Implantatmaterial bewährt. Die Oberfläche wird im Herstellungsprozess angeraut und bildet mit Sauerstoff eine Oxidschicht, wodurch eine bessere Osseointegration, aber auch eine Plaqueakkumulation begünstigt wird (Quirynen et al. 1996). Das Material ist damit aber auch besonders inert und wird auch durch bakterizide Lösungen nicht angegriffen. Damit bieten sich Desinfektionsmittel zur Dekontamination an.

Desinfektionslösungen mit Inhaltstoffen wie Zitronensäure, Chlorhexidindigluconat, Tetracyclinhydrochlorid, Wasserstoffperoxid, Zinnfluorid werden schon länger beschrieben und eingesetzt (Mombelli 2002).

Des Weiteren weist Titan eine geringere Härte als Edelstahl auf, aus dem die meisten Reinigungsinstrumente gefertigt werden. Diese können somit die Oberfläche beschädigen. Speziell gefertigte nichtmetallische Instrumente wie Küretten und Ultraschallspitzen sind jedoch zu schwach und ineffizient, um Ablagerungen zu entfernen (Matsuyama et al. 2003). Air-flow-Geräte bergen zusätzlich zur Veränderung der Implantatoberfläche das Risiko der Emphysembildung (Augthun et al. 1998). Neben konventionellen Therapiemethoden wie der chemischen oder mechanischen Desinfektion kommen heute auch verschiedene Bestrahlungs- und Lasersysteme (s. nächstes Kapitel) zum Einsatz (Schwarz et al. 2004). 
Die Eigenschaft der Titandioxid-Oberfläche, unter milder UV-Bestrahlung Sauerstoff- und Hydroxy-Radikale zu bilden, die dann zur Abtötung der besiedelnden Bakterien führen, ist eine Möglichkeit zur Keimreduktion, die sich in der Erprobung befindet (Riley et al. 2005). Ein ähnlicher Effekt wird photochemisch erzeugt, wenn unter dem Einfluss von Laserlicht mit geeigneten Farbstoffen z.B. Toluidin-Blau in Kombination mit einer Wellenlänge von $633 \mathrm{~nm}$ Sauerstoffradikale mit bakterizider Wirkung gebildet werden (Dortbudak et al. 2001).

Laser in der Periimplantitistherapie

Anders als andere Lichtquellen emittiert der Laser kohärente, monochromatische elektromagnetische Strahlung. Studien haben gezeigt, dass nur $\mathrm{CO}_{2^{-}}$, Dioden- und Erbium:YAG-Laser für die Behandlung von Implantatoberflächen geeignet sind. Der ebenfalls in der Literatur beschriebene Nd:YAG-Laser kann die Oberfläche schädigen, sie zum Schmelzen bringen und sollte deswegen nicht zur Periimplantitistherapie verwendet werden (Park et al. 2005). Die klinisch einsetzbaren Laser emittieren Licht mit Wellenlängen im mittleren und oberen infraroten Bereich, wie der Diodenlaser $(\lambda=810$ $960 \mathrm{~nm})$, der ER:YAG-Laser $(\lambda=2940 \mathrm{~nm})$ sowie der $\mathrm{CO}_{2}$-Laser $(\lambda=10600 \mathrm{~nm}$ und 9600 $\mathrm{nm})$.

Bei Lasern mit Wellenlängen im infraroten Bereich wird im Gewebe das Licht in thermische Energie umgewandelt. Das führt zur Denaturierung von Proteinen, zum Abbau von Gewebe und Mikroexplosionen von Zellwasser. Hierbei bestimmen vor allem die optischen Eigenschaften, die Wärmeleitfähigkeit und die Wärmespeicherung der Materie die Temperaturerhöhung und die Tiefenwirkung im Gewebe. Ein Laser kann so je nach Wellenlänge, Energiedichte, Oberflächenbeschaffenheit der Zielsubstanz und Handhabung schneiden, verdampfen oder koagulieren (Deppe und Horch 2007).

Die Verwendung von Lasern zur Weichgewebsbehandlung begann 1980 mit dem $\mathrm{CO}_{2-}$ Laser. Er hat eine Wellenlänge von 10600 nm. Da in diesem Bereich keine spezifischen Chromophore vorhanden sind, ist die Wasserabsorption der entscheidende Parameter. Seine Wirkung wird durch ein Verdampfen des biologischen Gewebes auf rein thermischer Basis erreicht (Schwarz und Becker 2003). Er entfernt Weichgewebe gut, sollte jedoch nicht zur Hartgewebsbearbeitung genutzt werden, da er hohe Temperaturen erzeugt, die zu Schäden von Knochen und Wurzeloberfläche führen können (Aoki et al. 2008).

Die besondere Arbeitswellenlänge des Erbium:Yttrium-Aluminium-Garnet-Lasers (Er:YAG-Laser) von 2940 nm stimmt mit der maximalen Absorption im Wasser überein (Walsh et al. 1989, Walsh und Cummings 1994, Araki et al. 2006). Die Wirkung dieses 
Lasers beruht auf einem speziellen thermomechanischen bzw. photomechanischen Entfernungsprozess ohne Erhitzung des unterliegenden Gewebes, also ohne Schädigung von Schmelz, Dentin oder Pulpa (Aoki et al. 2008). Der Abtrag (Ablation) entsteht dadurch, dass der Anteil des im Gewebe enthaltenen Wassers einen sprunghaften Übergang vom flüssigen in den gasförmigen Aggregatzustand erfährt. Begleitet durch die schnelle Explosion des intrazellulären Wassers, durch die Bakterien augenblicklich abgetötet werden, entsteht kurzzeitig ein Druck, um Gewebesubstanz in gewünschter Weise abzutragen (Keller und Hibst 1989). Er kann sowohl Weichgewebe, Plaque als auch mineralisierte Auflagerungen auf Zahn- und Implantatoberflächen effektiv entfernen, ohne diese zu beschädigen (Matsuyama et al. 2003, Kreisler et al. 2005).

Eine signifikante Schädigung von gesundem Gewebe oder der Titan-Oberfläche des Implantats wurde nicht beschrieben. In einer aktuellen vergleichenden Studie mit einem Diodenlaser und einem Er:YAG-Laser, die in einem in-vitro-Biofilmmodell auf Candia albicans einwirkten, erwies sich der Er:YAG-Laser als wirksamer (Sennhenn-Kirchner et al. 2009b).

Die Wellenlänge des Erbium:Yag-Lasers wird ebenso im Wellenlängenbereich des Hydroxylapatits absorbiert. Dadurch kann er nicht nur zur Desinfektion, sondern auch zur Kavitätenpräparation und Kariesentfernung genutzt werden (Sulewski 2000).

Eine antimikrobielle Wirkung lässt sich ebenfalls unter dem Einsatz von Diodenlasern beobachten (Sennhenn-Kirchner et al. 2002, Sennhenn-Kirchner et al. 2007b, Sennhenn-Kirchner et al. 2009b,). Diodenlaser arbeiten im Dauerstrich- oder gepulsten Modus und sind sehr effektiv zur Inzision, Koagulation und Hämostase. Durch ihre Wellenlänge von 810 oder $980 \mathrm{~nm}$ ist ihre Penetration in das Gewebe relativ hoch (2-3 $\mathrm{mm})$. Sie absorbieren leicht in Pigmenten, im Hämoglobin und im Wasser. Die Dekontaminierung erfolgt über einen photothermischen Effekt, der u.a. bakterielle Proteine denaturiert (Deppe et al. 2001, Sennhenn-Kirchner et al. 2002, Kreisler et al. 2003). In in-vitro-Studien, aber auch in einer Untersuchung mit in vivo gebildeten Biofilmen erscheint dieser Ansatz vielversprechend (Sennhenn-Kirchner et al. 2007b). Diodenlaserlicht bewirkt auch bei hoher Energiedichte keine Veränderung der Titanoberfläche und ist so zur Periimplantitistherapie geeignet (Romanos et al. 2000). Ein Problem ergibt sich allerdings dadurch, dass durch das Licht an der Spitze der Glasfaser des Diodenlasers eine Temperatur von mehr als $500^{\circ} \mathrm{C}$ entstehen kann, deren direkter Kontakt mit Gewebe vermieden werden muss (Aoki et al. 2008). Zur Dekontamination von Implantat- und Wurzeloberflächen sollten Leistungen von 1,5 Watt 
nicht überschritten werden, um thermische Schäden des umliegenden Gewebes zu vermeiden (Bach et al. 1998).

Durch die dünnen Arbeitsenden beider Laser ist eine Behandlung parodontaler oder periimplantärer Taschen ohne chirurgische Intervention möglich.

Antiseptische Spüllösungen in der Periimplantitistherapie

Wenn mechanische Biofilmentfernung nicht möglich ist oder unterstützt werden soll, ist die chemische Desinfektion die Methode der Wahl. Nach einer Studie sind die Lösungen Octenisept $^{\circledR}$, Olaflour, $\mathrm{CHX}$ und $\mathrm{NaCl}$ in abnehmender Reihenfolge wirksam (Decker et al. 2003). Zitronensäure (20\%ig) erreichte ähnlich gute Ergebnisse wie Octenisept ${ }^{\circledR}$, sowohl in einem Modell mit Bakteriensuspensionen (Sennhenn-Kirchner et al. 2004) als auch auf einem zehn Tage alten Biofilm (Sennhenn-Kirchner et al. 2009a).

Das am besten untersuchte Antiseptikum in der Zahnmedizin ist Chlorhexidin (CHX). Da es in Wasser schlecht löslich ist, wird es für den Gebrauch als Spüllösung als Chlorhexidindiglukonat verwendet. Chlorhexidindigluconat unterstützt die Prävention oraler Entzündungen und führt zur Hemmung der Plaqueentwicklung. Es ist ein kationisches Biozid mit niedriger Toxizität und mit einem breiten Spektrum an antibakterieller Aktivität. Der primäre Mechanismus ist die Zerstörung der Zellmembran der Bakterien. Die Spüllösung führt konzentrationsabhängig zu einer Wachstumshemmung oder zum Zelltod. Weitere Wechselwirkungen führen zur Hemmung von proteolytischen und glykosidischen Enzymen. Die kationische Ladung ermöglicht $\mathrm{CHX}$ die Bindung an Zahnoberflächen und orale Mukosa und verhindert so die Pellikelbildung durch kontinuierliche Abgabe des Wirkstoffes (McBain et al. 2003, Moore et al. 2008). Die bakterizide Aktivität betrifft vor allem aerobe und anaerobe grampositive und -negative Bakterien sowie umhüllte Viren.

Chlorhexidingluconat-Spülung führt zu einer signifikanten Abnahme von anaeroben und aeroben/fakultativ anaeroben Bakterien, wobei eine geringere Reduktion bei gramnegativen Anaerobiern festgestellt wurde. $\mathrm{CHX}$ führt zu einer Abnahme der mikrobiellen Vielfältigkeit, und kann so selektiv das Gleichgewicht stören, indem es symbiotisch zusammenlebende Bakterien abtötet (Decker et al. 2003).

Insbesondere sind Actinomyces naes/undii, Veillonella dispar, Prevotella nigrescens, und Streptokokken sensibel auf CHX, während Lactobacillus rhamnosus, Fusobacterium nucleatum und Neisseria subflava am unempfindlichsten reagieren (McBain et al. 2003). Die ebenfalls kommerziell erhältliche Octeniseptlösung ${ }^{\circledR}(0,1 \%$ Octenidindihydrochlorid/ 2-Phenoxyethanol) wird als Desinfektionsmittel für Haut und Schleimhaut vor 
medizinischen und zahnmedizinischen Untersuchungen und chirurgischen Eingriffen verwendet.

Octenidindihydrochlorid ist ein Bispyridinamin aus der Substanzklasse der

Bisbiguanide. Hierzu gehört auch das Chlorhexidindigluconat (Hübner et al. 2010). Diese Stoffe sind kationenaktive Lipide. Im Falle des Octenidindihydrochlorids stellt das Pyridinamin den kationischen Teil der Verbindung dar. Als kationenaktive Substanz wirkt Octenidindihydrochlorid an der Zellmembran und führt somit zur Zerstörung der Zellfunktion (Bailey et al. 1984). Das Phenoxyethanol als Derivat des Ethanols hat eine ergänzende, synergistische Wirkung. Die weiteren Bestandteile von Octenisept ${ }^{\circledR}$ dienen zur pH-Einstellung, Feuchthaltung des desinfizierten Areals und sorgen für eine gleichmäßige Verteilung auf der Schleimhaut bzw. Haut.

Die Lösung ist sowohl gegen gram-positive und gram-negative Bakterien, als auch gegen Hefen, Dermatophyten und lipophile Viren wirksam (Harke 1989). Sogar gegen Chlamydien und Mykoplasmen sowie Methicillin-resistente Staphylokokken (MRSA) zeigt es eine hohe Wirksamkeit (Buehlmann et al. 2008).

Die Verträglichkeit wird als gut beschrieben (Sennhenn-Kirchner et al. 2004, Tietz et al. 2005, Dettenkofer et al. 2010), wobei es einen aktuellen Hinweis auf die Gefahr der Ödembildung und Gewebeschädigung bei unsachgemäßem Gebrauch, wie Einbringen der Lösung in weiches Gewebe unter starkem Druck, gibt (Eigenbrod und Frosch 2010).

\section{Polymerase-Kettenreaktion (PCR)}

Die Polymerase-Kettenreaktion (Polymerase Chain Reaction, PCR) ist eine molekularbiologische Methode zur in-vitro-Vermehrung ("Amplifikation") definierter DNA mit Hilfe des Enzyms DNA-Polymerase. Sie erlaubt den schnellen, empfindlichen Direktnachweis von DNA oder RNA. Ihr Einsatz hat innerhalb der letzten 15 Jahre fast alle Bereiche der Wissenschaft und Medizin, einschließlich die forensische Medizin, pränatale Diagnostik genbedingter Erkrankungen, Gewebetypisierung für Organtransplantation, Onkologie, Paläontologie und nicht zuletzt die mikrobiologische Diagnostik revolutioniert (Sachse 2003).

In der zahnärztlichen Praxis wird die PCR bisher im Rahmen der Keimspektrenbestimmung bei Entzündungsreaktionen und zur Verlaufskontrolle nach antibiotischer Therapie der Entzündung genutzt. Darüber hinaus wird diese molekularbiologische Methode zur Typisierung von Bakterien in oralen Biofilmen erfolgreich eingesetzt (Abiko et al. 2010, Wolff et al. 2010).

Mit der PCR wird ein spezifischer DNA-Abschnitt, d.h. ein direkter Bestandteil eines Mikroorganismus nachgewiesen. Das Verfahren ist hochsensitiv, denn theoretisch kann 
ein einziges DNA-Molekül (bzw. ein Krankheitserreger) nachgewiesen werden. Praktisch weist die PCR ca. 10-100 Krankheitserreger/ml nach. Eine hohe Spezifität wird durch die Nukleotidsequenz der ausgewählten Primer erreicht. Das Verfahren unterscheidet, im Gegensatz zur kulturellen Vermehrung, nicht zwischen vermehrungsfähigen und abgetöteten Mikroorganismen, bei denen die DNA noch amplifizierbar bleibt (Josephson et al. 1993).

Ergebnisse über PCR-Analysen nach Dekontaminationsbehandlungen von in vivo hergestellten und ex vivo gewonnenen Biofilmen sind in der Literatur kaum zu finden. 


\section{Aufgabenstellung}

Der Eliminierung von Mikroorganismen in einem Biofilm auf dentalen Implantatoberflächen kommt eine Schlüsselrolle bei Prophylaxe und Therapie einer Periimplantitis zu. Auf der Suche nach einem optimalen Dekontaminationsverfahren werden in der vorliegenden Arbeit verschiedene Methoden auf ihre Effizienz untersucht und miteinander verglichen. Die Wirkung der Behandlungen wird anhand ihres bakteriziden Effekts und über die Beseitigung der abgetöteten Bakterien beurteilt. Ein großer Wert bei den Dekontaminationsversuchen wird auf Bedingungen gelegt, die die klinische Behandlungssituation simulieren. Im Einzelnen werden dazu folgende Teilaufgaben bearbeitet:

a. Herstellung eines oralen Biofilms in vivo auf einer Titanoberfläche

b. Behandlung des Biofilms mit zwei verschiedenen Laser-Verfahren und zwei chemischen Desinfektionslösungen in einem Phantomkopf

c. Ermittlung des bakteriziden Effekts mit Hilfe mikrobiologisch-kultureller Methoden

d. Ermittlung des Eliminierungseffekts auf den Biofilm durch Einsatz der Polymerase-Kettenreaktion

e. Vergleich und Bewertung der Versuchsergebnisse. 


\section{Versuchsablauf}

Der Versuchsablauf gliedert sich in die in-vivo-Herstellung eines zehn Tage alten oralen Biofilms auf einer geeigneten Titanoberfläche und dessen mikrobiologische und molekularbiologische Charakterisierung. Die in-vivo-Darstellung des Biofilms erfolgte in Anlehnung an das Verfahren von Sennhenn-Kirchner et al. (2007b und 2009a). Bei allen 20 freiwilligen Probanden wurde eine individuelle Tiefziehschiene für den Unterkiefer angepasst, in die sechs offene Titanröhrchen eingeschlossen waren (Abb. 2). Anwendung finden diese Titanbohrhülsen sonst als Messelemente in der präimplantologischen Diagnostik und als Bohrführungshilfen in der Implantologie. Die Schienen wurden für zehn Tage getragen und lediglich kurzzeitig zur Nahrungsaufnahme entnommen. Nach Reifung des Biofilms über den definierten Zeitraum folgte die randomisierte Bearbeitung des Biofilms mit vier verschiedenen Methoden zur Dekontamination. Dabei kamen zwei lasergestützte Verfahren und zwei Desinfektionslösungen zum Einsatz.

Die Beurteilung der Dekontaminationswirkung erfolgt über kulturelle Vermehrung und eine Quantifizierung der Bakterien des präparierten Biofilms ohne und nach dekontaminierenden Behandlungen.

Die semiquantitative Polymerase-Kettenreaktion für Zielsequenzen von in Vorversuchen definierten oralen Bakterien wurde genutzt, um darüber hinaus eine Aussage über den Zustand des Biofilms nach den Behandlungen zu ermöglichen.

Eine Übersicht über die durchgeführten Experimente, deren Ergebnisse im Folgenden gezeigt werden, ist in Abb. 1 dargestellt. 
Individuelle Unterkieferschienen-Herstellung mit jeweils 6 bukkalen Titanbohrhülsen in definierter Probandengruppe $(\mathrm{N}=20)$

In-vivo-Generierung eines individuellen Biofilms während einer Schienentragedauer von 10 Tagen
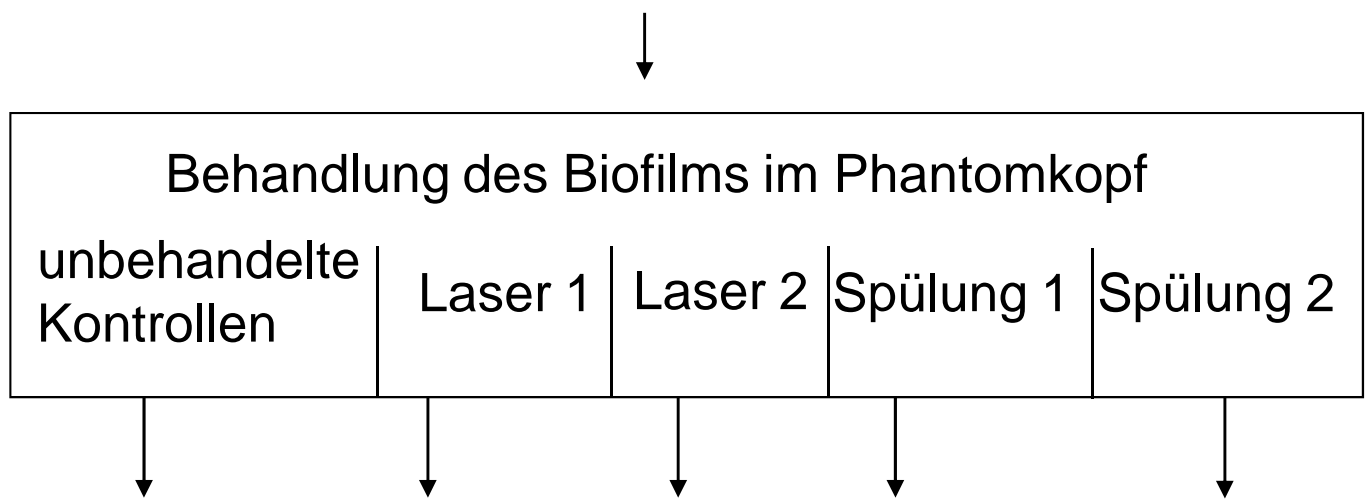

Gewinnung des individuellen Biofilmmaterials

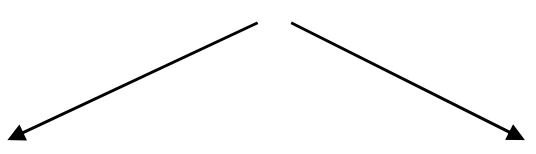

Kulturelle Bestimmung der bakteriellen Überlebensrate

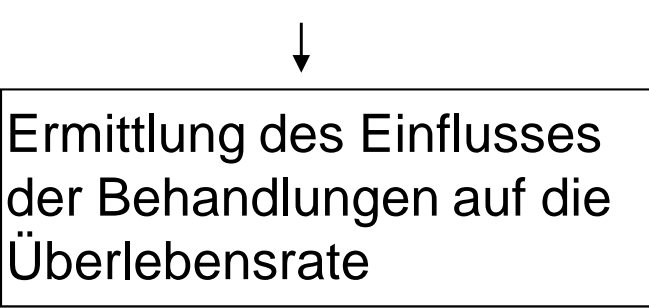

Semiquantitativer Nachweis der DNA ausgewählter Bakterien mit der PCR

\begin{tabular}{|l|}
\hline \\
\multicolumn{1}{|c|}{$\downarrow$} \\
Ermittlung des Einflusses der \\
Behandlungen auf die \\
Eliminierung des Biofilms
\end{tabular}




\section{Material und Methoden}

\subsection{Material}

\subsubsection{Geräte}

Brutschrank, reach in

Diodenlaser, Elexxion duros

Er:YAG-Laser, Elexxion duros

Gasbrenner, Flammy S

Agarosegel-Elektrophoresekammer

Geldokumentation, BioDoc II

Light Cycler

Phantomkopf

pH-Meter, 766 Calimatic

Plasmasterilisator, Sterrad 100 NX

Spannungsgerät, EPS 601

Thermomixer, comfort

Ultraschallbad

Vortex-Gerät, VortexVF 2

Zentrifuge, centrifuge5424
Scientific, Marietta, USA

Elexxion, Radolfszell

Elexxion, Radolfszell

Schütt, Göttingen

Kreutz-Labortechnik, Reiskirchen

Biometra, Göttingen

Roche, Rotkreuz, Schweiz

Frasaco, Tettnang

Knick, Berlin

Johnson u. Johnson, New Brunswick, USA

Amersham Pharmacia, Freiburg

Eppendorff, Hamburg

Branson, Danbury, USA

Janke und Klunke, Staufen

Eppendorff, Hamburg

\subsubsection{Verbrauchsmaterialien und Zubehör}

Aluminiumoxid

Bakteriologische Identifizierungssysteme

Api rapid 32a u. api strep

Chlorhexidindigluconat $\left(\operatorname{Paroex}^{\circledR}\right.$ )

Columbiablut-Kulturplatten
OmniDent, Niederröden

Biomerieux, Nürtingen

Butler, Kriftel

Biomerieux, Nürtingen 
DNA-Marker 100bp DNA-Ladder

Octenidindihydrochlorid/

2-Phenoxyethanol (Octenisept ${ }^{\circledR}$ )

Kochblut-Kulturplatten

Kunststoffschiene Erkodur

Titanhülsen u. -Plättchen

Tiefziehschienen Stärke 1mm

Interdentalbürsten

Pipettenspitzen

Proteinase $\mathrm{K}$

QIAmp Tissue Kit

QiAmp DNA Mini Kit

Reaktionsgefäße
Fermentas, St. Leon-Roth

Schülke \& Mayr, Norderstedt

Biomerieux, Nürtingen

Erkodent, Pfalzgrafenweiler

Steco, Hamburg

Dentsply, Konstanz

Curadent, Kriens, Schweiz

Sarstedt, Nümbrecht

Qiagen, Hilden

Qiagen, Hilden

Qiagen, Hilden

Sarstedt, Nümbrecht

\subsubsection{Puffer und Nährlösungen}

Alle Puffer und Nährlösungen wurden in der Abteilung Medizinische Mikrobiologie der Universtität Göttingen hergestellt.

PBS Puffer

RTF-Puffer

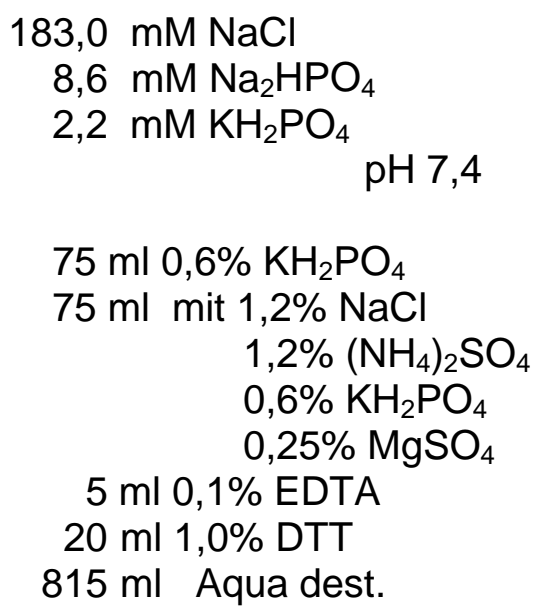

$\mathrm{pH} 8,0$
BHI-Kulturmedium

Oxoid, Wesel

Elutionspuffer $\mathrm{AE}$
Qiagen, Hilden 
Lysispuffer AL u. ATL

Qiagen, Hilden

Waschpuffer AW1 u. AW2

Qiagen, Hilden

\subsubsection{Primer}

Die folgenden Primer wurden von der Fa. Sigma Genosys (Steinheim) bereit gestellt.

Prevotella intermedia: Forward: TCC ACC GAT GAA TCT TTG GTC

Reverse: ATC CAA CCT TCC CTC CAC TC

Fusobacterium nucleatum: Forward: CGC AGA AGG TGA AAG TCC TGT AT

Reverse: TGG TCC TCA CTG ATT CAC ACA GA

Eikenella corrodens: Forward: GCC GCT TGG AAA GCT GCC ATG

Reverse: AGG ATG TTG CGG GCG ACT TTC

\subsubsection{Bakterienstämme}

Die verwendeten Bakterienkontrollstämme wurden der Bakteriensammlung der Abteilung Medizinische Mikrobiologie der UMG entnommen:

Fusobacterium nucleatum: ATCC (American Typeculture Collection) 10953; Eikenella corrodens: ATCC 23834; Prevotella intermedia: ATCC 25611. Vor den Experimenten wurden die Stämme auf Blutagarplatten unter anaeroben Bedingungen für $72 \mathrm{~h}$ bei $37^{\circ} \mathrm{C}$ unter standardisierten Bedingungen kultiviert.

\subsection{Probanden}

Es nahmen 20 freiwillige Teilnehmer im Alter zwischen 22 und 28 Jahren an der Studie teil. Bei der Aufnahme für die Studie wurden eine allgemeine und spezielle Anamnese, sowie die Erhebung eines intraoralen und parodontalen Befundes durchgeführt. Einschlusskriterien für die Studie waren der gesunde Allgemeinzustand, eine konservierend suffiziente Versorgung und ein parodontal gesunder Zustand der Probanden. Als Ausschlusskriterien wurden Nikotingenuss, Antibiotikaeinnahme in den letzten vier Wochen und der Gebrauch von Mundspüllösungen in den letzten zwei Wochen vor Studienbeginn festgelegt.

Die Studie wurde von der Ethikkommission der UMG (Antrag Nr.9/3/06) genehmigt. 


\subsection{Durchführung}

\subsubsection{Generierung eines oralen Biofilms in vivo}

Herstellung der Probekörper/Schienen

Zunächst wurden Ober- und Unterkiefer der Probanden mit Alginat abgeformt, in Hartgipsmodelle überführt und gelenkbezüglich einartikuliert. Nun wurde für jeden Teilnehmer eine individuelle Kunststoffschiene (Erkodur, Fa. Erkodent, Pfalzgrafenweiler, Deutschland) mit einer Stärke von $1 \mathrm{~mm}$ mittels Tiefziehverfahren für den Unterkiefer (Erkodent RVE) angefertigt. Es wird beschrieben, dass die Biofilmbildung auf oralen Schienen an der bukkalen Seite unabhängig von ihrer Lokalisation in Ober- oder Unterkiefer und ihrer jeweiligen bukkalen Position in der Mundhöhle gleich ist. An palatinal/lingualer Seite ist die Biofilmbildung reduziert (Auschill et al. 2004). Daher wurden an den beiden vestibulären Seiten im Seitenzahnbereich der Schienen jeweils approximal der beiden Prämolaren und des ersten Molaren drei Titanhülsen (Steco, Hamburg, Deutschland) mit den Maßen 5mm hoch, Innenradius 2,5mm, Außenradius 3,5mm hochkant mit Hilfe eines unter UV-Licht aushärtenden, fließfähigen Kunststoffs (Triad Gel clear colorless, Dentsply, Konstanz, Deutschland) fixiert. Die Innenseiten der Titanhülsen wurden vorher für $20 \mathrm{sec}$. mit Aluminiumoxid (Alcastral, $150 \mu \mathrm{m}$, OmniDent; Rodgau, Niederröden, Deutschland) sandgestrahlt um eine gleichmäßige Rauheit der Innenflächen zu erzielen. Zum besseren Tragekomfort und zur Vermeidung von Kiefergelenksbeschwerden wurde eine individuelle Okklusion eingestellt und jede Schiene nach vorangegangener Desinfektion nach Herstellerangaben in einem Plasmasterilisator (Sterrad 100 NX, Johnson und Johnson, New Brunswick, USA) bei $47^{\circ} \mathrm{C}$ sterilisiert.

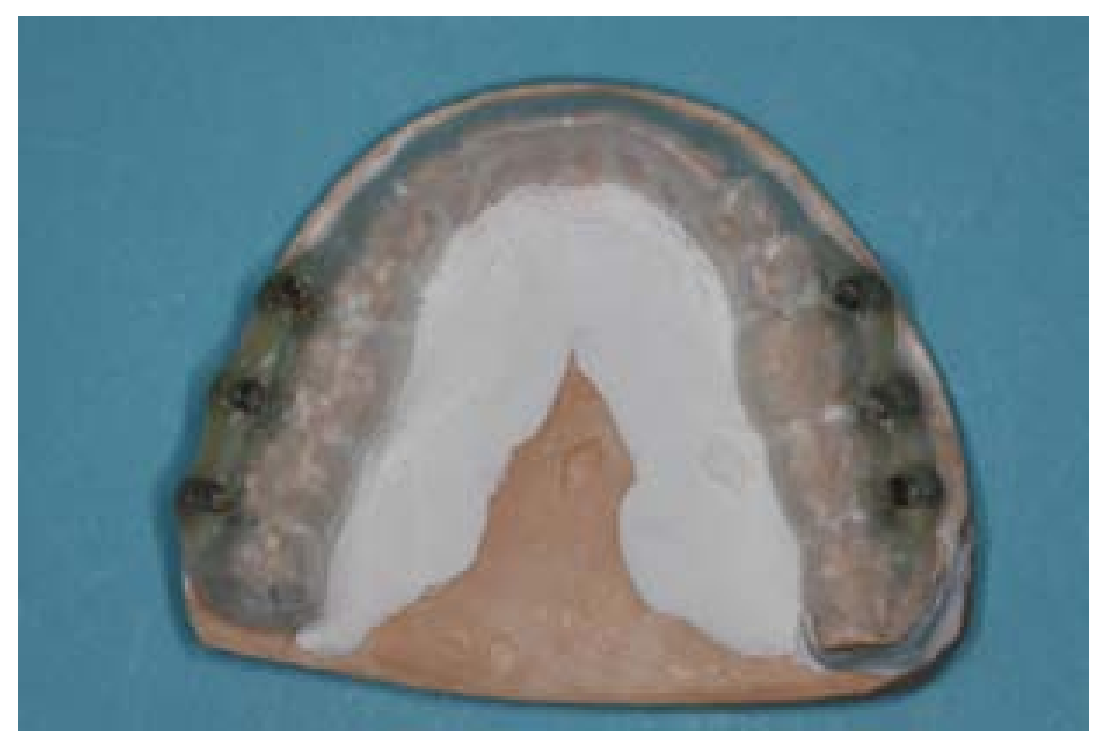

Abb. 2: Individuelle Tiefziehschiene mit integrierten Titan-Röhrchen. 


\section{Biofilmbildung}

Die individuellen Schienen mit den sechs Titankörpern wurden von den Probanden an zehn aufeinanderfolgenden Tagen mindestens 22 Stunden täglich getragen und nur zur Mundhygiene und zu den Mahlzeiten entfernt. Während dieser Zeit wurden die Schienen in sterilen, verschlossenen Beuteln verpackt und darauf geachtet, dass zu jeder Zeit ein Speichelfilm in den Röhrchen verblieb. Die Schiene durfte, unter Aussparung der Titankörper, zwischendurch vorsichtig mit Leitungswasser und Zahnbürste von Nahrungsresten gereinigt werden. Die Mundhygiene wurde während der Tragezeit wie gewohnt beibehalten, es musste jedoch auf den Gebrauch jeder Form von Mundspüllösung verzichtet werden.

\subsubsection{Behandlung der Titankörper}

Nach zehn Tagen Tragezeit wurden die Schienen direkt aus dem Mund der Probanden entnommen und unverzüglich, um eine Austrocknung des Biofilms zu vermeiden, auf ein individuelles Hartgipsmodell des Patienten in einen Phantomkopf (Frasaco, Tettnang, Deutschland) mit Gesichtsmaske zur Behandlung der Titankörper überführt. Durch den gewählten Versuchsaufbau wurden die eingeschränkte Sicht und der erschwerte Zugang zur Behandlungssituation der klinischen Situation entsprechend simuliert.

\section{Randomisierung}

Welches der sechs Titanröhrchen auf welche Weise $z u$ behandeln war, wurde einer Randomisierungstabelle entnommen, die freundlicherweise von der Abteilung Medizinische Statistik (UMG) erstellt wurde. Auf diese Weise wurde ein Einfluss der Position der Titanhülsen, beispielsweise durch unterschiedliche Biofilmentwicklung, auf die Untersuchungsergebnisse ausgeschlossen

\section{Verblindung}

Alle Versuche wurden von demselben Behandler durchgeführt, der von einem Assistenten unterstützt wurde. Um eine unbewusste Einflussnahme der Behandlungsweise der Titanhülsen durch den Behandler zu vermeiden, wurden die verschiedenen Spüllösungen von der Assistenz in undurchsichtigen Spritzen und Kanülen angereicht. Die zwei unterschiedlichen Laserbehandlungen konnten durch die jeweiligen Bedienungsvorschriften für die Laser für den Behandler nicht verblindet werden. Die Behandlung mit den einzelnen Lasern folgte aber einer standardisierten Vorschrift immer auf dieselbe Weise. Nach Zuteilung des Probenmaterials in ein jeweils 
randomisiert nummeriertes Eppendorf-Gefäß erfolgte die weitere Bearbeitung ebenfalls verblindet.

\subsubsection{Kontrollproben}

Pro Proband wurden zwei Titanhülsen unbehandelt als Kontrollen verwendet. Um einen mechanischen Spüleffekt auch in diesem Fall nicht zu vernachlässigen, wurden sie mit $20 \mathrm{ml} \mathrm{NaCl}$ für zwei Minuten gespült, danach wurde unverzüglich der Biofilm zur weiteren Untersuchung wie in 4.3 .3 beschrieben aus den Titanhülsen entnommen.

\subsubsection{Behandlung mit Lasern}

Jeweils eine der randomisiert ausgewählten Biofilm-besiedelten Titanhülsen wurde mit dem Diodenlaserlicht und eine mit dem Erbium:YAG-Laserlicht bestrahlt. Beide sind in einem Gerät integriert (Elexxion duros Laser, Fa. Elexxion, Radolfszell, Deutschland). Dabei wurden für beide Laser Bedingungen gewählt, die in Untersuchungen von Sennhenn-Kirchner (Sennhenn-Kirchner et al. 2007b, Sennhenn-Kirchner et al. 2009b) definiert worden waren.

Eine Titanhülse wurde mit einem Diodenlaserstrahl $(\lambda: 810 \mathrm{~nm})$ mit einer Quarzglasfaser (Durchmesser $600 \mu \mathrm{m}$ ) mit 1 Watt Leistung in Dauerstrich-Modus (continuous wave) für 4x 20 Sekunden behandelt. Dabei wurde der Laserstrahl auf die Oberfläche des Biofilms im inneren Teil der Titanhülse gerichtet und unter sehr leichtem direktem Kontakt der Spitze mit der Oberfläche bewegt (Abb.3). Nach jeweils 20 Sekunden Einwirkzeit wurde eine Bestrahlungspause von 30 Sekunden zum Abkühlen eingehalten. Die Energiedichte entsprach 353,7 W/cm² (Sennhenn-Kirchner et al. 2009b).

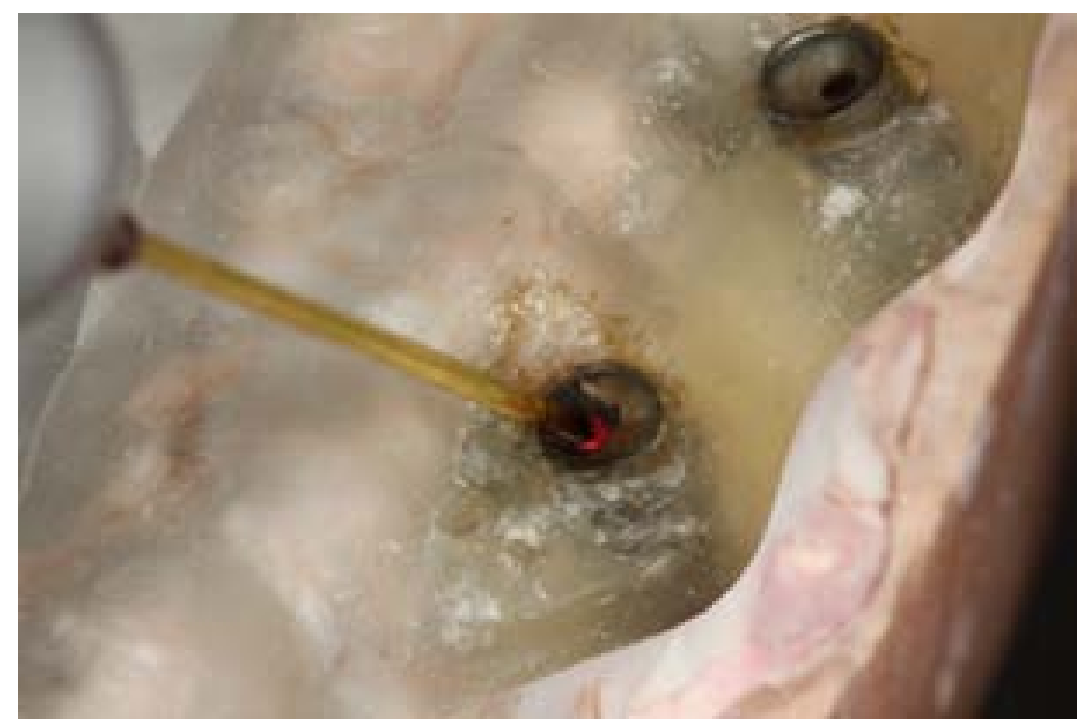

Abb.3 :Behandlung mit dem Diodenlaser 
Ein weiteres Titanröhrchen wurde für 80 Sekunden durchgehend mit einem Abstand von 0,5-1 mm von der zu bestrahlenden Oberfläche mit dem Laserlicht eines Er:YAG-Laser behandelt (Abb.4). Ein Kontakt der Saphirspitze wurde zu jedem Zeitpunkt vermieden. Der Erbium:Yag Laser ( $\lambda: 2940$ nm) wurde in einem gepulsten Modus bei $100 \mathrm{~mJ}, 10 \mathrm{~Hz}$ mit einer Pulsdauer von 300 us pro Puls angewendet. Die Saphierspitze (Durchmesser: $800 \mu \mathrm{m}$ ) wurde kontinuierlich mit kaltem, sterilen, destillierten Wasser gekühlt. Die

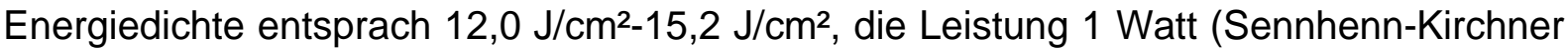
et al. 2009b).

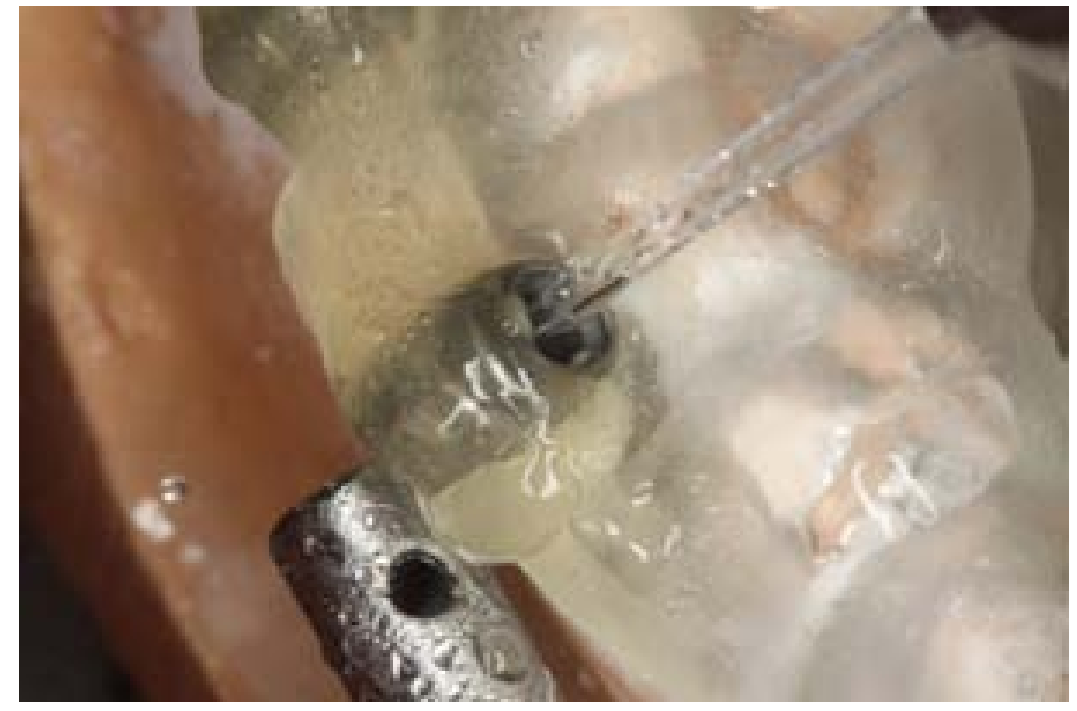

Abb. 4: Behandlung mit dem Er:YAG-Laser

Beide bestrahlten Hülsen wurden nach der Behandlung gleichermaßen mit $10 \mathrm{ml} \mathrm{NaCl}$ gespült, um dasselbe Protokoll wie bei den beiden gespülten Hülsen und Kontrollhülsen zu erfüllen.

\subsubsection{Behandlungen mit Spüllösungen}

Zwei randomisiert ausgewählte Hülsen wurden jeweils mit einer der beiden Spüllösungen behandelt, eine mit 0,12\% Chlorhexidindigluconat (Paroex ${ }^{\circledR}$, Butler, Kriftel, Deutschland), die andere mit 0,1\% Octenidindihydrochlorid/2-Phenoxyethanol (Octenisept $^{\circledR}$, Schülke\&Mayr, Norderstedt, Deutschland). Beide Spüllösungen wurden unverdünnt angewendet.

Dafür wurden $20 \mathrm{ml}$ der jeweiligen Lösung innerhalb von zwei Minuten kontinuierlich unter gleichbleibendem Druck von oben mit kreisenden Hubbewegungen ohne Kontakt mit einer stumpfen Kanüle in die Hülsen appliziert und nach Austritt aus dem unteren Hülsenbereich mit einem sterilen Sauger abgesaugt (Abb. 5). Dabei wurde darauf 
geachtet, dass die Flüssigkeiten insgesamt zwei Minuten einwirken konnten. Um die Einwirkzeit zu beenden, wurden die Titanhülsen mit $10 \mathrm{ml} \mathrm{NaCl}$ nachgespült. Alle Arbeiten wurden unter sterilen Kautelen von demselben Behandler und auf identische Weise durchgeführt

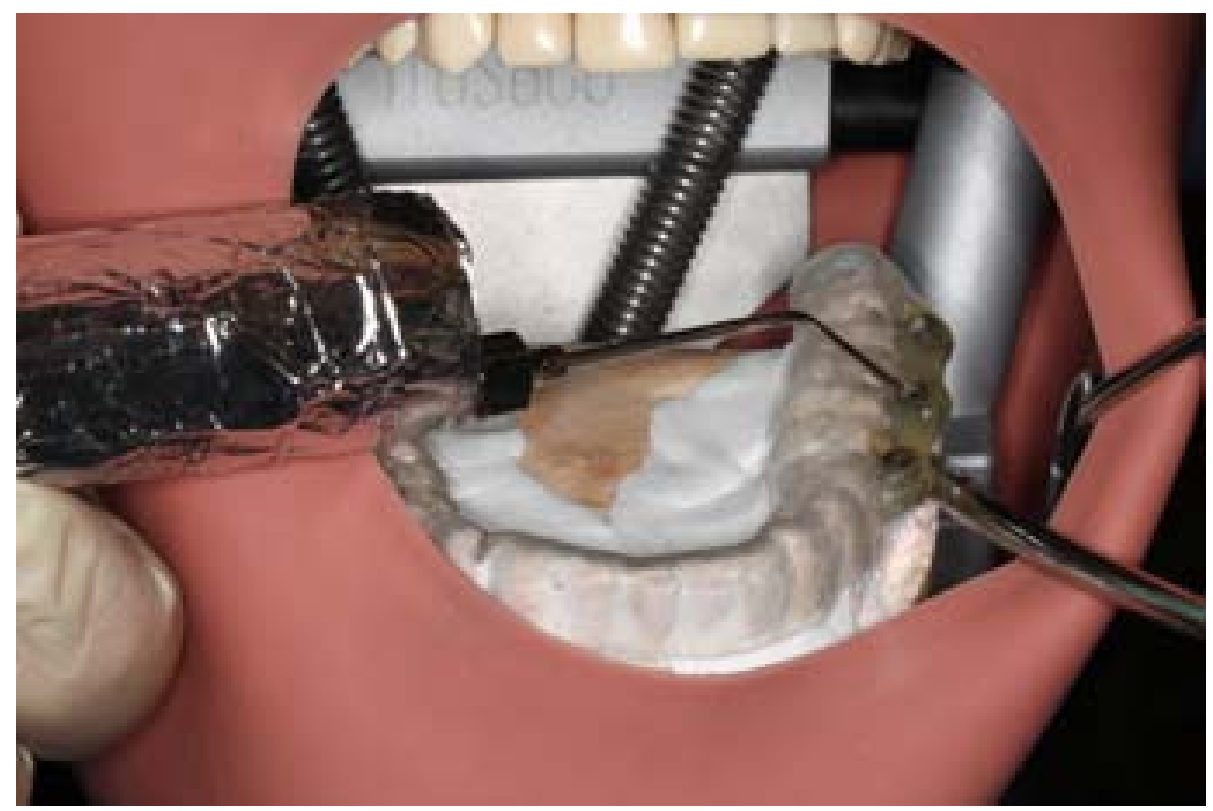

Abb. 5: Behandlung mit den Spüllösungen

Um eine mögliche Einflussnahme des Behandlers auszuschließen, wurden die Spritzen mit undurchsichtiger Folie versehen und undurchsichtige chirurgische Spülkanülen und Sauger verwendet. Der Behandler wusste somit nicht, welche Spüllösung zur Anwendung kam. Lediglich die Assistenz, die die Spritzen aufgezogen und angereicht hat, war über den Inhalt informiert. Die Bedingungen für die praktische Durchführung wurden in Anlehnung an vorausgegangene Studien gewählt (Sennhenn-Kirchner et al. 2004, Sennhenn-Kirchner et al. 2009a).

\subsubsection{Präparation des Biofilms}

Direkt nach der Behandlung einer Titanhülse wurde der Biofilm aus dem Inneren mit Hilfe einer sterilen Pinzette und eines sterilisierten Interdentalbürstchens (Curaprox CPS 12 regular, Curadent, Kriens, Schweiz) mit einer beschriebenen Abstrichmethode (Kite et al. 1997, Sennhenn-Kirchner et al. 2007b) entnommen. Besondere Sorgfalt wurde auf die Entnahme aller sichtbaren und nach der Behandlung verbliebenen Biofilmbestandteile mithilfe einer definierten Anzahl von zehn Bürstenstrichen mit Hubbewegungen durch das jeweilige Röhrchen verwendet. Nach der Biofilmentnahme 
wurden die kontaminierten Bürstchen direkt in sterile Reaktionsgefäße $(2 \mathrm{ml})$ (Sarstedt, Nümbrecht, Deutschland) mit 1,8 ml sterilem RTF-Puffer überführt (Abb. 6).

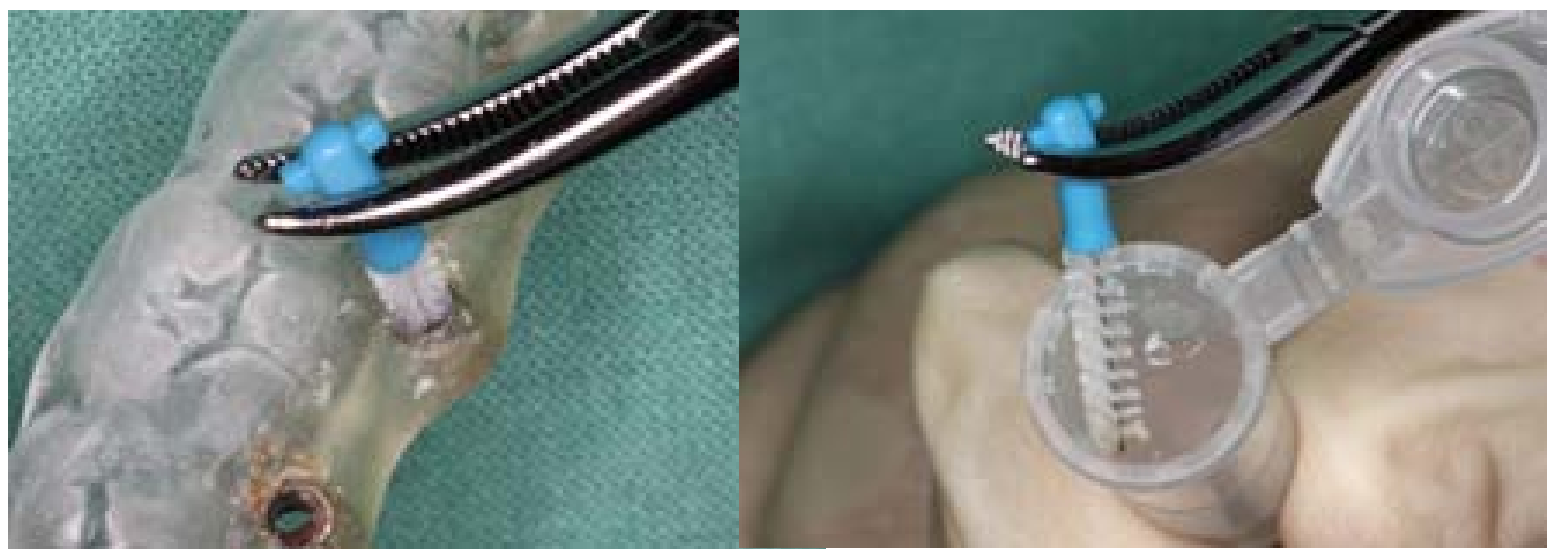

Abb. 6: Gewinnung des Biofilmmaterials

Der RTF-Puffer wurde von der Abteilung Medizinische Mikrobiologie der UMG hergestellt (Syed und Loesche 1972).

Direkt im Anschluss wurden mikrobiologische Kulturen mit den gewonnenen Proben angelegt (s. Kapitel 5.3.5). Für die weitere Bearbeitung mit der PolymeraseKettenreaktion wurden die Reste der einzelnen Proben in kleinen Portionen bei $-20^{\circ} \mathrm{C}$ eingelagert.

\subsubsection{Vorversuche}

Die kulturellen und molekularbiologischen Untersuchungen wurden von mir in der Abteilung Medizinische Mikrobiologie der UMG durchgeführt. Dazu waren Vorversuche notwendig, um vorab geeignete Bedingungen zur Quantifizierung der kulturell untersuchten Bakterien zu ermitteln, sowie eine Auswahl der zu untersuchenden Keime für die PCR zu treffen. Darüber hinaus mussten die Auswirkungen der Dekontaminationsverfahren auf die Amplifikation bakterieller DNA untersucht werden. Für die ersten beiden Vorversuche wurden drei Schienen von drei Probanden vorschriftsmäßig für zehn Tage getragen und der entstandene Biofilm unbehandelt, wie oben beschrieben, gewonnen. Für die Untersuchung der Stabilität der DNA nach Dekontamination wurden kultivierte Bakterien verwendet. 


\subsubsection{Ermittlungen geeigneter Kulturbedingungen und Verdünnungsstufen}

Um zu entscheiden, ob es geeigneter ist, aerobe oder anaerob kultivierte Bakterienkolonien zu zählen, und um die sinnvollste Verdünnung der Bakteriensuspension zur Auszählung der Kolonienzahlen zu bestimmen, erfolgte bei den drei Probanden die kulturelle Anzucht der Bakterien aus den gewonnenen Proben nach Verdünnung in BHI-Medium in zehner Schritten (bis 1:105) auf konventionellen Columbiablut-Platten (Süßmuth et al. 1999). Die Bebrütung fand bei $37^{\circ} \mathrm{C}$ über $48 \mathrm{~h}$ unter aerober und anaerober Atmosphäre statt. Durch Zählen der Bakterienkolonien ließen sich bestgeeignete Bedingungen zur Quantifizierung der Bakterien im gewonnenen Biofilmmaterial ermitteln. Die Ergebnisse sind in Kapitel 5.1.1 zusammengestellt.

\subsubsection{Typisierung von drei Bakterienspezies im Biofilm}

Für die im weiteren Verlauf geplanten molekularbiologischen Untersuchungen zur Beurteilung des Biofilmzustands war es notwendig, die Anwesenheit und relative Menge definierter Bakterienarten zu kennen. Durch biochemische Untersuchungen sollten Bakterienspezies nachgewiesen werden, die im Biofilm aller Probanden auftraten.

Nach Ausstreichen der wie oben beschriebenen Proben und Bebrüten der Platten wurden gezielt einzelne und sich morphologisch unterscheidende Kolonien von anaeroben Platten mit einer sterilen Öse abgeimpft, neu ausgestrichen und wieder für 48h unter anaeroben Bedingungen im Brutschrank inkubiert (siehe 2.4.1) Damit wurden Reinkulturen erzeugt, die sich zur Charakterisierung weiter verwenden ließen.

Zur genauen Typisierung der Bakterien wurden die standardisierten Identifizierungssysteme api rapid ID 32A und api 20 strep (Biomerieux, Nürtingen, Deutschland), die biochemische Eigenschaften berücksichtigen, verwendet. Die Durchführung erfolgte nach den Angaben des Herstellers. Die Ergebnisse der Farbreaktionen der Indikatoren ließen sich in einem Zahlencode erfassen, über die Datenbank des Herstellers auswerten und damit definierten Bakterien-Spezies zuordnen. So wurde eine Auswahl an vorliegenden anaeroben Keimen nachgewiesen, deren Quantität in der PCR bestimmt werden konnte (s. Ergebnisteil Vorversuche 5.1.2)

\subsubsection{Auswirkungen der Behandlungen auf die bakterielle DNA}

Damit die PCR die im behandelten Biofilm noch vorhandene bakterielle DNA nachweisen kann, ist es Voraussetzung, dass die bakterielle DNA nicht derart geschädigt wird, dass der molekularbiologische Nachweis beeinträchtigt ist. Um dies zu untersuchen, wurden 
alle vier Behandlungsmethoden auf Titanplättchen mit bakteriellen Reinkulturen angewendet und die beschriebenen kulturellen und molekularbiologischen Auswertungen vorgenommen.

Für den Vorversuch wurden Reinkulturen von Eikenella corrodens, Prevotella oralis und Fusobacterium nucleatum hergestellt und definierte Mengen der Kolonien in $5 \mathrm{ml}$ 0,9\%iger $\mathrm{NaCl}$ Lösung suspendiert, bis die MacFarland-Trübung $>7,5$ erreicht wurde. Davon wurden $10 \mu \mathrm{l}$ auf die Oberfläche von runden Titanplättchen (5 mm Durchmesser) verteilt und für $1 \mathrm{~h}$ bei $37^{\circ} \mathrm{C}$ getrocknet. Die so beschichteten Plättchen benetzte man jeweils mit Chlorhexidindigluconat oder Octenidindihydrochlorid/2-Phenoxyethanol für zwei Minuten oder bearbeitete die Oberfläche mit einem der Laser-Verfahren unter denselben Bedingungen, die auch bei der Behandlung der Titanhülsen mit dem Biofilm gewählt wurden. Ein unbehandeltes Titanplättchen diente als Kontrolle. Alle Maßnahmen wurden in einer sterilen 250-ml-Glasschale durchgeführt. Um auch die durch die Behandlung eventuell abgelösten Bakterien und ihre Bestandteile aufzufangen, wurde das austretende Kühlwasser des Er:Yag-Lasers $(13 \mathrm{ml})$ in der Glasschale gesammelt und, um gleiche Voraussetzungen zu schaffen, bei dem mit Diodenlaser behandelten Plättchen, bei der Kontrollprobe und den mit Chlorhexidindigluconat und Octenidindihydrochlorid/2-Phenoxyethanol gespülten Plättchen zum Schluss 13 ml RTFPuffer in die Glasschalen zugefügt. Der komplette Inhalt der Glasschalen (Plättchen und 13ml Flüssigkeit) wurde in sterile Reaktionsgefäße überführt.

Nach Einwirkung von Ultraschall (1 min) und intensivem Schütteln (2 min) der Plättchen in diesen $13 \mathrm{ml}$ Puffer wurde jeweils ein Aliquot von $200 \mu$ für die PCR eingesetzt und der Rest der gesammelten Suspension auf bluthaltigen Agarplatten unter anaeroben Bedingungen inkubiert.

Durch Bestimmung der Kolonienzahl ließen sich überlebende anaerobe Bakterien nachweisen. Die PCR zeigte den Anteil unzerstörter DNA bei der Kontrolle und nach den verschiedenen Behandlungen und somit die Auswirkung von Lasern und Spüllösungen auf die bakterielle DNA.

\subsubsection{Mikrobiologisch kulturelle Untersuchung}

Die nach der Präparation des Biofilms jeweils gewonnene Probe (Bürstenabstrich im RTF-Puffer) wurde in einem sterilen Reaktionsgefäß (Fa. Sarstedt, Nümbrecht, Deutschland) 60 Sekunden in einem Ultraschallbad bei 44 kHz (Fa. Branson, Danbury, Connecticut, USA) behandelt und anschließend maschinell gründlich durchmischt 
(VortexVF 2, Janke und Klunke, Staufen i. Br., Deutschland). Anschließend wurden, den Ergebnissen der Vorversuche entsprechend, $100 \mu \mathrm{l}$ der Probe für die folgende Anzucht der Bakterien mit flüssigem Kulturmedium (BHI, Fa. Oxoid, Wesel, Deutschland) in 10er Schritten $(100 \mu \mathrm{l}$ Probe $+900 \mu \mathrm{l}$ Medium) bis 1:1000 verdünnt und jeweils $10 \mu \mathrm{l}$ gleichmäßig auf bluthaltigen Agarplatten (Columbia-Blut, Fa. Biomerieux, Nürtingen, Deutschland) ausgespatelt. Die Platten wurden in einer anaeroben Atmosphäre (Genbox anaer, Fa. Biomerieux, Nürtingen, Deutschland) für $48 \mathrm{~h}$ bei $37^{\circ} \mathrm{C}$ in einem Brutschrank (Reach-in incubator, Scientific, Marietta, Ohio, USA) inkubiert. Am Ende der Inkubation konnten die entstandenen Bakterienkolonien gezählt werden.

Der verbliebene Rest der einzelnen Proben wurde zur Weiterverarbeitung in vier 1,5-ml-Reaktionsgefäße aufgeteilt und bei $-20^{\circ} \mathrm{C}$ aufbewahrt.

\subsubsection{Molekularbiologische Untersuchung}

Die oben beschriebene kulturelle Anzüchtungsmethode ermöglicht sichere Aussagen über die Effizienz des Abtötens von Bakterien im Biofilm nach Einwirkung der Laser und der beiden Spüllösungen. Ein Hinweis über die Auswirkung der Verfahren auf den verbleibenden Biofilm, in dem sich die abgetöteten Bakterien unter Umständen noch befinden können, kann mit den kulturellen Methoden nicht gewonnen werden. So soll mit Techniken, die lebende und auch abgetötete Bakterien nachweisen, der Biofilm vor und nach den Behandlungen untersucht werden. Die Polymerase-Kettenreaktion erlaubt es, bestimmte DNA-Abschnitte exponentiell zu vermehren und danach zu identifizieren, unterscheidet hingegen nicht zwischen vermehrungsfähigen und abgetöteten Bakterien, wenn die DNA noch intakt ist. Um die Reduktion bakterieller DNA vor und nach den Behandlungen $\mathrm{zu}$ ermitteln, wurden semiquantitative Real-Time-PCR-Analysen durchgeführt.

Die semiquantitative Real-Time PCR beruht auf dem Prinzip der herkömmlichen PCR, bietet aber zusätzlich die Möglichkeit der Quantifizierung mit Fluoreszenz-Messungen während und am Ende eines PCR-Zyklus. Eine gelelektrophoretische Auftrennung der Fragmente ist nicht unabdingbar notwendig, und das Kontaminationsrisiko ist gering. Zur Quantifizierung der PCR-Produkte ist die Nutzung von DNA-Farbstoffen wie Ethidiumbromid, oder, wie in unserem Fall, SYBR-Green möglich. Die Fluoreszenzfarbstoffe lagern sich in die DNA ein, wodurch das Fluoreszenzsignal der Wellenlänge $525 \mathrm{~nm}$ in Abhängigkeit von der neu gebildeten DNA emittiert wird. 
Nach abgelaufener PCR kann eine Schmelzkurvenanalyse durchgeführt werden, durch die die Fragmentlänge und somit die Spezifität bestimmt werden kann. Bei dieser Analyse wird die DNA aufgeschmolzen, indem die Temperatur langsam erhöht wird. Jedes DNA-Fragment hat eine spezifische Schmelztemperatur (TM-Wert), ab welcher der Doppelstrang dissoziiert. Dabei wird der Fluoreszenzfarbstoff freigesetzt und eine Fluoreszenzabnahme (Cp-Wert) gemessen. Spezifische PCR-Produkte haben einen höheren Schmelzpunkt als unspezifische Primerdimere, die nach Durchlauf vieler PCRZyklen entstehen können.

\subsubsection{Isolierung und Reinigung bakterieller DNA}

Zur Isolierung und Reinigung der bakteriellen DNA aus dem gewonnenen Biofilmmaterial wurde ein standardisiertes Säulensystem (QIAmp Tissue Kit, Fa. Qiagen, Hilden, Deutschland) nach Angaben des Herstellers durchgeführt.

Dieser Arbeitsschritt dient der Vorbereitung der DNA für den Einsatz in der PCR.

Das Verfahren basiert auf einer Standard-Anleitung.

Als Materialien wurden eingesetzt: Proteinase K (20 mg/ml), Lysispuffer ATL, Lysispuffer AL, QIAamp Filterröhrchen, Waschpuffer AW 1 und AW 2, Elutionspuffer AE. Diese Reagenzien wurden zum direkten Einsatz kommerziell bezogen (Fa. Qiagen, Hilden, Deutschland). Weiterhin wurden benötigt: Ethanol, steriles bidestilliertes Wasser, $1 \mathrm{M}$ Tris- $\mathrm{HCl} \mathrm{pH}$ 7,6, 0,5 M EDTA pH 8,0.

Das Prinzip des Säulensystems ist, dass nach einer Lyse der bakteriellen Hüllproteine mit Proteinase $\mathrm{K}$ die freigewordene DNA während eines Zentrifugationsschrittes an eine Silikagelmembran einer Spinnsäule gebunden wird (Festphasenextraktion). Diese DNA wird in der Folge in zwei Schritten von kontaminierenden Stoffen gereinigt und mit einem kleinen Volumen Extraktionspuffer eluiert. Es wird eine Negativkontrolle ohne Extraktionsmaterial mitgeführt.

Im Einzelnen wurden folgende Arbeitsprozeduren durchlaufen:

- Proben auf Raumtemperatur bringen

- Thermomixer auf $56^{\circ} \mathrm{C}$ vorheizen

- pro Probe ein 1,5-ml-Reaktionsgefäß vorbereiten, ein zusätzliches

Reaktionsgefäß als Negativkontrolle vorbereiten

- $20 \mu$ l Proteinase-K-Lösung zu jedem Reaktionsgefäß pipettieren

- $200 \mu \mathrm{l}$ der jeweiligen zu untersuchenden Proben und als Negativkontrolle $200 \mu \mathrm{l}$

Steriles $\mathrm{H}_{2} \mathrm{O}$ in das vorgesehene und beschriftete jeweilige Reaktionsgefäß pipettieren und mit den zwei vorgelegten Lösungen mischen 
- $180 \mu$ des Puffers AL (QIAamp DNA Mini Kit, Qiagen, Hilden, Deutschland) zugeben, das Reaktionsgefäß verschließen und mit einem Mischgerät (VortexVF 2, Janke und Klunke, Staufen i. Br., Deutschland) durch 10-maliges 'Puls-vortexen' mischen

- 2 h oder über Nacht bei $56^{\circ} \mathrm{C}$ im Thermomixer (Thermomixer comfort, Fa. Eppendorf, Hamburg, Deutschland) inkubieren

- kurz (ca. 5 Sek.) bei 8000 rpm (Eppendorf centrifuge 5424, Eppendorf, Hamburg) zentrifugieren, um Flüssigkeit aus dem Deckel des

Reaktionsgefäßes zu entfernen und beim Öffnen Kontaminationen zu vermeiden

- $200 \mu \mathrm{l}$ des AL Puffers zugeben und nach kurzem Mischen 10 min bei $70^{\circ} \mathrm{C}$ im Wasserbad inkubieren

- kurz (ca. 5 Sek.) bei 8000 rpm zentrifugieren

- $200 \mu \mathrm{l}$ Ethanol zugeben, das Reaktionsgefäß verschließen und mit dem Vortex-Mischgerät durch 10-maliges 'Puls-vortexen' mischen

- kurz (ca. 5 Sek.) bei 8000 rpm zentrifugieren

- Gemisch vorsichtig auf eine zuvor beschriftete Spinsäule mit 2-ml-Auffangröhrchen (QIAamp DNA Mini Kit, Qiagen, Hilden, Deutschland) geben, Säule mit Deckel verschließen

- Spinsäule zusammen mit dem 2-ml-Auffangröhrchen während 1 min bei 8000 rpm zentrifugieren

- Spinsäule in ein neues 2-ml-Auffangröhrchen (QIAamp DNA Mini Kit, Qiagen, Hilden, Deutschland) überführen und $500 \mu$ des Puffers AW1 zugeben

- Spinsäule verschließen und mit Auffangröhrchen während 1 min bei 8000 rpm zentrifugieren

- Spinsäule in ein neues 2-ml-Auffangröhrchen stellen und $500 \mu \mathrm{l}$ des Puffers AW2 zugeben

- Spinsäule verschließen und mit Auffangröhrchen während 3 min bei 13500 rpm (Eppendorf centrifuge 5424, Eppendorf, Hamburg, Deutschland) zentrifugieren - Spinsäule in 1,5-ml-Reaktionsgefäß überführen und $200 \mu \mathrm{l}$ des Puffers AE zugeben (Puffer muss direkt auf die Membran in der Mitte der Spinsäule getropft werden), 1 min stehen lassen

- Spinsäule verschließen und mit dem 1,5-ml-Reaktionsgefäß während 1 min bei 8000 rpm zentrifugieren

- Spinsäule aus dem Reaktiongefäß entfernen und verwerfen, Reaktionsgefäß mit dem DNA-Extrakt verschließen. 


\subsubsection{Oligonukleotide und PCR-Durchführung}

Für die bei allen Probanden u.a. nachweisbaren Bakterienspezies Prevotella intermedia, Fusobacterium nucleatum und Eikenella corrodens, deren Beteiligung zur Entstehung einer Periimplantitis bekannt ist (Kolenbrander 2000), wurden Nukleinsäureamplifikationsnachweise etabliert. Die Zielsequenzen innerhalb der Genome der jeweiligen Erreger wurden für Prevotella intermedia (Kuboniwa et al. 2004), Fusobacterium nucleatum (Suzuki et al. 2004) und Eikenella corrodens (Azakami et al. 2006) der Literatur entnommen.

Alle Primer wurden von der Fa. Sigma Genosys (Steinheim, Deutschland) bezogen. Die von der Firma angegebenen TM-Werte für die drei Keime konnten in einem Vorversuch mit Kontrollproben bestätigt werden.

Für jede dieser drei typischen Bakterienarten des oralen Biofilms wurde ein PCRTestverfahren etabliert. Die speziespezifischen Primer wurde nach Reaktionsbedingungen in Anlehnung an Standardprotokolle der Abteilung Medizinische Mikrobiologie (UMG) auf einen Lightcycler (Lightcycler 1,5, Roche, Rotkreuz, Schweiz) übertragen.

Zur Analyse benötigte man neben der DNA der Probe noch einen Mastermix mit den spezifischen Primern, der für jedes zu untersuchende Bakterium immer frisch angesetzt werden musste.

Reagenzien für den Mastermix wurden in der unten angeführten Reihenfolge in ein steriles Reaktionsgefäß pipettiert und gut mit der Pipettenspitze durchmischt (Tab. 1).

Tab.1: Pipetierschema (Mastermix) zur PCR-Vorbereitung

\begin{tabular}{|lcccc|l|}
\hline Reagenzien & $\begin{array}{c}\text { Pro Probe } \\
(\mu \mathrm{l})\end{array}$ & $\begin{array}{c}\text { x Probenanzahl } \\
\text { (6 Proben+Negativkontrolle+Sicherheit) }\end{array}$ & $\begin{array}{l}\text { Menge pro } \\
\text { Ansatz }(\mu \mathrm{l})\end{array}$ \\
\hline Fast Start DNA Master & $4,00 \mu \mathrm{l}$ & $\mathrm{x}$ & 8 & 32,0 \\
Primer 1 (10 pmol) & $0,25 \mu \mathrm{l}$ & $\mathrm{x}$ & 8 & 2,0 \\
Primer 2 (10 pmol) & $0,25 \mu \mathrm{l}$ & $\mathrm{x}$ & 8 & 2,0 \\
$\mathrm{H}_{2} \mathrm{O}$ & $5,50 \mu \mathrm{l}$ & $\mathrm{x}$ & 8 & 44,0 \\
\hline
\end{tabular}

PCR-Ansatz:

- in jede Kapillare $10 \mu$ l Mastermix pipettieren

- das aufgereinigte Probenmaterial $(10 \mu \mathrm{l})$ in die dafür vorgesehenen

Kapillare überführen 
- in eine Kapillare $10 \mu \mathrm{l} \mathrm{H}_{2} \mathrm{O}$ (Negativkontrolle) pipettieren

- in eine weitere Kapillare $5 \mu$ l aufgereinigte DNA (Positivkontrolle) pipettieren

- alle Kapillaren verschließen und bei 800xg (3000 rpm, Eppendorf centrifuge 5424, Eppendorf, Hamburg) für $15 \mathrm{sec}$ bei RT zentrifugieren

- Proben unmittelbar danach im LightCycler (LightCycler 1.5, Roche, Rotkreuz,

Schweiz) analysieren

Das folgende Protokoll des Ablaufs der PCR im Lightcycler entspricht einem Programm, das von Dr. Raimond Lugert (Institut für Medizinische Mikrobiologie, UMG) etabliert worden ist.

Tab. 2 : Protokoll des PCR-Ablaufs (Originalprotokoll)

\begin{tabular}{|l|l|l|l|l|l|l|l|}
\hline \multicolumn{3}{|l|}{ Programm: Denaturation } & \multicolumn{2}{|l|}{ Type: None } & \multicolumn{1}{c|}{ Cycles: } & 1 \\
\hline $\begin{array}{l}\text { Segment } \\
\text { Number }\end{array}$ & $\begin{array}{c}\text { Target } \\
\text { Temp. }\left({ }^{\circ} \mathrm{C}\right)\end{array}$ & $\begin{array}{l}\text { Hold Time } \\
(\mathrm{sec})\end{array}$ & $\begin{array}{l}\text { Slope } \\
\left({ }^{\circ} \mathrm{C} / \mathrm{sec}\right)\end{array}$ & $\begin{array}{l}\text { 20 } \\
2^{\circ} \text { Target } \\
\text { Temp }\left({ }^{\circ} \mathrm{C}\right)\end{array}$ & $\begin{array}{l}\text { Step } \\
\text { Size } \\
\left({ }^{\circ} \mathrm{C}\right)\end{array}$ & $\begin{array}{l}\text { Step Delay } \\
(\text { Cycles })\end{array}$ & $\begin{array}{l}\text { Acquisition } \\
\text { Mode }\end{array}$ \\
\hline 1 & 95 & 600 & 20 & 0 & 0 & 0 & None \\
\hline
\end{tabular}

\begin{tabular}{|c|c|c|c|c|c|c|c|}
\hline \multicolumn{4}{|c|}{$\begin{array}{l}\text { Programm: } \\
\text { Amplification }\end{array}$} & \multicolumn{2}{|c|}{$\begin{array}{l}\text { Type: } \\
\text { Quantification }\end{array}$} & \multirow{2}{*}{\begin{tabular}{l}
\multicolumn{1}{c}{ Cycles: } \\
$\begin{array}{l}\text { Step Delay } \\
\text { (Cycles) }\end{array}$
\end{tabular}} & \multirow{2}{*}{$\begin{array}{l}36 \\
\text { Acquisition } \\
\text { Mode }\end{array}$} \\
\hline $\begin{array}{l}\text { Segment } \\
\text { Number }\end{array}$ & $\begin{array}{c}\text { Target } \\
\text { Temp. }\left({ }^{\circ} \mathrm{C}\right) \\
\end{array}$ & $\begin{array}{l}\text { Hold Time } \\
(\mathrm{sec})\end{array}$ & $\begin{array}{l}\text { Slope } \\
\left({ }^{\circ} \mathrm{C} / \mathrm{sec}\right)\end{array}$ & $\begin{array}{l}2^{\circ} \text { Target } \\
\text { Temp }\left({ }^{\circ} \mathrm{C}\right)\end{array}$ & $\begin{array}{l}\text { Step } \\
\text { Size } \\
\left({ }^{\circ} \mathrm{C}\right)\end{array}$ & & \\
\hline 1 & 95 & 10 & 20 & p & 0 & 0 & None \\
\hline 2 & 65 & 10 & 20 & 60 & 1 & 10 & None \\
\hline 3 & 72 & 20 & 20 & $p$ & 0 & 0 & Single \\
\hline
\end{tabular}

\begin{tabular}{|c|c|c|c|c|c|c|c|}
\hline \multicolumn{4}{|c|}{ Programm: Melting Curve } & \multicolumn{2}{|c|}{$\begin{array}{|ll|}\text { Type: } & \text { Melting } \\
\text { Curves } & \\
\end{array}$} & Cycles: & 1 \\
\hline $\begin{array}{l}\text { Segment } \\
\text { Number }\end{array}$ & $\begin{array}{c}\text { Target } \\
\text { Temp. }\left({ }^{\circ} \mathrm{C}\right)\end{array}$ & $\begin{array}{l}\text { Hold Time } \\
(\mathrm{sec})\end{array}$ & $\begin{array}{l}\text { Slope } \\
\left({ }^{\circ} \mathrm{C} / \mathrm{sec}\right)\end{array}$ & $\begin{array}{l}2^{\circ} \text { Target } \\
\text { Temp }\left({ }^{\circ} \mathrm{C}\right)\end{array}$ & $\begin{array}{l}\text { Step } \\
\text { Size } \\
\left({ }^{\circ} \mathrm{C}\right)\end{array}$ & $\begin{array}{l}\text { Step Delay } \\
\text { (Cycles) }\end{array}$ & $\begin{array}{l}\text { Acquisition } \\
\text { Mode }\end{array}$ \\
\hline 1 & 95 & 20 & 20 & p & 0 & 0 & None \\
\hline 2 & 66 & 20 & 20 & p & 0 & 0 & None \\
\hline 3 & 95 & p & 0,2 & p & 0 & 0 & Continuous \\
\hline
\end{tabular}

\begin{tabular}{|l|l|l|l|l|l|l|l|}
\hline \multicolumn{2}{|l|}{ Programm: Cooling } & \multicolumn{2}{|l|}{ Type: None } & \multicolumn{1}{c|}{ Cycles: } & 1 \\
\hline $\begin{array}{l}\text { Segment } \\
\text { Number }\end{array}$ & $\begin{array}{c}\text { Target } \\
\text { Temp. }\left({ }^{\circ} \mathrm{C}\right)\end{array}$ & $\begin{array}{l}\text { Hold Time } \\
(\mathrm{sec})\end{array}$ & $\begin{array}{l}\text { Slope } \\
\left({ }^{\circ} \mathrm{C} / \mathrm{sec}\right)\end{array}$ & $\begin{array}{l}\text { 20 } \\
2^{\circ} \text { Target } \\
\text { Temp }\left({ }^{\circ} \mathrm{C}\right)\end{array}$ & $\begin{array}{l}\text { Step } \\
\text { Size } \\
\left({ }^{\circ} \mathrm{C}\right)\end{array}$ & $\begin{array}{l}\text { Step Delay } \\
(\text { Cycles })\end{array}$ & $\begin{array}{l}\text { Acquisition } \\
\text { Mode }\end{array}$ \\
\hline 1 & 40 & 30 & 20 & 0 & 0 & 0 & None \\
\hline
\end{tabular}

\section{Auswertung}

Zur quantitativen Auswertung wird die Differenz zwischen den ermittelten Crossingpoints der zu vergleichenden Proben $(\Delta C p)$ ermittelt, und mit dem erhaltenen Wert der Faktor 
für die Änderung der DNA-Menge (x) errechnet. Als Crossingpoint bezeichnet man den Zeitpunkt einer PCR, bei dem ein spezifisches Signal detektiert wird. Je höher der Wert des Crossingpoints, desto geringer die enthaltene DNA Menge der Probe. So kann der Crossingpoint eine Aussage über die Menge der zu detektierenden DNA treffen.

Es gilt: $x=2^{\Delta c p}$.

Zur Veranschaulichung seien hier Beispiele der Berechnung genannt. Bei identischer DNA-Menge von Kontrolle und Behandlungsprobe ist $\triangle \mathrm{CP}=0$, damit folgt $\mathrm{x}=1$, oder $0 \%$ Reduktion. Bei einem Cp der Kontrolle von 16,53 und nach Behandlung von 17,16 ergibt sich für $\Delta C p=0,63$. X ergibt mit $2^{0,63}=0,646$, das entspricht einer Reduktion um 35,4\%. Die Kontrollen enthielten in allen Fällen eine höhere DNA-Menge im Vergleich zu den behandelten Proben, damit ist die Differenz immer mit einem positiven Vorzeichen gesetzt.

Es folgt die Schmelzkurvenanalyse, bei der der Tm-Wert (Temperatur of melting) ermittelt wird. Er beschreibt ab welcher Temperatur sich die Einzelstränge der Nukleinsäure bei Absinken der Temperatur wieder hybridisieren. Er gibt für einen definierten Doppelstrang die Temperatur an, bei der $50 \%$ der Doppelstränge als Einzelstränge vorliegen. Für jede doppelsträngige Nukleinsäure gibt es einen definierten Wert.

So kann die Spezifität des Amplifikats durch Abgleich der Schmelzpunkte (Tm-Werte) von Probe und Positivkontrolle überprüft werden. Die Tm-Werte müssen hierbei also übereinstimmen.

\subsubsection{Vermeidung von Kontaminationen}

Um Kontaminationen zu vermeiden, wurden Strategien gewählt, die das Risiko des Verschleppens von DNA mindern sollten.

Es wurde stets eine Negativkontrolle mitgeführt.

Die DNA-Extraktion fand in einem separaten Raum mit eigenem Arbeitsmaterial statt.

Es fand spezielles Wasser Verwendung, das nach Herstellerangaben DNAseund RNAsefrei und sterilisiert geliefert wurde (Sigma, Taufkirchen).

Es wurden ausschließlich gestopfte und sterile Pipettierspitzen (Fa. Sarstedt, Nümbrecht, Deutschland) benutzt.

Puffer, Primer und Untersuchungsmaterial wurden in kleine Portionen fraktioniert, 
die zur Vermeidung von Kontaminationen nur einmal verwendet wurden.

Es wurden separate Arbeitsplätze für die einzelnen Arbeitsschritte mit den Versuchsproben benutzt.

\subsubsection{Agarosegelelektrophorese}

Zum Nachweis der Amplifikations-Produkte wird in der Regel die DNA mit Ethidiumbromid gefärbt, in Agarosegel elektrophoretisch aufgetrennt und unter UV-Licht betrachtet. Eine sichtbare Bande der erwarteten Länge (nach Vergleich mit DNALängenstandards) wird als positiv bewertet.

Die Darstellung der PCR-Amplifikate erfolgte in der vorliegenden Untersuchung in 1\%igen (w/v) Agarosegelen. Die Agarose wurde in $1 \times$ TBE mit Hilfe eines Mikrowellengeräts vollständig aufgelöst und nach dem Abkühlen auf $55^{\circ} \mathrm{C}$ mit Ethidiumbromid versetzt (Endkonzentration 0,5 $\mu \mathrm{g} / \mathrm{ml}$ ). Das flüssige Gel wurde in eine Kammer überführt und ein Kamm hinein gesetzt, der nach Auspolymerisierung die Taschen im Gel formt.

Nach den Amplifikationen der LightCycler PCR wurden die Kapillaren kopfüber anzentrifugiert und in Reaktionsgefäße (2 ml) (Eppendorf, Hamburg, Deutschland) überführt. Anschließend wurden die Eluate mit $20 \mu$ eines Größenstandards (100 bp ladder, MBI Fermentas, St. Leon Rot, Deutschland) versehen, in die Geltaschen pipettiert und elektrophoretisch in einer Flachbettelektrophoresekammer (Fa. Peqlab, Erlangen, Deutschland) aufgetrennt. Danach erfolgte die Beurteilung und Dokumentation der Banden unter einem UV-Transiluminator (Biodocll, Fa. Biometra, Göttingen, Deutschland). Die Lage der Banden zeigt die Spezifität der DNA Produkte und die Intensität der Banden lässt eine abschätzende Aussage über die Quantität zu.

\subsection{Statistik}

Ziel der durchgeführten Untersuchungen ist, die Effizienz der Verfahren zur Abtötung und Eliminierung von anaeroben Bakterien im Biofilm zu ermitteln. Dazu ist es erforderlich, biometrische Verfahren anzuwenden. Diese Auswertung wurde maßgeblich von Dr. Frank Konietschke, Abteilung Medizinische Statistik der UMG, vorgenommen. Die Reduktion der Bakterien unter Anwendung der vier Methoden Diodenlaser, Erbium:YAG-Laser, Spülung 1 und Spülung 2 wurde miteinander verglichen. 
Die Globalhypothese Ho „Die vier erwarteten Reduktionen sind gleich“ wird zunächst getestet. Wird die Globalhypothese abgelehnt, werden multiple Vergleiche mit paired-tTests durchgeführt und das multiple Niveau nach Tukey adjustiert. 


\section{Ergebnisse}

\subsection{Ergebnisse Vorversuche}

\subsubsection{Ermittlung geeigneter Kulturbedingungen und Verdünnungsstufen}

Zur Orientierung erfolgte bei drei Probanden die kulturelle Anzucht der Bakterien aus der Probensuspension nach Verdünnung in zehner Schritten auf konventionellen Columbiablut-Platten. Die Bebrütung fand unter aerober und anaerober Atmosphäre statt. Durch Zählen der gewachsenen Einzelkolonien ließen sich die geeigneten Bedingungen zur Quantifizierung der Bakterien im gewonnenen Biofilmmaterial ermitteln. Die Kolonienzahl ließ sich demnach gut bei einer Verdünnung von 1:1000 bestimmen und lag damit im Bereich von ca. 10 bis 500 Kolonien pro Columbiablut-Platte.

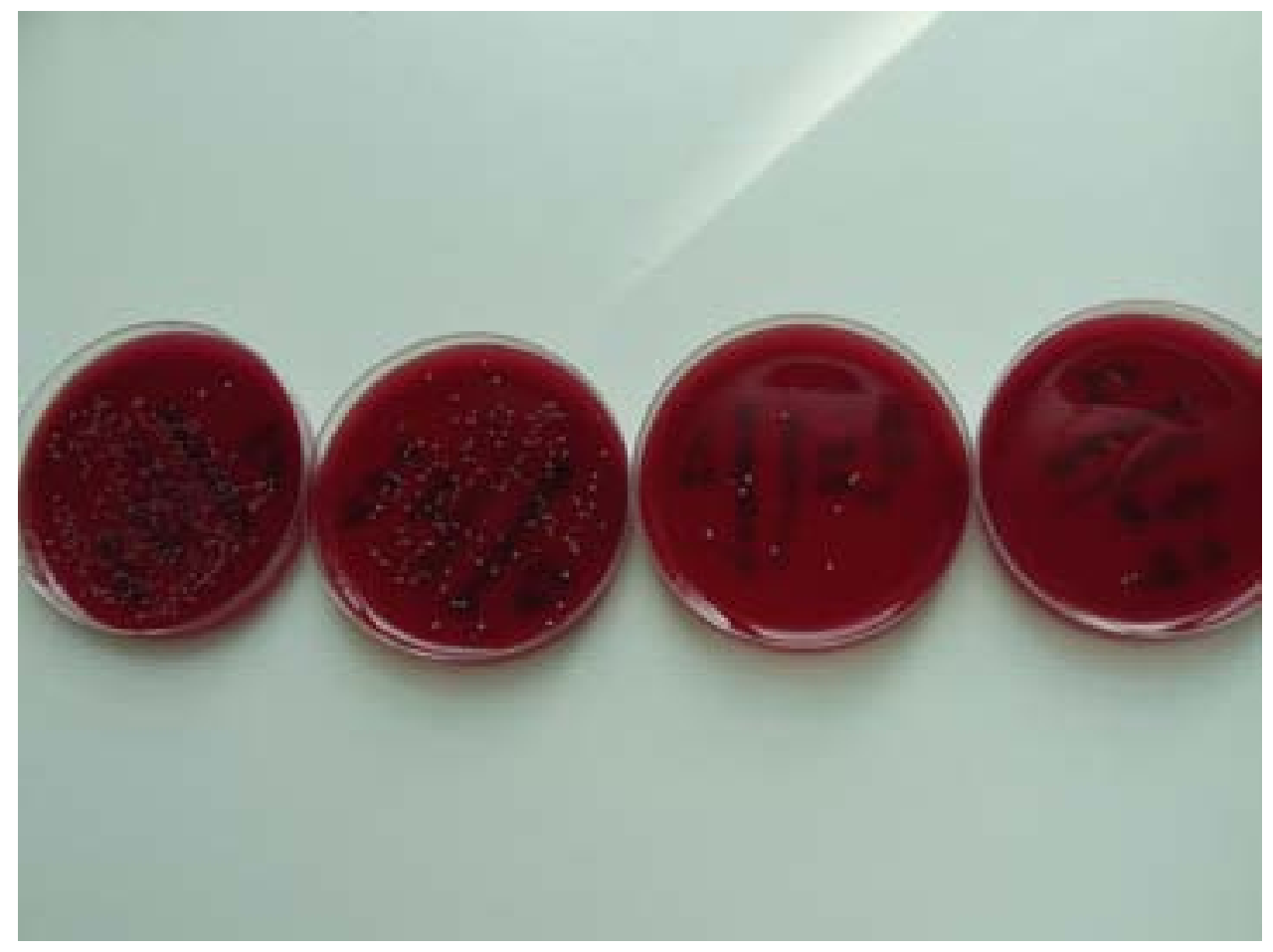

Abb.7 : Bakterienkolonien aus einer Kontrolle auf Columbiablut-Platten mit unterschiedlichen Verdünnungen (Verdünnungsstufen von links nach rechts: 1:100, 1:1000, 1:10000, 1:100000)

Der Einfluss von Luftsauerstoff auf die Kolonienzahl wurde orientierend bei drei Probanden untersucht. Die Ergebnisse sind in Tab. 3 dargestellt. 
Tab. 3: Exemplarischer Vergleich der Kolonienzahl der Biofilmpräparation unter aeroben und anaeroben Bedingungen.

Gezählte Kolonien (Doppelansatz) der Biofilmpräparation von drei Probanden bei einer Verdünnung von 1:1000 (Spalten 2, 4, 6), Mittelwerte (Spalten 3, 5, 7).

\begin{tabular}{|c|c|c|c|c|c|c|}
\hline 1 & 2 & 3 & 4 & 5 & 6 & 7 \\
\hline Aerobe Bedingungen & $\begin{array}{l}18 \\
24\end{array}$ & 21 & $\begin{array}{l}36 \\
15\end{array}$ & 26 & $\begin{array}{l}39 \\
20\end{array}$ & 30 \\
\hline Anaerobe Bedingungen & $\begin{array}{l}238 \\
250\end{array}$ & 244 & $\begin{array}{l}414 \\
298\end{array}$ & 356 & $\begin{array}{l}358 \\
408\end{array}$ & 383 \\
\hline $\begin{array}{l}\text { Anteil Bakterien unter aeroben } \\
\text { zu anaeroben Bedingungen in } \\
\text { (\%) }\end{array}$ & & 7,93 & & 6,81 & & 7,26 \\
\hline
\end{tabular}

Unter aeroben Wachstumsbedingungen ließen sich nur 6,81\% bis 7,93\% der Bakterienkolonien nachweisen, die sich sonst unter Ausschluss von Luftsauerstoff zeigen.

Die Resultate dieser Versuche liefern für die folgenden Hauptversuche wichtige Erkenntnisse. Zur Ermittlung der Reduktion vermehrungsfähiger Bakterien durch die verschiedenen Dekontaminationsverfahren soll die Inkubation unter anaeroben Bedingungen erfolgen, da durch die höheren Kolonienzahlen die Wirkung genauer eingeschätzt werden kann.

Die Verdünnung der Bakteriensuspension auf 1:1000 bietet eine praktikable Orientierung für die folgenden Versuche, um gut auszählbare und reproduzierbare Ergebnisse zu erzielen.

\subsubsection{Bakterientypisierung}

Die Vielzahl morphologisch unterschiedlicher Bakterienkolonien (siehe Abb. 3) spiegelt die große Heterogenität der bakteriellen Population der Mundflora wider, die sich auch in einem oralen Biofilm nachweisen lässt. Einige ausgewählte Bakterienkolonien, die sich morphologisch unterschieden, aber offenbar bei allen Probanden erkennbar waren, wurden als Reinkultur dargestellt. Es folgte die biochemische Charakterisierung mit Standardverfahren. 


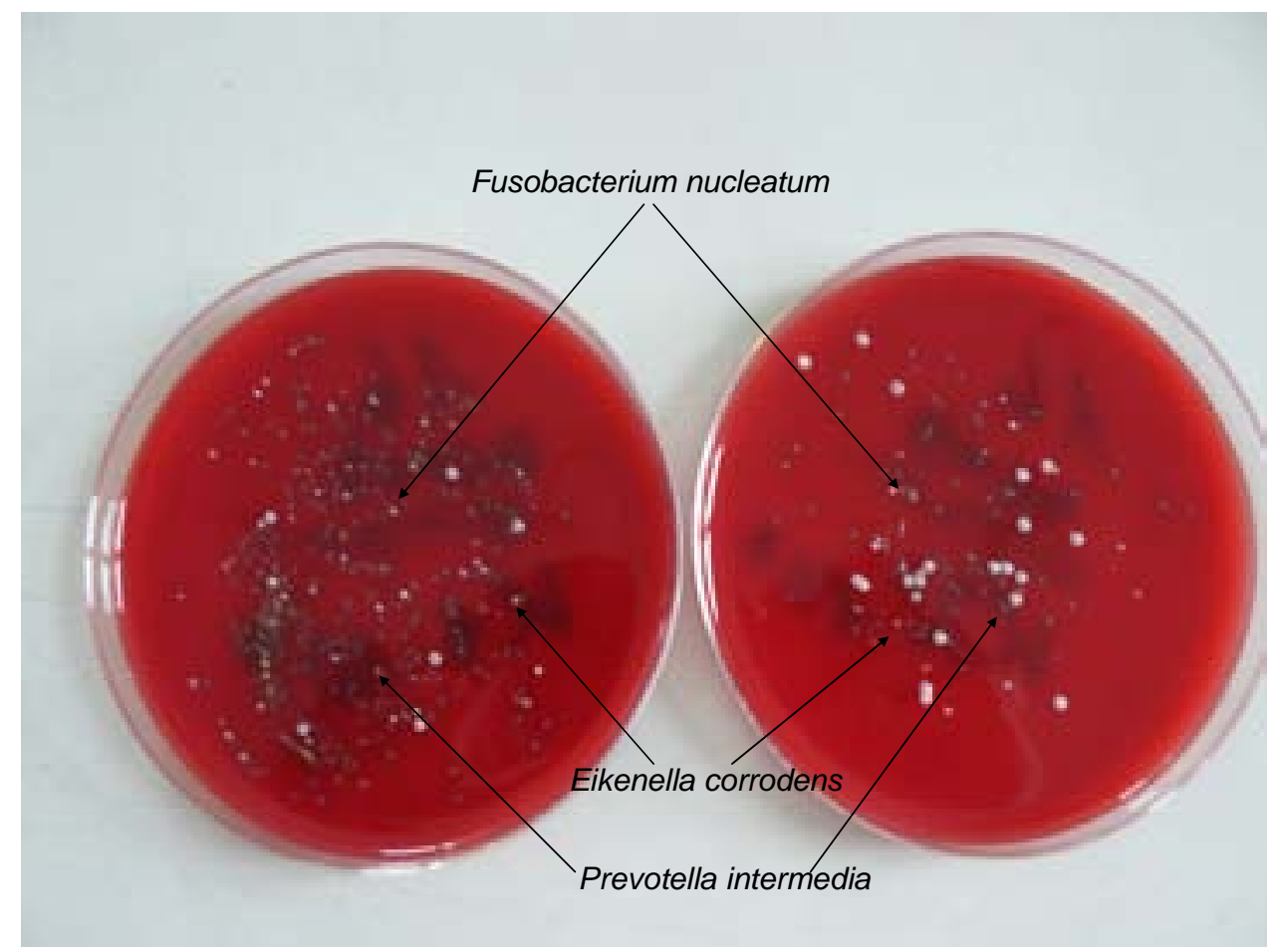

Abb. 8: Morphologische Identifizierung von drei Bakterienspezies (Prevotella intermedia; Fusobacterium nucleatum; C: Eikenella corrodons), die bei allen Probanden nachweisbar waren und auch biochemisch charakterisiert worden sind.

Die Identifizierung der drei untersuchten Kolonie-Arten mittels definierter Stoffwechseleigenschaften führte $\mathrm{zu}$ folgenden Speziesbestimmungen (Abb. 8): Eikenella corrodens, Prevotella intermedia und Fusobacterium nucleatum.

Alle drei Arten gehören zur physiologischen Mundflora und können an der Entstehung von Periodontitis und Periimplantitis beteiligt sein (Rutar et al. 2001, Mombelli 2002, Quirynen et al. 2002a, Renvert et al. 2007). Der molekularbiologische Nachweis im Biofilm und die Auswirkungen der Dekontaminationsverfahren auf diese Bakterien werden in den folgenden Kapiteln dargestellt.

\subsubsection{Auswirkungen der Behandlung auf die bakterielle DNA}

Der Nachweis der spezifischen Bakterien-DNA ist nicht mit der Vitalität dieser Bakterien gleichzusetzen. Auch abgetötete Bakterien können mit dieser Methode nachgewiesen werden, wenn ihre DNA nicht zerstört wurde.

Für diesen Ansatz war es also notwendig, den Effekt der Dekontaminationsverfahren auf die Stabilität der bakteriellen DNA im Zusammenhang mit der PCR zu ermitteln.

Mit diesem Vorversuch ließ sich der bakterizide Effekt und die Auswirkung auf die bakterielle DNA durch die verschiedenen Behandlungsmethoden ermitteln (Tab. 4). Im Vergleich zu den Kontrollen konnte für alle Dekontaminationsverfahren eine Reduktion 
vermehrungsfähiger Bakterien von 98,7-99,8\% gemessen werden. Das traf für alle drei der untersuchten Spezies zu.

Zusätzlich wurde eine speziesspezifische PCR durchgeführt und die Crossingpunkte (Cp) erfasst. Durch Differenzbildung zu den Cps der Kontrollen konnte die Reduktion bakterieller DNA nach der jeweiligen Behandlung bestimmt werden (Tab. 4)

Die mit der PCR erfassbare DNA verringerte sich in den behandelten Proben um 10,7\% bis maximal 22,48\% (Tab. 4). Ein bedeutsamer Unterschied zwischen den Bakterienarten und den Dekontaminationsverfahren bestand nicht. Es wurde damit auch belegt, dass abgetötete Bakterien weiterhin zumindest zu mehr als 75\% mit der PCR detektierbar waren.

Tab. 4: Semiquantitative Erfassung spezifischer bakterieller DNA mit der PCR vor und nach Dekontamination mit den Verfahren L1, L2, S1 und S2

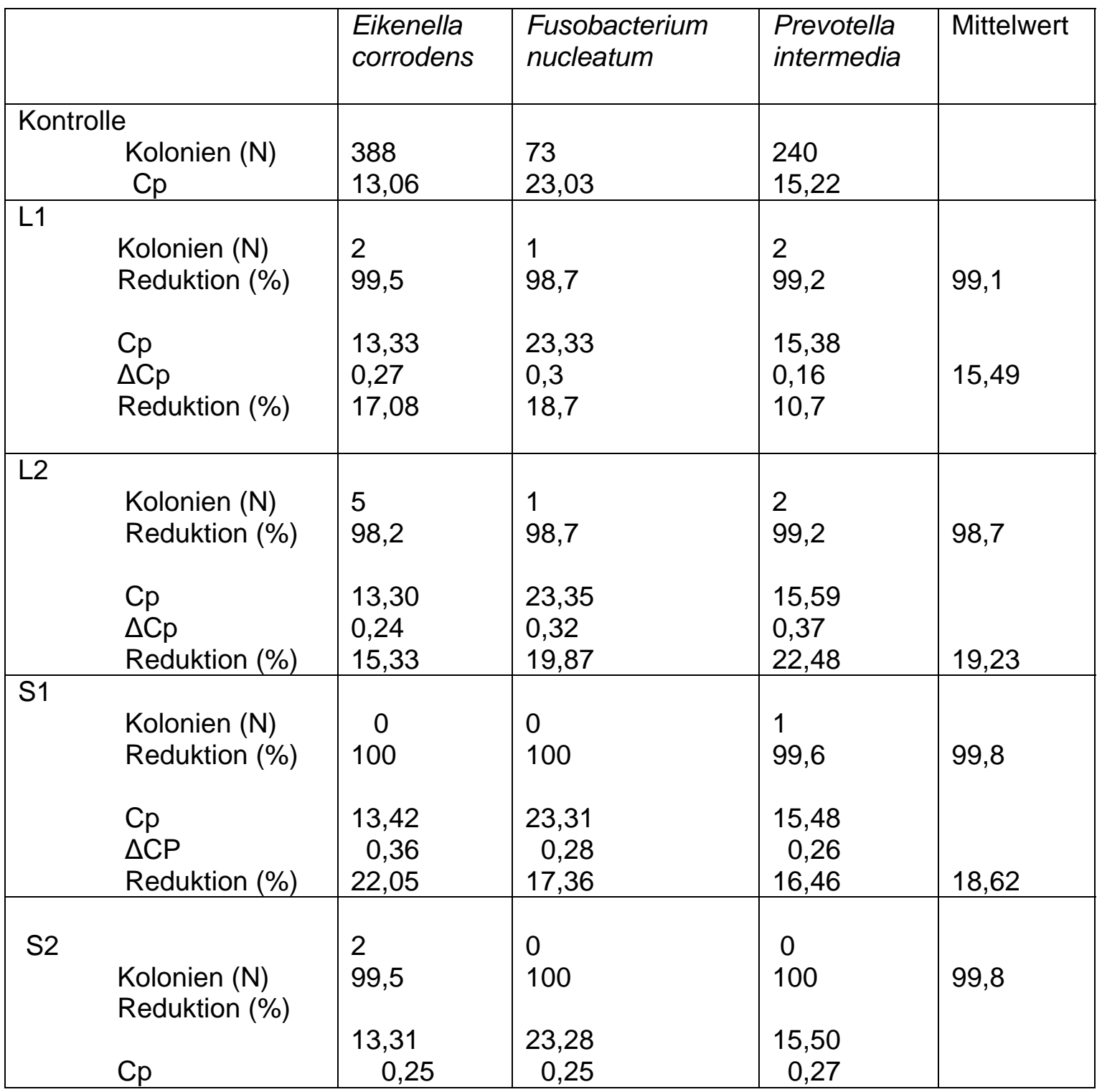




\begin{tabular}{|l|l|l|l|l|}
\hline $\begin{array}{l}\Delta \mathrm{CP} \\
\text { Reduktion (\%) }\end{array}$ & 16,89 & 16,89 & 17,08 & 16,95 \\
\hline
\end{tabular}

\subsection{Kulturelle Untersuchung nach Behandlung der Titanhülsen}

Die oben genannten Einschlusskriterien konnten nicht von allen Probanden eingehalten werden. Zwei mussten aufgrund von Harnwegsinfektionen Antibiotika einnehmen, zwei weitere konnten das geforderte Protokoll nicht konsequent einhalten. Diese Schienen wurden nicht weiter bearbeitet. Damit verblieben für die folgenden Untersuchungen noch von 16 Probanden Titanhülsen mit Biofilmen.

\subsubsection{Dekontamination mit dem Diodenlaser}

Die mikrobiologischen Untersuchungen der entnommenen Proben der 16 Probanden erfolgten immer in Doppelansätzen. $10 \mu \mathrm{l}$ der gut durchmischten Bakteriensuspension wurden nach einer Verdünnung von 1:1000 mit BHI-Medium auf bluthaltigen Agarplatten ausgespatelt und unter anaeroben Bedingungen inkubiert. Die nach 48h erkennbaren Bakterienkolonien wurden gezählt und mit denen der Kontrollproben verglichen. Die Reduktion der Kolonienzahl und die entsprechende Angabe in Prozent beziehen sich auf die jeweils mitlaufenden Kontrollen (Tab. 5).

Die Reduktion überlebender anaerober Bakterien nach Behandlung der Röhrchen mit dem Diodenlaser ist in Tab. 5 dargestellt.

Die durchschnittliche Dekontamination durch den Diodenlaser unter Einbeziehung aller 16 Probanden lag bei $92,22 \%$. 
Tab. 5 : Reduktion der Bakterienkolonien aus dem Biofilm nach Behandlung mit dem Diodenlaser

\begin{tabular}{|c|c|c|c|c|}
\hline Proband & $\begin{array}{l}\text { Kontrolle } \\
\mathrm{N}=\text { Kolonien }\end{array}$ & $\begin{array}{l}\text { Diodenlaser } \\
\mathrm{N}=\text { Kolonien }\end{array}$ & Reduktion (\%) & Mittelwert Reduktion (\%) \\
\hline 1 & $\begin{array}{l}238 \\
250\end{array}$ & $\begin{array}{l}20 \\
9\end{array}$ & $\begin{array}{l}91,6 \\
96,4\end{array}$ & 94 \\
\hline 2 & $\begin{array}{l}414 \\
298\end{array}$ & $\begin{array}{l}19 \\
22\end{array}$ & $\begin{array}{l}95,41 \\
92,62\end{array}$ & 94,015 \\
\hline 3 & $\begin{array}{l}358 \\
408\end{array}$ & $\begin{array}{l}33 \\
29\end{array}$ & $\begin{array}{l}90,78 \\
92,89\end{array}$ & 91,835 \\
\hline 4 & $\begin{array}{l}88 \\
57\end{array}$ & $\begin{array}{l}5 \\
2\end{array}$ & $\begin{array}{l}94,32 \\
96,49\end{array}$ & 95,405 \\
\hline 5 & $\begin{array}{l}496 \\
640\end{array}$ & $\begin{array}{l}16 \\
33\end{array}$ & $\begin{array}{l}96,77 \\
94,84\end{array}$ & 95,805 \\
\hline 6 & $\begin{array}{l}260 \\
312\end{array}$ & $\begin{array}{l}42 \\
46\end{array}$ & $\begin{array}{l}83,85 \\
85,26\end{array}$ & 84,555 \\
\hline 7 & $\begin{array}{l}642 \\
520\end{array}$ & $\begin{array}{l}48 \\
62\end{array}$ & $\begin{array}{l}92,52 \\
88,08\end{array}$ & 90,3 \\
\hline 8 & $\begin{array}{l}132 \\
115\end{array}$ & $\begin{array}{l}11 \\
9\end{array}$ & $\begin{array}{l}91,67 \\
92,17\end{array}$ & 91,92 \\
\hline 9 & $\begin{array}{l}420 \\
376\end{array}$ & $\begin{array}{l}11 \\
33\end{array}$ & $\begin{array}{l}97,38 \\
91,22\end{array}$ & 94,3 \\
\hline 10 & $\begin{array}{l}312 \\
279\end{array}$ & $\begin{array}{l}8 \\
19\end{array}$ & $\begin{array}{l}97,44 \\
93,19\end{array}$ & 95,315 \\
\hline 11 & $\begin{array}{l}87 \\
124\end{array}$ & $\begin{array}{l}9 \\
13\end{array}$ & $\begin{array}{l}89,66 \\
89,52\end{array}$ & 89,59 \\
\hline 12 & $\begin{array}{l}32 \\
21\end{array}$ & $\begin{array}{l}0 \\
2\end{array}$ & $\begin{array}{l}100 \\
90,48\end{array}$ & 95,24 \\
\hline 13 & $\begin{array}{l}452 \\
389\end{array}$ & $\begin{array}{l}39 \\
48\end{array}$ & $\begin{array}{l}91,37 \\
87,66\end{array}$ & 89,515 \\
\hline 14 & $\begin{array}{l}240 \\
282\end{array}$ & $\begin{array}{l}19 \\
11\end{array}$ & $\begin{array}{l}92,08 \\
96,1\end{array}$ & 94,04 \\
\hline 15 & $\begin{array}{l}37 \\
46\end{array}$ & $\begin{array}{l}4 \\
7\end{array}$ & $\begin{array}{l}89,19 \\
84,78\end{array}$ & 86,985 \\
\hline 16 & $\begin{array}{l}188 \\
232\end{array}$ & $\begin{array}{l}13 \\
18\end{array}$ & $\begin{array}{l}93,09 \\
92,24\end{array}$ & 92,665 \\
\hline
\end{tabular}

\subsubsection{Dekontamination mit dem Erbium:YAG-Laser}

Die Methode zur Quantifizierung des bakteriziden Effekts des Er:YAG-Lasers auf den oralen Biofilm wurde analog zum Diodenlaser angewendet. 
Die Ergebnisse der quantitativen kulturellen mikrobiologischen Untersuchungen der Kontrollproben und denen, die nach der Behandlung des Erbium:YAG-Lasers gewonnen wurden, sind in Tab. 6 dargestellt.

Der durchschnittliche Dekontaminationserfolg durch den Einsatz des Erbium:YAGLasers konnte mit 93,91\% ermittelt werden.

Tab. 6 : Reduktion der Bakterienkolonien aus dem Biofilm nach Behandlung mit dem Er:YAG-Laser

\begin{tabular}{|c|c|c|c|c|}
\hline Proband & $\begin{array}{l}\text { Kontrolle } \\
\mathrm{N}=\text { Kolonien }\end{array}$ & $\begin{array}{l}\text { Er:YAG-Laser } \\
\mathrm{N}=\text { Kolonien }\end{array}$ & Reduktion (\%) & Mittelwert Reduktion (\%) \\
\hline 1 & $\begin{array}{l}238 \\
250\end{array}$ & $\begin{array}{l}12 \\
13\end{array}$ & $\begin{array}{l}94,96 \\
94,8\end{array}$ & 94,88 \\
\hline 2 & $\begin{array}{l}414 \\
298\end{array}$ & $\begin{array}{l}15 \\
11\end{array}$ & $\begin{array}{l}96,38 \\
96,31\end{array}$ & 96,345 \\
\hline 3 & $\begin{array}{l}358 \\
408\end{array}$ & $\begin{array}{l}26 \\
26\end{array}$ & $\begin{array}{l}92,74 \\
93,63\end{array}$ & 93,185 \\
\hline 4 & $\begin{array}{l}88 \\
57\end{array}$ & $\begin{array}{l}2 \\
4\end{array}$ & $\begin{array}{l}97,73 \\
92,98\end{array}$ & 95,355 \\
\hline 5 & $\begin{array}{l}496 \\
640\end{array}$ & $\begin{array}{l}8 \\
26\end{array}$ & $\begin{array}{l}98,39 \\
95,94\end{array}$ & 97,165 \\
\hline 6 & $\begin{array}{l}260 \\
312\end{array}$ & $\begin{array}{l}18 \\
24\end{array}$ & $\begin{array}{l}93,08 \\
92,31\end{array}$ & 92,695 \\
\hline 7 & $\begin{array}{l}642 \\
520\end{array}$ & $\begin{array}{l}33 \\
44\end{array}$ & $\begin{array}{l}94,86 \\
91,54\end{array}$ & 93,2 \\
\hline 8 & $\begin{array}{l}132 \\
115\end{array}$ & $\begin{array}{l}2 \\
7\end{array}$ & $\begin{array}{l}98,48 \\
93,91\end{array}$ & 96,195 \\
\hline 9 & $\begin{array}{l}420 \\
376\end{array}$ & $\begin{array}{l}9 \\
21\end{array}$ & $\begin{array}{l}97,86 \\
94,41\end{array}$ & 96,135 \\
\hline 10 & $\begin{array}{l}312 \\
279\end{array}$ & $\begin{array}{l}7 \\
13\end{array}$ & $\begin{array}{l}97,76 \\
95,34\end{array}$ & 96,55 \\
\hline 11 & $\begin{array}{l}87 \\
124\end{array}$ & $\begin{array}{l}11 \\
9\end{array}$ & $\begin{array}{l}87,36 \\
92,74\end{array}$ & 90,05 \\
\hline 12 & $\begin{array}{l}32 \\
21\end{array}$ & $\begin{array}{l}1 \\
1\end{array}$ & $\begin{array}{l}96,88 \\
95,24\end{array}$ & 96,06 \\
\hline 13 & $\begin{array}{l}452 \\
389\end{array}$ & $\begin{array}{l}40 \\
44\end{array}$ & $\begin{array}{l}91,15 \\
88,69\end{array}$ & 89,92 \\
\hline 14 & $\begin{array}{l}240 \\
282\end{array}$ & $\begin{array}{l}25 \\
19\end{array}$ & $\begin{array}{l}89,58 \\
93,26\end{array}$ & 91,42 \\
\hline 15 & $\begin{array}{l}37 \\
46\end{array}$ & $\begin{array}{l}2 \\
6\end{array}$ & $\begin{array}{l}94,59 \\
86,96\end{array}$ & 90,775 \\
\hline 16 & $\begin{array}{l}188 \\
232\end{array}$ & $\begin{array}{l}15 \\
16\end{array}$ & $\begin{array}{l}92,02 \\
93,1\end{array}$ & 92,56 \\
\hline
\end{tabular}




\subsubsection{Dekontamination mit Chlorhexidindigluconat}

Die Aufarbeitung des mit Chlorhexidindigluconat gespülten Biofilms zur weiteren kulturellen Anzucht der überlebenden Bakterien fand analog zu 5.2.1 statt.

Die Reduktion überlebender anaerober Bakterien nach Behandlung der Röhrchen mit der Chlorhexidindigluconat-Spülung ist in Tab. 7 dargestellt.

Die durchschnittliche Eliminierungsrate vermehrungsfähiger Bakterien durch die Dekontaminationsversuche mit Chlorhexidindigluconat unter den angegebenen Bedingungen liegt unter Einbeziehung aller Probanden bei 77,51\%.

Tab. 7: Reduktion der Bakterienkolonien aus dem Biofilm nach Behandlung mit Chlorhexidindigluconat

\begin{tabular}{|c|c|c|c|c|}
\hline Proband & $\begin{array}{l}\text { Kontrolle } \\
\text { (Kolonien) }\end{array}$ & $\begin{array}{l}\text { Chlorhexidin- } \\
\text { digluconat (S1) } \\
\text { (Kolonien) }\end{array}$ & Reduktion (\%) & Mittelwert Reduktion (\%) \\
\hline 1 & $\begin{array}{l}238 \\
250\end{array}$ & $\begin{array}{l}52 \\
38\end{array}$ & $\begin{array}{l}78,15 \\
84,8\end{array}$ & 81,475 \\
\hline 2 & $\begin{array}{l}414 \\
298\end{array}$ & $\begin{array}{l}57 \\
42\end{array}$ & $\begin{array}{l}86,23 \\
85,91\end{array}$ & 86,07 \\
\hline 3 & $\begin{array}{l}358 \\
408\end{array}$ & $\begin{array}{l}61 \\
80\end{array}$ & $\begin{array}{l}82,96 \\
80,39\end{array}$ & 81,65 \\
\hline 4 & $\begin{array}{l}88 \\
57\end{array}$ & $\begin{array}{l}13 \\
7\end{array}$ & $\begin{array}{l}85,23 \\
87,72\end{array}$ & 86,475 \\
\hline 5 & $\begin{array}{l}496 \\
640\end{array}$ & $\begin{array}{l}87 \\
108\end{array}$ & $\begin{array}{l}82,46 \\
83,13\end{array}$ & 82,795 \\
\hline 6 & $\begin{array}{l}260 \\
312\end{array}$ & $\begin{array}{l}76 \\
89\end{array}$ & $\begin{array}{l}70,77 \\
71,47\end{array}$ & 71,12 \\
\hline 7 & $\begin{array}{l}642 \\
520\end{array}$ & $\begin{array}{l}232 \\
219\end{array}$ & $\begin{array}{l}63,86 \\
57,88\end{array}$ & 60,87 \\
\hline 8 & $\begin{array}{l}132 \\
115\end{array}$ & $\begin{array}{l}27 \\
18\end{array}$ & $\begin{array}{l}79,55 \\
84,35\end{array}$ & 81,95 \\
\hline 9 & $\begin{array}{l}420 \\
376\end{array}$ & $\begin{array}{l}46 \\
63\end{array}$ & $\begin{array}{l}89,05 \\
83,24\end{array}$ & 86,145 \\
\hline 10 & $\begin{array}{l}312 \\
279\end{array}$ & $\begin{array}{l}71 \\
56\end{array}$ & $\begin{array}{l}77,24 \\
79,93\end{array}$ & 78,585 \\
\hline 11 & $\begin{array}{l}87 \\
124\end{array}$ & $\begin{array}{l}34 \\
38\end{array}$ & $\begin{array}{l}60,92 \\
69,35\end{array}$ & 65,135 \\
\hline 12 & $\begin{array}{l}32 \\
21\end{array}$ & $\begin{array}{l}9 \\
3\end{array}$ & $\begin{array}{l}71,88 \\
85,71\end{array}$ & 78,795 \\
\hline 13 & $\begin{array}{l}452 \\
389\end{array}$ & $\begin{array}{l}208 \\
239\end{array}$ & $\begin{array}{l}53,98 \\
38,56\end{array}$ & 46,27 \\
\hline 14 & $\begin{array}{l}240 \\
282\end{array}$ & $\begin{array}{l}20 \\
17\end{array}$ & $\begin{array}{l}91,67 \\
93,97\end{array}$ & 92,82 \\
\hline
\end{tabular}




\begin{tabular}{|l|l|l|l|l|}
\hline 15 & 37 & 18 & 51,35 & 72,415 \\
& 46 & 3 & 93,48 & \\
\hline 16 & 188 & 28 & 85,11 & 87,6 \\
& 232 & 23 & 90,09 & \\
\hline
\end{tabular}

\subsubsection{Dekontamination mit Octenidindihydrochlorid/2-Phenoxyethanol}

Die Präparation des mit Octenidindihydrochlorid/2-Phenoxyethanol behandelten Biofilms und die mikrobiologische Untersuchung wurden analog zu 5.2.1 durchgeführt. Tab. 8 gibt die Kolonienzahl nach Anwendung der Spüllösung, sowie die Unterschiede im Vergleich zu den Kontrollen wieder.

Die Reduktion vermehrungsfähiger Bakterien durch Octenidindihydrochlorid/2Phenoxyethanol gemittelt über alle 16 Probanden beträgt 91,51\%.

Tab. 8: Reduktion der Bakterienkolonien aus dem Biofilm nach Behandlung mit Octenidindihydrochlorid/2-phenoxyethanol

\begin{tabular}{|c|c|c|c|c|}
\hline Proband & $\begin{array}{l}\text { Kontrolle } \\
\mathrm{N}=\text { Kolonien }\end{array}$ & $\begin{array}{l}\text { Octenidinhydrochlorid/ } \\
\text { 2-Phenoxyethanol (S2) } \\
\mathrm{N}=\text { Kolonien }\end{array}$ & Reduktion (\%) & Mittelwert Reduktion (\%) \\
\hline 1 & $\begin{array}{l}238 \\
250\end{array}$ & $\begin{array}{l}25 \\
12\end{array}$ & $\begin{array}{l}89,5 \\
95,2\end{array}$ & 92,35 \\
\hline 2 & $\begin{array}{l}414 \\
298\end{array}$ & $\begin{array}{l}20 \\
24\end{array}$ & $\begin{array}{l}95,17 \\
91,95\end{array}$ & 93,56 \\
\hline 3 & $\begin{array}{l}358 \\
408\end{array}$ & $\begin{array}{l}39 \\
35\end{array}$ & $\begin{array}{l}89,11 \\
91,42\end{array}$ & 90,265 \\
\hline 4 & $\begin{array}{l}88 \\
57\end{array}$ & $\begin{array}{l}13 \\
7\end{array}$ & $\begin{array}{l}93,18 \\
96,49\end{array}$ & 94,835 \\
\hline 5 & $\begin{array}{l}496 \\
640\end{array}$ & $\begin{array}{l}33 \\
47\end{array}$ & $\begin{array}{l}93,35 \\
92,66\end{array}$ & 93,005 \\
\hline 6 & $\begin{array}{l}260 \\
312\end{array}$ & $\begin{array}{l}41 \\
17\end{array}$ & $\begin{array}{l}84,23 \\
94,55\end{array}$ & 89,39 \\
\hline 7 & $\begin{array}{l}642 \\
520\end{array}$ & $\begin{array}{l}49 \\
75\end{array}$ & $\begin{array}{l}92,37 \\
85,58\end{array}$ & 88,975 \\
\hline 8 & $\begin{array}{l}132 \\
115\end{array}$ & $\begin{array}{l}11 \\
13\end{array}$ & $\begin{array}{l}91,67 \\
88,7\end{array}$ & 90,185 \\
\hline 9 & $\begin{array}{l}420 \\
376\end{array}$ & $\begin{array}{l}38 \\
8\end{array}$ & $\begin{array}{l}90,95 \\
97,87\end{array}$ & 94,41 \\
\hline 10 & $\begin{array}{l}312 \\
279\end{array}$ & $\begin{array}{l}9 \\
1\end{array}$ & $\begin{array}{l}97,12 \\
99,64\end{array}$ & $\begin{array}{l}98,38 \\
\end{array}$ \\
\hline 11 & $\begin{array}{l}87 \\
124\end{array}$ & $\begin{array}{l}12 \\
9\end{array}$ & $\begin{array}{l}86,21 \\
92,74\end{array}$ & 89,475 \\
\hline
\end{tabular}




\begin{tabular}{|l|l|l|l|l|}
\hline 12 & 32 & 0 & 100 & 97,62 \\
& 21 & 1 & 95,24 & \\
\hline 13 & 452 & 91 & 79,87 & 76,18 \\
& 389 & 107 & 72,49 & \\
\hline 14 & 240 & 12 & 95 & 94,485 \\
& 282 & 17 & 93,97 & \\
\hline 15 & 37 & 3 & 91,89 & 88,335 \\
& 46 & 7 & 84,78 & \\
\hline 16 & 188 & 17 & 90,96 & 92,68 \\
& 232 & 13 & 94,4 & \\
\hline
\end{tabular}

\subsubsection{Vergleich der Wirksamkeit der Dekontaminationsverfahren auf Grundlage der Kulturergebnisse}

Ziel der durchgeführten Untersuchungen war, die Effizienz der Verfahren zur Abtötung von lebenden anaeroben Bakterien im Biofilm zu ermitteln. Dazu ist es erforderlich, biometrische Verfahren anzuwenden.

Die Reduktionen lebender Bakterien unter Anwendung der vier Methoden mit Diodenlaser (L1) und Erbium:YAG-Laser (L2) sowie Spülung mit Chlorhexidindigluconat (S1) und Octenidindihydrochlorid/2-Phenoxyethanol (S2) wurden miteinander verglichen. In Tab. 9 sind die Mittelwerte der Reduktionen vermehrungsfähiger Bakterien durch die vier Verfahren für jeweils alle 16 Probanden zusammengefasst.

Tab. 9: Darstellung der Mittelwerte der Reduktion (\%) der kultivierbaren Bakterien im Biofilm der 16 Probanden durch Behandlung mit dem Diodenlaser (L1), Er:YAG-Laser (L2), Chlorhexidindigluconat (S1), sowie Octenidindihydrochlorid/2-Phenoxyethanol (S2)

\begin{tabular}{|l|l|l|l|}
\hline L1 & L2 & S1 & S2 \\
\hline 94 & 94,88 & 81,475 & 92,35 \\
\hline 94,015 & 96,345 & 86,07 & 93,56 \\
\hline 91,835 & 93,185 & 81,675 & 90,265 \\
\hline 95,405 & 95,355 & 86,475 & 94,835 \\
\hline 95,805 & 97,165 & 82,795 & 93,005 \\
\hline 84,555 & 92,695 & 71,12 & 89,39 \\
\hline 90,3 & 93,2 & 60,87 & 88,975 \\
\hline 91,92 & 96,195 & 81,95 & 90,185 \\
\hline 94,3 & 96,135 & 86,145 & 94,41 \\
\hline 95,315 & 96,55 & 78,585 & 98,38 \\
\hline 89,59 & 90,05 & 65,135 & 89,475 \\
\hline 95,24 & 96,06 & 78,795 & 97,62 \\
\hline 89,515 & 89,92 & 46,27 & 76,18 \\
\hline 94,09 & 91,42 & 92,82 & 94,485 \\
\hline 86,985 & 90,775 & 72,415 & 88,335 \\
\hline 92,665 & 92,56 & 87,6 & 92,68 \\
\hline & & & \\
\hline
\end{tabular}


Zur deskriptiven Übersicht wurden der Mittelwert, Standardfehler sowie 95\% Konfidenzintervalle für die erwarteten Reduktionen berechnet (Tab. 10).

Die Mittelwerte der vier Verfahren zeigen Eliminierungsraten von 92,2\% für den Diodenlaser (L1), 93,9\% für der Er:YAG-Laser (L2), sowie $\quad 77,5 \%$ für Chlorhexidindigluconat (S1) und 90,5\% für Octenidindihydrochlorid/2-Phenoxyethanol (S2) (Tab.10 und Abb.9). In Abb. 10 findet sich die entsprechende Box-Plot-Darstellung.

Tab. 10: Mittelwerte, Standardfehler, 95\% Konfidenzintervalle durch Behandlung mit den vier Dekontaminationsverfahren Diodenlaser (L1), Er:YAG-Laser (L2), Chlorhexidindigluconat (S1), Octenidindihydrochlorid/2-Phenoxyethanol (S2)

\begin{tabular}{|l|l|l|l|l|l|}
\hline $\begin{array}{l}\text { Probanden } \\
(\mathrm{N})\end{array}$ & Methode & Mittelwert & Standardfehler & $\begin{array}{l}\text { Untergrenze } \\
(95 \%)\end{array}$ & $\begin{array}{l}\text { Obergrenze } \\
(95 \%)\end{array}$ \\
\hline 16 & L1 & 92,22094 & 2,096795 & 87,92585 & 96,51603 \\
\hline 16 & L2 & 93,90562 & 2,807775 & 88,15416 & 99,65709 \\
\hline 16 & S1 & 77,51219 & 3,292154 & 70,76852 & 84,25586 \\
\hline 16 & S2 & 90,508 & 2,314101 & 85,76790 & 95,24835 \\
\hline
\end{tabular}




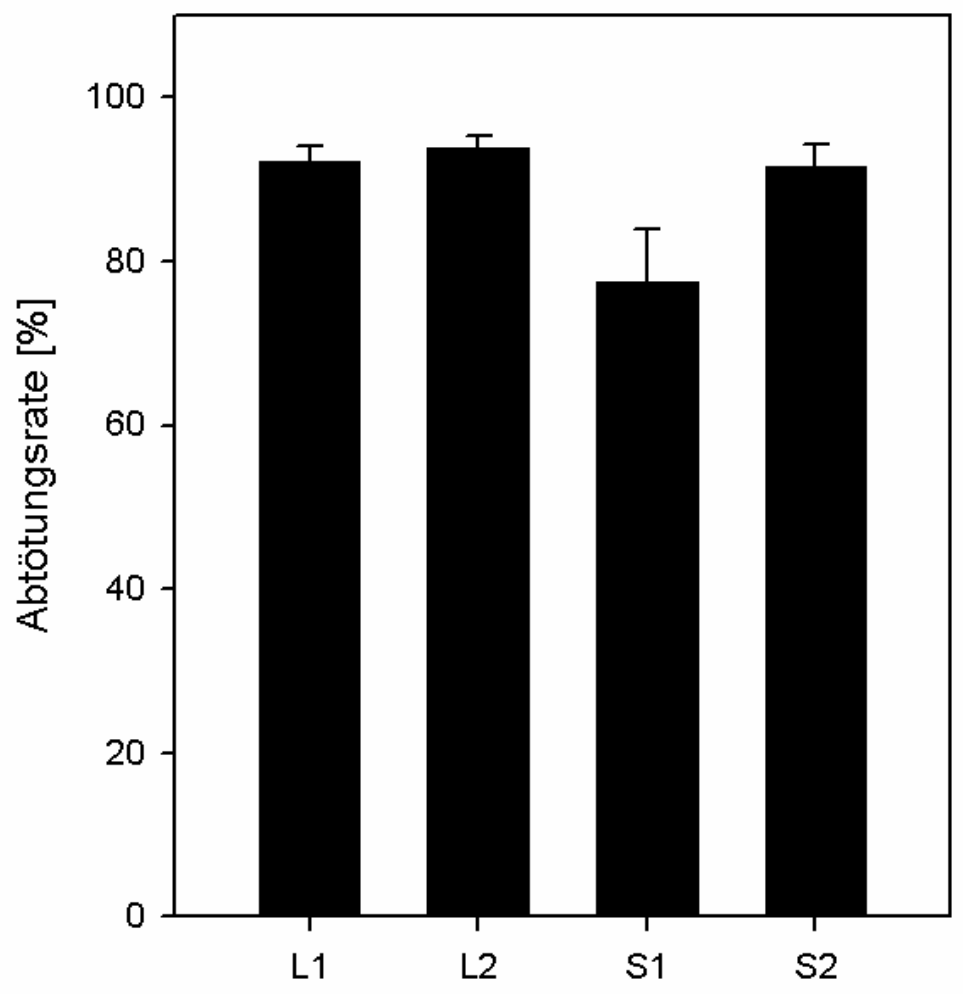

Dekontaminationsverfahren

Abb. 9: Abtötungsrate der kulturell vermehrbaren Bakterien in den Biofilmpräparationen nach Behandlung mit den Dekontaminationsverfahren Diodenlaser (L1), Er:YAG-Laser (L2), Chlorhexidindigluconat (S1), Octenidindihydrochlorid/2-Phenoxyethanol (S2) 


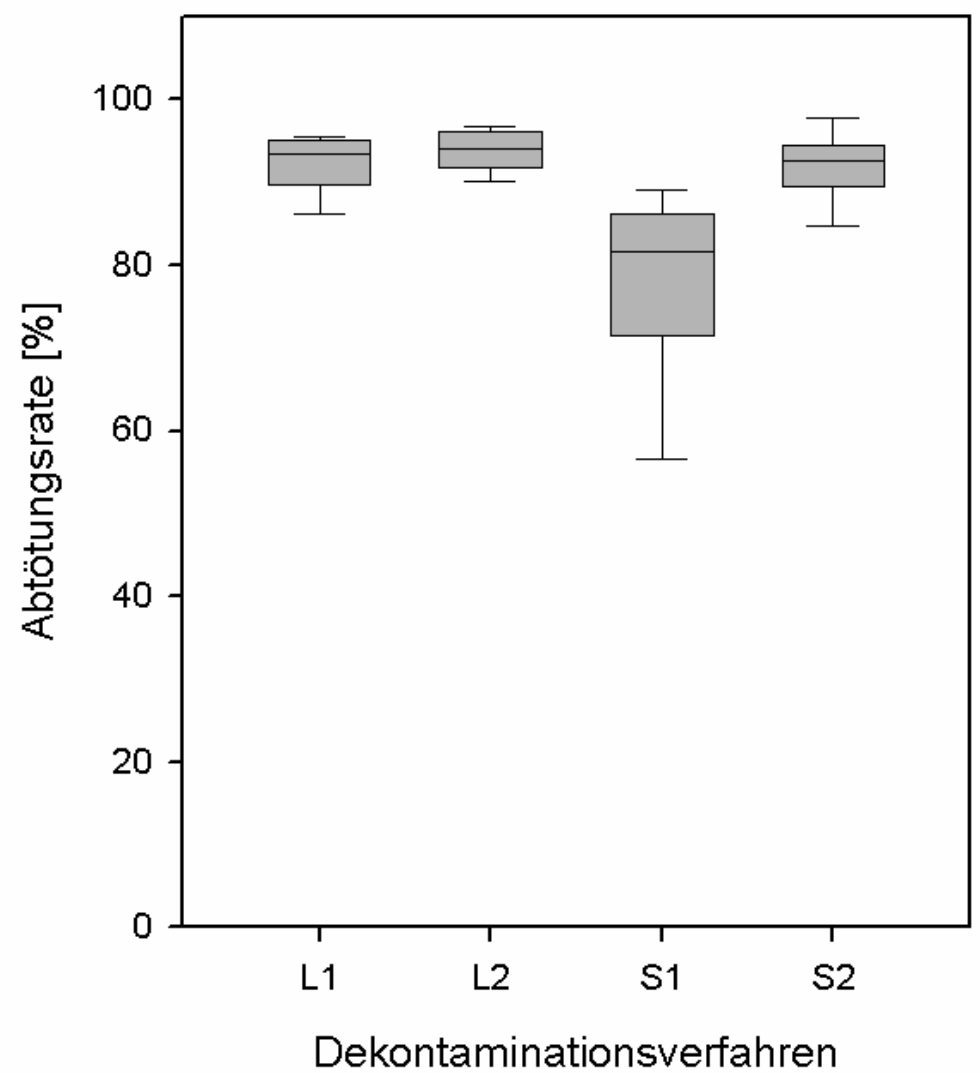

Abb. 10: Abtötungsrate der kulturell vermehrbaren Bakterien in den Biofilmpräparationen nach Behandlung mit den Dekontaminationsverfahren Diodenlaser (L1), Er:YAG-Laser (L2), Chlorhexidindigluconat (S1) sowie Octenidindihydrochlorid/2-Phenoxyethanol (S2) in der Box-PlotDarstellung

Die statistische Signifikanz der Unterschiede wird in der folgenden biometrischen Auswertung geprüft (Tab. 11)

Tab. 11: Multiple Vergleiche zur Bestimmung der Unterschiede der Dekontaminationsmethoden auf Signifikanz

\begin{tabular}{|l|c|l|l|l|}
\hline Vergleich & Mittelwertsdifferenz & $p$-Wert & $\begin{array}{l}\text { Adjustierter } \\
p \text {-Wert } \\
\text { (Tukey) }\end{array}$ & Interpretation \\
\hline L1 vs. L2 & $-1,68$ & 0,0126 & 0,0548 & $\begin{array}{l}\text { Nicht } \\
\text { signifikant }\end{array}$ \\
\hline L1 vs. S1 & 14,27 & 0,00004 & $\mathbf{0 , 0 0 0 2 4}$ & Signifikant \\
\hline L1 vs. S2 & 1,71 & 0,1366 & 0,4267 & $\begin{array}{l}\text { Nicht } \\
\text { signifikant }\end{array}$ \\
\hline L2 vs. S1 & 16,39 & 0,000020 & $\mathbf{0 , 0 0 0 1 2}$ & Signifikant \\
\hline L2 vs. S2 & 3,40 & 0,0101 & $\mathbf{0 , 0 4 4 7}$ & Signifikant \\
\hline S1 vs. S2 & $-12,99$ & 0,000032 & $\mathbf{0 , 0 0 0 2}$ & Signifikant \\
\hline
\end{tabular}


Die multiplen Vergleiche der Dekontaminationseffekte der verschiedenen Methoden belegen keinen signifikanten Unterschied zwischen den beiden Laser-Verfahren und ebenso nicht zwischen dem Diodenlaser (L1) und Octenidindihydrochlorid/2Phenoxyethanol (S2). Chlorhexidindigluconat (S1) erscheint signifikant weniger wirksam als Octenidindihydrochlorid/2-Phenoxyethanol (S2).

Der Diodenlaser (L1) zeigt eine signifikant größere Wirkung gegenüber der Behandlung mit Chlorhexidindigluconat (S1). Der Er:YAG-Laser eliminiert lebende Bakterien signifikant deutlicher als die Spüllösungen Chlorhexidindigluconat (S1) und Octenidindihydrochlorid/2-Phenoxyethanol (S2).

Zusammenfassend zeigte unter den beschriebenen Bedingungen anaerob wachsende Bakterien im oralen Biofilm der Er:YAG-Laser die deutlichste Dekontaminationswirkung, es folgt der Diodenlaser, allerdings ohne signifikanten Unterschied. An dritter Stelle steht Octenidindihydrochlorid/2-Phenoxyethanol mit signifikantem Abstand zum Er:YAG-Laser, aber nicht zum Diodenlaser. Den geringsten Dekontaminationseffekt erreicht in dem Versuchsaufbau Chlorhexidindigluconat mit signifikantem Abstand zu allen anderen Verfahren.

\subsection{Molekularbiologische Untersuchung nach Behandlung der}

\section{Titankörper}

Nach Etablierung der spezifischen Polymerase-Kettenreaktion und den gewonnenen Erfahrungen aus dem Vorversuch mit den getrockneten Bakteriensuspensionen erfolgte die semiquantitative Analyse der Bakterien im Biofilm. Die Untersuchungen sollten Aufschluss darüber geben, in welchem Ausmaß der Biofilm durch die Dekontaminationsverfahren entfernt wird. Als Marker wurde dafür der PCR-Nachweis der DNA der Zielbakterien Eikenella corrodens, Fusobacterium nucleatum und Eikenella intermedia verwendet, der sowohl lebende als auch den größten Teil der abgetöteten Mikroorganismen erfasst.

Die Präparation des nach den Behandlungen verbleibenden Biofilms erfolgte ebenso wie bei den Kontrollen, wie unter 4.3.3 beschrieben.

Die PCR ist von ihrem Prinzip her eine außerordentlich sensitive Methode und damit sehr störanfällig für Kontaminationen. Es wurden im Folgenden nur Ergebnisse von denjenigen Probanden dargestellt, bei deren Untersuchungen keine Hinweise auf Kontaminationen oder technisch bedingte Probleme vorlagen. Kontaminationen, 
erkennbar u.a. an einer positiven Reaktion der negativen $\mathrm{H}_{2} \mathrm{O}$-Kontrollen, war ein wiederholt auftretendes Problem der hochsensitiven PCR-Methode und führte zu nicht verwertbaren Daten. Ebenso wurden nur die Ergebnisse der semiquantitativen PCR derjenigen Probanden eingeschlossen, bei denen die unbehandelten Kontrollen im Doppelansatz eine Abweichung von weniger als den Faktor zwei auseinanderlagen und in den Proben für alle vier Dekontaminationsverfahren auswertbar waren. Somit verblieben bei der Analyse auf DNA von Fusobacterium nucleatum sechs Probanden und für Eikenella corrodens sowie Prevotella intermedia je fünf Probanden zur Auswertung. Zur Spezifitätskontrolle wurden die Amplifikate in einer Agarosegelelektrophorese auf ihre entsprechende Größe untersucht (Abb. 11). Bei allen weiter untersuchten Probanden konnte die charakterisierende Größe bestätigt werden.

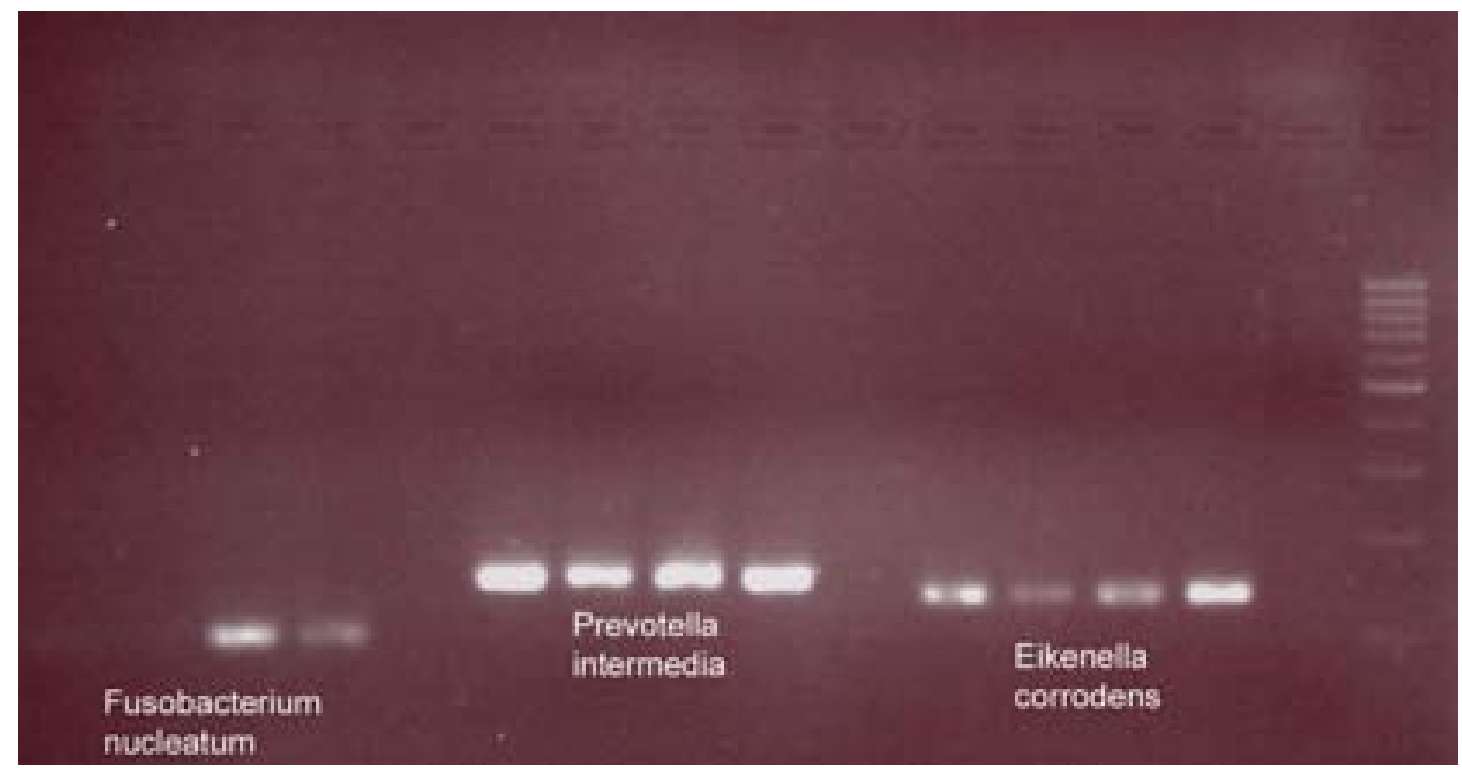

Abb. 11: Auftrennung der Amplifikate nach der PCR in der Agarosegelelektrophorese zur Spezifitätskontrolle. Die dargestellten Amplifikate der untersuchten Bakterienspezies Fusobacterium nucleatum, Prevotella intermedia und Eikenella corrodens entsprechen den erwarteten Größen

Alle PCR-Untersuchungen wurden je einmal wiederholt und jeweils der Crossingpoint (Cp) bestimmt. In die Berechnung der Reduktion der Bakterienmenge wurden die resultierenden Mittelwerte eingesetzt. Der Cp-Wert der jeweils unbehandelten Kontrollen diente als Bezugspunkt für die semiquantitative Auswertung. Aus der Differenz der CpWerte $(\Delta C p)$ ergab sich wie oben genannt über $X=2^{\Delta C p}$ die Abnahme der bakteriellen DNA, die sich in \% zum Kontrollwert angeben ließ. 


\subsubsection{Untersuchung von Fusobacterium nucleatum}

Die DNA-Menge von Fusobacterium nucleatum im Biofilmmaterial reduzierte sich nach der Chlorhexidindigluconat-Behandlung um 7,4\%, nach Octenidindihydrochlorid/2Phenoxyethanol-Behdandlung um 11,4\%. Die Behandlung mit dem Diodenlaser ergab eine Reduktionsrate von 30,4\%. Die größte Reduktionsrate erwies sich bei dem Er:YAG-Laser mit 46\% (Tab.12; Abb.12).

Tab. 12: Einfluss der Dekontaminationsverfahren Diodenlaser (L1), Erbium:YAG-Laser (L2), Chlorhexidindigluconat (S1) und Octendindihydrochlorid/2-Phenoxyethanol (S2), auf den DNA Nachweis von Fusobacterium nucleatum im Biofilm (Cp = crossingpoint)

\begin{tabular}{|l|l|l|l|l|l|l|}
\hline $\begin{array}{l}\text { Fusobacterium } \\
\text { nucleatum }\end{array}$ & Proband 1 & Proband 3 & Proband 5 & Proband 6 & Proband 7 & Proband 13 \\
\hline $\begin{array}{l}\text { Cp } \\
\text { Kontrollen }\end{array}$ & 17,31 & 10,97 & 11,17 & 9,97 & 17,58 & 22,52 \\
\hline M CpKontr. & 15,74 & 10,33 & 11,69 & 9,52 & 18,16 & 20,74 \\
\hline Cp-L1 & 17,37 & 10,65 & 11,43 & 9,75 & 17,87 & 21,63 \\
\hline mCp-L1 & 16,94 & 11,5 & 11,67 & 10,28 & 18,63 & 23,05 \\
\hline$\Delta$ Cp & 17,16 & 11,36 & 11,5 & 10,14 & 18,71 & 21,15 \\
\hline $2^{\Delta C p}$ & 0,63 & 0,71 & 0,16 & 0,46 & 0,8 & 0,47 \\
\hline Reduktion (\%) & 3,646 & 0,611 & 0,895 & 0,727 & 0,574 & 0,722 \\
\hline Cp-L2 & 35,38 & 38,87 & 10,5 & 27,3 & 42,57 & 27,8 \\
\hline M Cp-L2 & 17,62 & 12,1 & 11,92 & 11,37 & 19,83 & 22,31 \\
\hline$\Delta$ Cp & 17,2 & 11,54 & 11,7 & 10,15 & 19,27 & 22,09 \\
\hline $2^{\Delta C p}$ & 17,41 & 11,82 & 11,81 & 10,76 & 19,55 & 22,2 \\
\hline Reduktion (\%) & 0,88 & 1,17 & 0,38 & 1,01 & 1,68 & 0,57 \\
\hline Cp-S1 & 0,543 & 0,444 & 0,768 & 0,497 & 0,312 & 0,674 \\
\hline m Cp-S1 & 17,16 & 10,42 & 12,04 & 9,47 & 18,11 & 19,94 \\
\hline$\Delta$ Cp & 16,22 & 10,88 & 11,18 & 10,62 & 17,63 & 23,34 \\
\hline $2^{\Delta C p}$ & 16,69 & 10,65 & 11,61 & 10,05 & 18,87 & 21,6 \\
\hline Reduktion (\%) & 0,16 & 0,0 & 0,18 & 0,3 & 0,0 & 0,05 \\
\hline Cp-S2 & 10,5 & 0,0 & 11,73 & 18,77 & 0,0 & 3,41 \\
\hline m Cp-S2 & 17,27 & 10,99 & 11,36 & 10,33 & 17,99 & 22,83 \\
\hline$\Delta$ Cp & 16,52 & 10,31 & 11,71 & 9,8 & 18,21 & 20,5 \\
\hline & 16,86 & 10,65 & 11,54 & 10,07 & 18,13 & 21,67 \\
\hline & 0,37 & 0,00 & 0,11 & 0,32 & 0,26 & 0,03 \\
\hline & & 1,0 & 0,883 & 0,812 & 1,0 & 0,966 \\
\hline
\end{tabular}




\begin{tabular}{|l|l|l|l|l|l|l|}
\hline $2^{\mathrm{ACp}}$ & 0,774 & 0,998 & 0,927 & 0,801 & 0,835 & 0,979 \\
\hline Reduktion (\%) & 22,62 & 0,0 & 7,34 & 19,89 & 16,49 & 2,06 \\
\hline
\end{tabular}

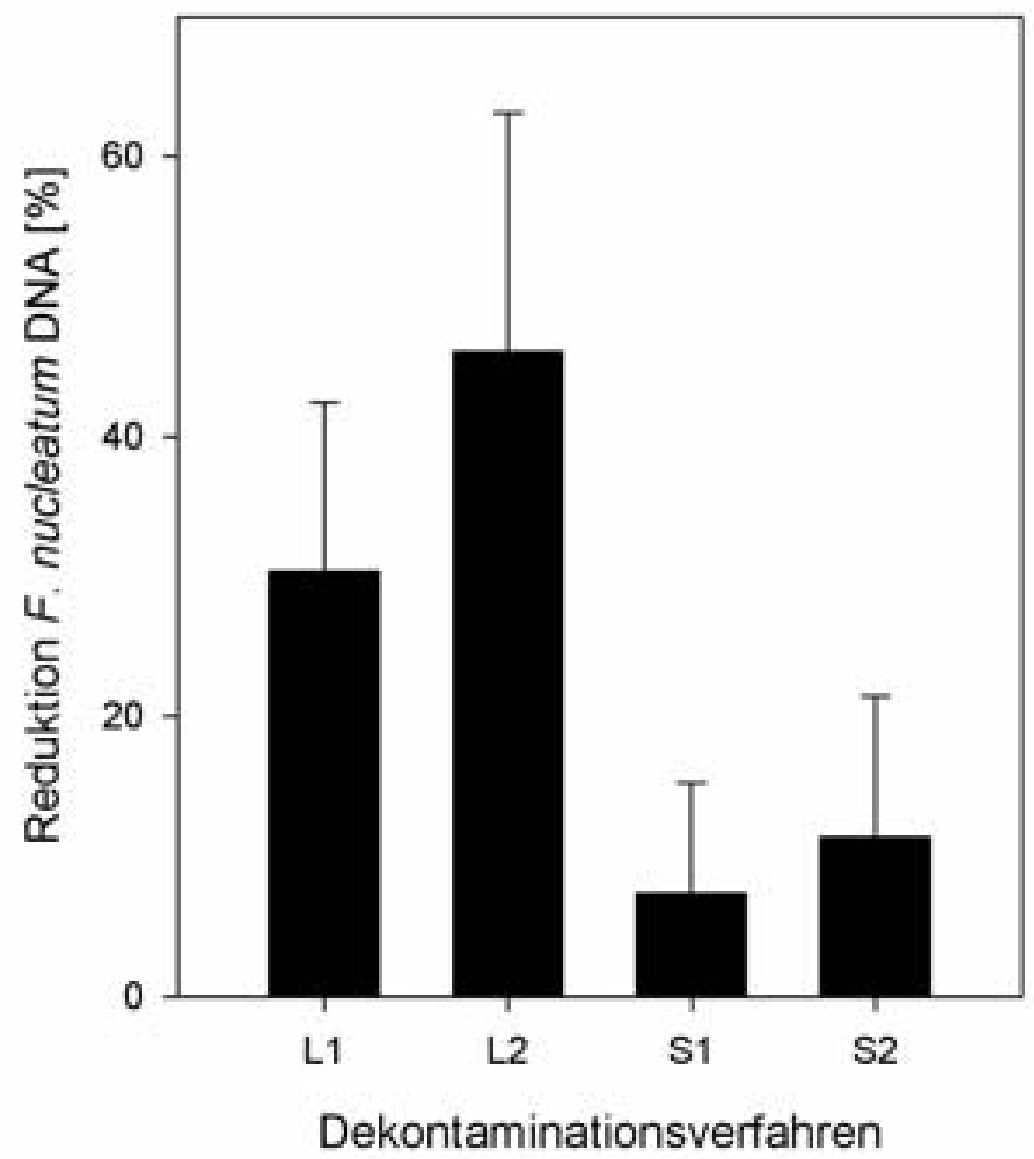

Abb. 12: Reduktion der DNA von Fusobacterium nucleatum nach Behandlung des Biofilms mit den Dekontaminationsverfahren Diodenlaser (L1), Er:YAG-Laser (L2), Chlorhexidindigluconat (S1) sowie Octenidindihydrochlorid/2-Phenoxyethanol (S2)

Die statistische Signifikanz der Unterschiede wird in der folgenden biometrischen Auswertung geprüft (Tab. 13) 
Tab. 13: Multiple Vergleiche zur Bestimmung der Unterschiede der Dekontaminationsmethoden auf Signifikanz auf der Basis der DNA von Fusobacterium nucleatum

\begin{tabular}{|l|l|l|l|l|}
\hline Vergleich & Mittelwertsdifferenz & $p$-Wert & $\begin{array}{l}\text { Adjustierter } \\
p-W e r t \\
\text { (Tukey) }\end{array}$ & Interpretation \\
\hline L1 vs. L2 & $-15,62$ & 0,005 & $\mathbf{0 , 0 1 8 5}$ & Signifikant \\
\hline L1 vs. S1 & 23,05 & 0,0208 & 0,0724 & $\begin{array}{l}\text { Nicht } \\
\text { signifikant }\end{array}$ \\
\hline L1 vs. S2 & 18,99 & 0,0184 & 0,0641 & $\begin{array}{l}\text { Nicht } \\
\text { signifikant }\end{array}$ \\
\hline L2 vs. S1 & 38,67 & 0,0056 & $\mathbf{0 , 0 2 0 8}$ & Signifikant \\
\hline L2 vS. S2 & 34,61 & 0,0031 & $\mathbf{0 , 0 1 1 7}$ & Signifikant \\
\hline S2 vs. S1 & $-12,99$ & 0,28465 & 0,6638 & $\begin{array}{l}\text { Nicht } \\
\text { signifikant }\end{array}$ \\
\hline
\end{tabular}

Der Unterschied des Er:YAG-Lasers zum Diodenlaser erwies sich statistisch als signifikant (Tab. 13). Damit bestand auch eine signifikant deutlichere Eliminierung des Biofilms durch die Er:YAG-Laserbestrahlung zu den Behandlungen mit den beiden chemischen Desinfektionsmitteln.

\subsubsection{Untersuchung von Eikenella corrodens}

Die Anwendung des Er:YAG-Lasers bewirkte eine Reduktion um 50\% und des Diodenlasers um 37,7\%. Die beiden chemischen Desinfektionsmittel ergaben eine Beseitigung des Biofilms zu 25,1\% durch Octenidindihydrochlorid/2-Phenoxyethanol sowie 16,8\% durch Chlorhexidindigluconat (Tab. 14; Abb. 13)

Tab. 14: Einfluss der Dekontaminationsverfahren Diodenlaser (L1), Erbium:YAG-Laser (L2), Chlorhexidindigluconat (S1) und Octenidindihydrochlorid/2-Phenoxyethanol (S2), auf den DNA Nachweis von Eikenella corrodens im Biofilm

(Cp = crossingpoint)

\begin{tabular}{|l|l|l|l|l|l|}
\hline $\begin{array}{l}\text { Eikenella } \\
\text { corrodens }\end{array}$ & Proband 1 & Proband 3 & Proband 6 & Proband 7 & Proband 13 \\
\hline Cp & 22,06 & 13,28 & 25,66 & 17,71 & 27,17 \\
Kontrollen & 21,25 & 12,29 & 26,17 & 16,4 & 28,72 \\
\hline m CpKontr. & 21,67 & 12,79 & 25,92 & 17,06 & 27,95 \\
\hline Cp-L1 & 21,84 & 14,59 & 26,84 & 18,05 & 27,03 \\
& 22,49 & 12,86 & 26,73 & 17,74 & 29,59 \\
\hline m Cp-L1 & 22,17 & 13,73 & 26,79 & 17,9 & 28,31 \\
\hline$\Delta$ Cp & 0,5 & 0,94 & 0,87 & 0,84 & 0,36 \\
\hline $2^{\Delta C p}$ & 0,707 & 0,521 & 0,547 & 0,559 & 0,779 \\
\hline
\end{tabular}




\begin{tabular}{|l|l|l|l|l|l|}
\hline Reduktion (\%) & 29,29 & 47,88 & 45,29 & 44,14 & 22,08 \\
\hline Cp-L2 & 22,82 & 14,46 & 26,99 & 18,33 & 27,89 \\
& 23,03 & 13,12 & 27,38 & 18,01 & 29,04 \\
\hline m Cp-L2 & 22,93 & 13,79 & 27,16 & 18,17 & 28,47 \\
\hline$\Delta$ Cp & 1,26 & 1,00 & 1,26 & 1,11 & 0,52 \\
\hline $2^{\Delta C p}$ & 0,418 & 0,50 & 0,418 & 0,463 & 0,697 \\
\hline Reduktion (\%) & 58,25 & 50,00 & 58,25 & 53,67 & 30,26 \\
\hline Cp-S1 & 21,1 & 12,14 & 25,76 & 17,9 & 27,15 \\
& 23,59 & 13,44 & 26,69 & 17,81 & 29,00 \\
\hline m Cp-S1 & 22,34 & 12,79 & 26,23 & 17,91 & 28,08 \\
\hline$\Delta$ Cp & 0,18 & 0,00 & 0,31 & 0,85 & 0,13 \\
\hline $2^{\Delta C p}$ & 0,883 & 1,00 & 0,807 & 0,555 & 0,914 \\
\hline Reduktion (\%) & 11,73 & 0,00 & 19,34 & 44,52 & 8,62 \\
\hline Cp-S2 & 22,77 & 13,17 & 26,18 & 17,92 & 26,79 \\
& 22,38 & 12,56 & 26,56 & 17,7 & 28,94 \\
\hline m Cp-S2 & 22,58 & 12,87 & 26,37 & 17,81 & 27,87 \\
\hline$\Delta$ Cp & 0,91 & 0,08 & 0,45 & 0,75 & 0,09 \\
\hline $2^{\Delta C p}$ & 0,532 & 0,946 & 0,732 & 0,595 & 0,940 \\
\hline Reduktion (\%) & 46,78 & 5,39 & 26,8 & 40,54 & 6,05 \\
\hline
\end{tabular}




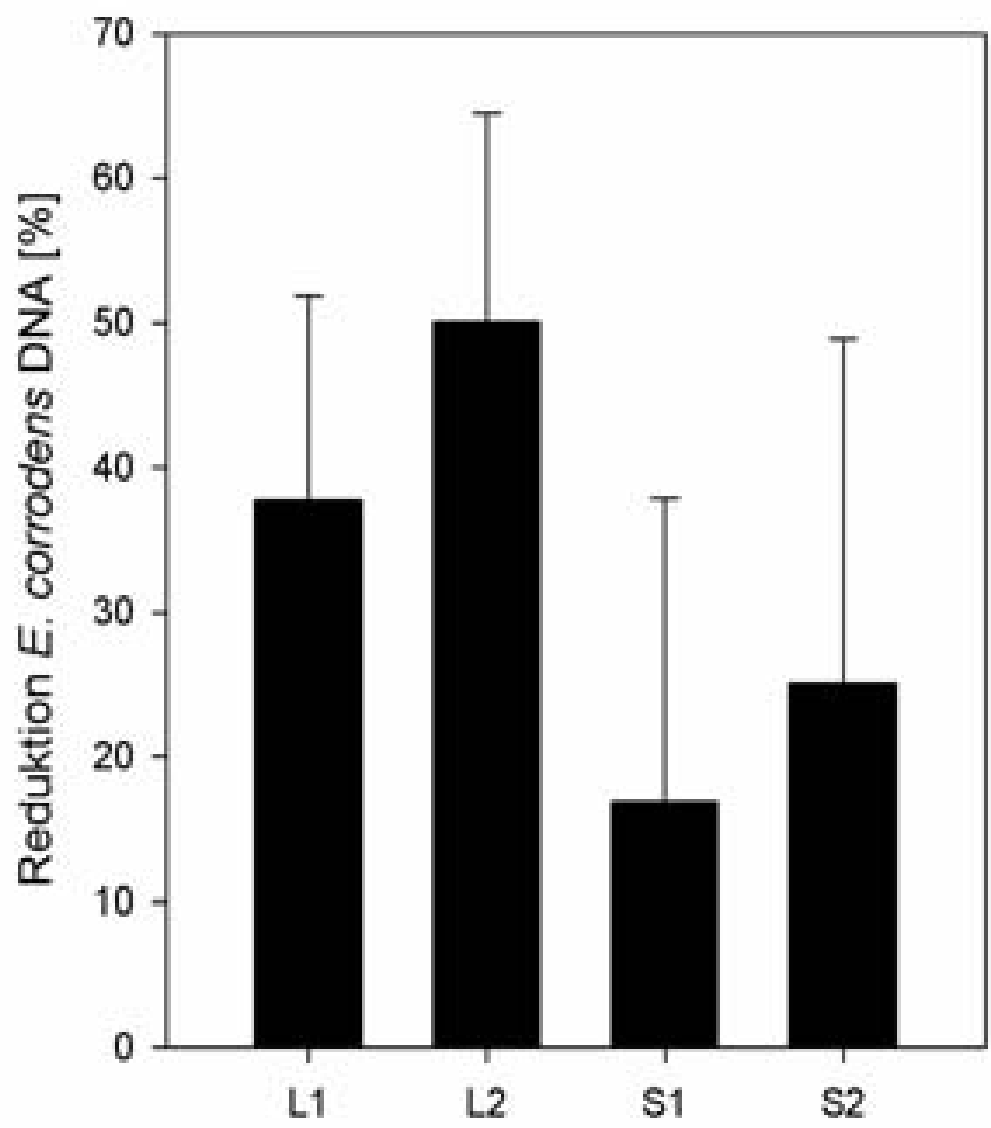

\section{Dekontaminationsverfahren}

Abb. 13: Reduktion der DNA von Eikenella corrodens nach Behandlung des Biofilms mit den Dekontaminationsverfahren Diodenlaser (L1), Er:YAG-Laser (L2), Chlorhexidindigluconat (S1) sowie Octenidindihydrochlorid/2-Phenoxyethanol (S2)

Eine statistische Signifikanz der unterschiedlichen Eliminierungsraten ergab sich aber lediglich für die größere Wirkung des Er:YAG-Lasers gegenüber den beiden Spüllösungen (Tab. 15).

Tab. 15: Multiple Vergleiche zur Bestimmung der Unterschiede der Dekontaminationsmethoden auf Signifikanz auf der Basis der DNA von Eikenella corrodens

\begin{tabular}{|l|l|l|l|l|}
\hline Vergleich & Mittelwertsdifferenz & $p$-Wert & $\begin{array}{l}\text { Adjustierter } \\
p-W e r t \\
\text { (Tukey) }\end{array}$ & Interpretation \\
\hline L1 vs. L2 & $-12,35$ & 0,0518 & 0,1583 & $\begin{array}{l}\text { Nicht } \\
\text { signifikant }\end{array}$ \\
\hline L1 vs. S1 & 20,89 & 0,059 & 0,1774 & $\begin{array}{l}\text { Nicht } \\
\text { signifikant }\end{array}$ \\
\hline L1 vs. S2 & 12,62 & 0,268 & 0,6149 & $\begin{array}{l}\text { Nicht } \\
\text { signifikant }\end{array}$ \\
\hline L2 vs. S1 & 33,24 & 0,013 & $\mathbf{0 , 0 4 2 4}$ & Signifikant \\
\hline
\end{tabular}




\begin{tabular}{|l|l|l|l|l|}
\hline L2 vS. S2 & 24,97 & 0,0151 & $\mathbf{0 , 0 4 9 8}$ & Signifikant \\
\hline S2 vs. S1 & 8,27 & 0,3057 & 0,6716 & $\begin{array}{l}\text { Nicht } \\
\text { signifikant }\end{array}$ \\
\hline
\end{tabular}

\subsubsection{Ergebnisse der Untersuchung von Prevotella intermedia}

Die Wirkung der Dekontaminationsverfahren auf die DNA-Menge von Prevotella intermedia war vergleichbar mit der, der anderen Bakterien. Der Er:YAG-Laser erreichte auch hier den größten Dekontaminationseffekt mit 58,5\%, gefolgt vom Diodenlaser mit 43,7\%. Deutlich geringer in ihrer Eliminierungsfähigkeit zu den Laserverfahren, aber mit $28,01 \%$ für Chlorhexidindigluconat und $28,36 \%$ für Octenidindihydrochlorid/2Phenoxyethanol untereinander nahezu identisch, zeigten sich die chemischen Spüllösungen (Tab. 16; Abb. 14).

Tab. 16: Einfluss der Dekontaminationsverfahren) Diodenlaser (L1), Erbium:YAG-Laser (L2), Chlorhexidindigluconat (S1), Octenidindihydrochlorid/2-Phenoxyethanol (S2) auf den DNA-Nachweis von Prevotella intermedia im Biofilm

(Cp = crossingpoint)

\begin{tabular}{|l|l|l|l|l|l|}
\hline $\begin{array}{l}\text { Prevotella } \\
\text { intermedia }\end{array}$ & Proband 2 & Proband 4 & Proband 8 & Proband 14 & Proband 16 \\
\hline Cp & 11,51 & 15,43 & 20,86 & 19,54 & 23,65 \\
Kontrollen & 12,78 & 16,84 & 22,57 & 18,06 & 25,53 \\
\hline m CpKontr. & 12,15 & 16,14 & 21,72 & 18,80 & 24,59 \\
\hline Cp-L1 & 12,36 & 16,57 & 21,51 & 21,16 & 23,91 \\
& 14,50 & 17,22 & 23,45 & 18,55 & 26,12 \\
\hline m Cp-L1 & 13,43 & 16,90 & 22,48 & 19,86 & 25,02 \\
\hline$\Delta$ Cp & 1,28 & 0,76 & 0,76 & 1,06 & 0,43 \\
\hline $2^{\Delta C p}$ & 0,418 & 0,590 & 0,590 & 0,480 & 0,742 \\
\hline Reduktion (\%) & 58,82 & 40,95 & 40,95 & 52,04 & 25,77 \\
\hline Cp-L2 & 13,97 & 17,07 & 22,30 & 21,74 & 25,19 \\
& 14,89 & 18,13 & 23,71 & 18,84 & 24,85 \\
\hline m Cp-L2 & 14,43 & 17,60 & 23,01 & 20,29 & 25,02 \\
\hline$\Delta$ Cp & 2,28 & 1,46 & 1,29 & 1,49 & 0,43 \\
\hline $2^{\Delta C p}$ & 0,206 & 0,363 & 0,409 & 0,356 & 0,742 \\
\hline Reduktion (\%) & 79,41 & 63,65 & 59,10 & 64,40 & 25,77 \\
\hline Cp-S1 & 11,97 & 15,92 & 21,47 & 21,23 & 24,17 \\
& 13,31 & 16,93 & 22,88 & 18,11 & 25,66 \\
\hline m Cp-S1 & 12,64 & 16,42 & 22,18 & 19,67 & 24,91 \\
\hline
\end{tabular}




\begin{tabular}{|l|l|l|l|l|l|}
\hline$\Delta \mathrm{Cp}$ & 0,49 & 0,29 & 0,46 & 0,87 & 0,33 \\
\hline $2^{\Delta \mathrm{Cp}}$ & 0,712 & 0,818 & 0,727 & 0,547 & 0,796 \\
\hline Reduktion (\%) & 28,80 & 18,21 & 27,3 & 45,29 & 20,45 \\
\hline Cp-S2 & 12,53 & 16,07 & 21,09 & 20,37 & 23,83 \\
& 12,88 & 16,91 & 22,97 & 19,33 & 25,89 \\
\hline m Cp-S2 & 12,71 & 16,49 & 22,03 & 19,85 & 24,84 \\
\hline$\Delta \mathrm{Cp}$ & 0,56 & 0,35 & 0,31 & 1,05 & 0,27 \\
\hline $2^{\Delta \mathrm{Cp}}$ & 0,678 & 0,785 & 0,807 & 0,483 & 0,829 \\
\hline Reduktion (\%) & 32,17 & 21,54 & 19,34 & 51,7 & 17,07 \\
\hline
\end{tabular}

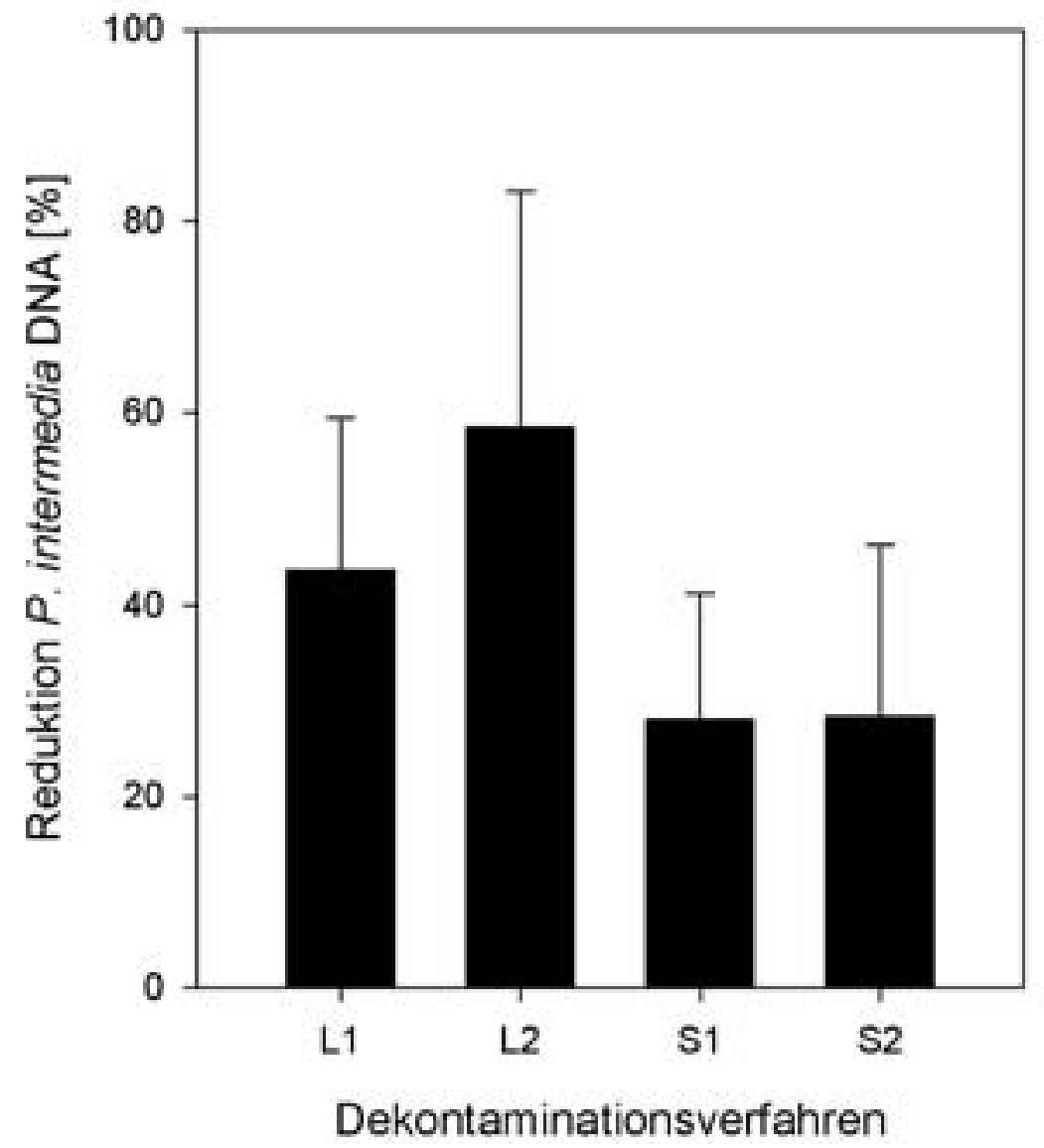

Abb. 14: Reduktion der DNA von Prevotella intermedia nach Behandlung des Biofilms mit den Dekontaminationsverfahren Diodenlaser (L1), Er:YAG-Laser (L2), Chlorhexidindigluconat (S1) sowie Octenidindihydrochlorid/2-Phenoxyethanol (S2)

Die mit der DNA von Prevotella intermedia gemessenen Unterschiede in der BiofilmEliminierungsrate durch die vier Dekontaminationsmethoden erwiesen sich statistisch als nicht signifikant (Tab. 17). 
Tab. 17: Multiple Vergleiche zur Bestimmung der Unterschiede der Dekontaminationsmethoden auf Signifikanz auf der Basis der DNA von Prevotella intermedia

\begin{tabular}{|l|l|l|l|l|}
\hline Vergleich & Mittelwertsdifferenz & $p$-Wert & $\begin{array}{l}\text { Adjustierter } \\
\text { p-Wert } \\
\text { (Tukey) }\end{array}$ & Interpretation \\
\hline L1 vs. L2 & $-14,76$ & 0,022 & 0,0721 & $\begin{array}{l}\text { Nicht } \\
\text { signifikant }\end{array}$ \\
\hline L1 vs. S1 & 15,69 & 0,029 & 0,0933 & $\begin{array}{l}\text { Nicht } \\
\text { signifikant }\end{array}$ \\
\hline L1 vs. S2 & 15,34 & 0,032 & 0,1017 & $\begin{array}{l}\text { Nicht } \\
\text { signifikant }\end{array}$ \\
\hline L2 vs. S1 & 30,45 & 0,021 & 0,0704 & $\begin{array}{l}\text { Nicht } \\
\text { signifikant }\end{array}$ \\
\hline L2 vs. S2 & 30,10 & 0,020 & 0,0650 & $\begin{array}{l}\text { Nicht } \\
\text { signifikant }\end{array}$ \\
\hline S2 vs. S1 & 0,35 & 0,899 & 0,9990 & $\begin{array}{l}\text { Nicht } \\
\text { signifikant }\end{array}$ \\
\hline
\end{tabular}

\subsubsection{Vergleich der Resultate unabhängig von der Bakterienspezies}

Ein Vergleich der Auswirkung der verschiedenen Behandlungen auf den Biofilm unabhängig von der Bakterienspezies ist in Abb. 15 dargestellt. Abb. 16 zeigt die Dekontaminationswirkung im Box-Plot-Verfahren.

Die Zusammenfassung der DNA-Eliminierungsraten der drei als Maßstab gewählten Bakterienspezies zeigten für den Er:YAG-Laser den größten Effekt mit 51,18\%, 36,85\% für den Diodenlaser, gefolgt von der Behandlung mit Octenidindihydrochlorid/2Phenoxyethanol mit 20,99\%. Die Spülung mit Chlorhexidindigluconat erwies die geringste Reduktion des Biofilms mit 16,87\% (Abb. 15; Abb. 16). 


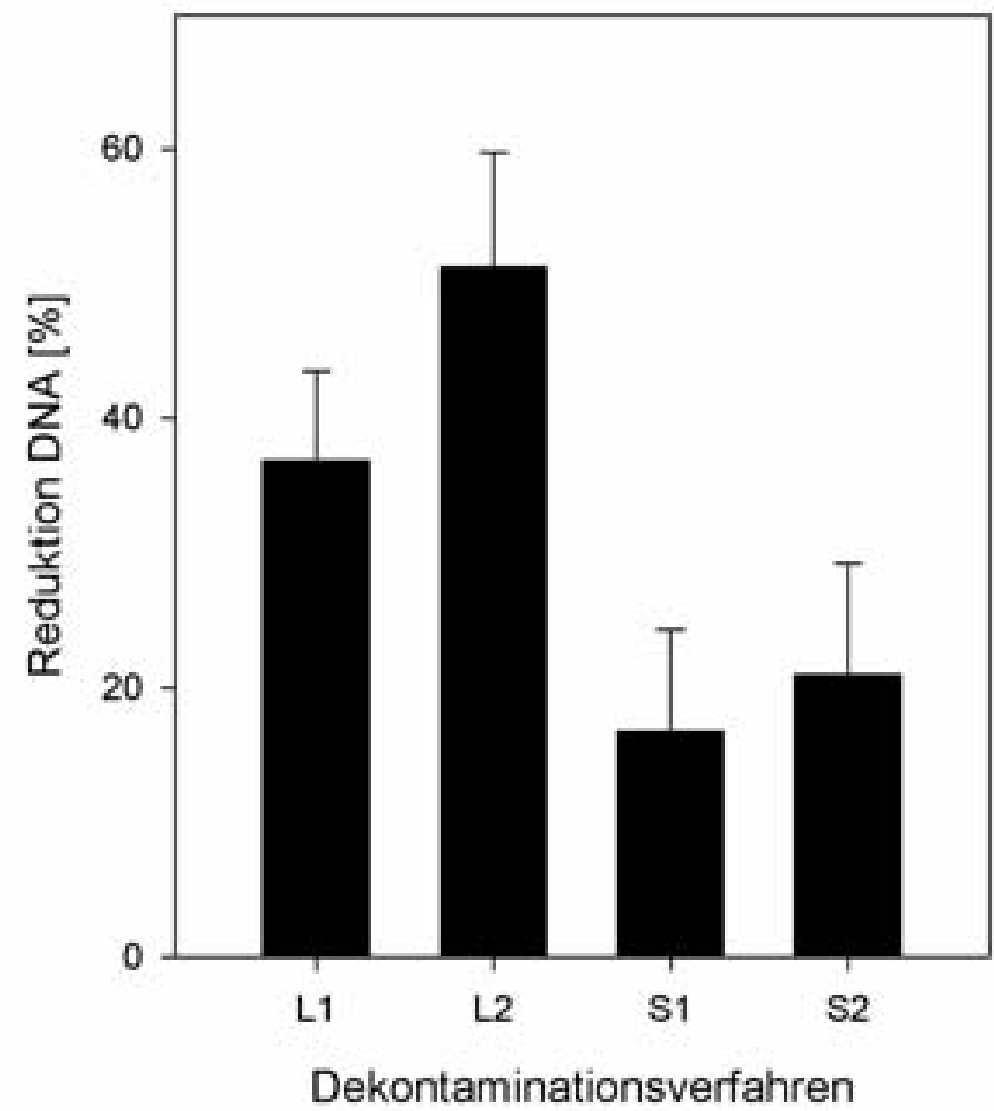

Abb. 15: Zusammengefasste Reduktion der DNA aller drei Bakterienarten nach Behandlung des Biofilms mit den Dekontaminationsverfahren Diodenlaser (L1), Er:YAG-Laser (L2), Chlorhexidindigluconat (S1) sowie Octenidindihydrochlorid/2-Phenoxyethanol (S2) 


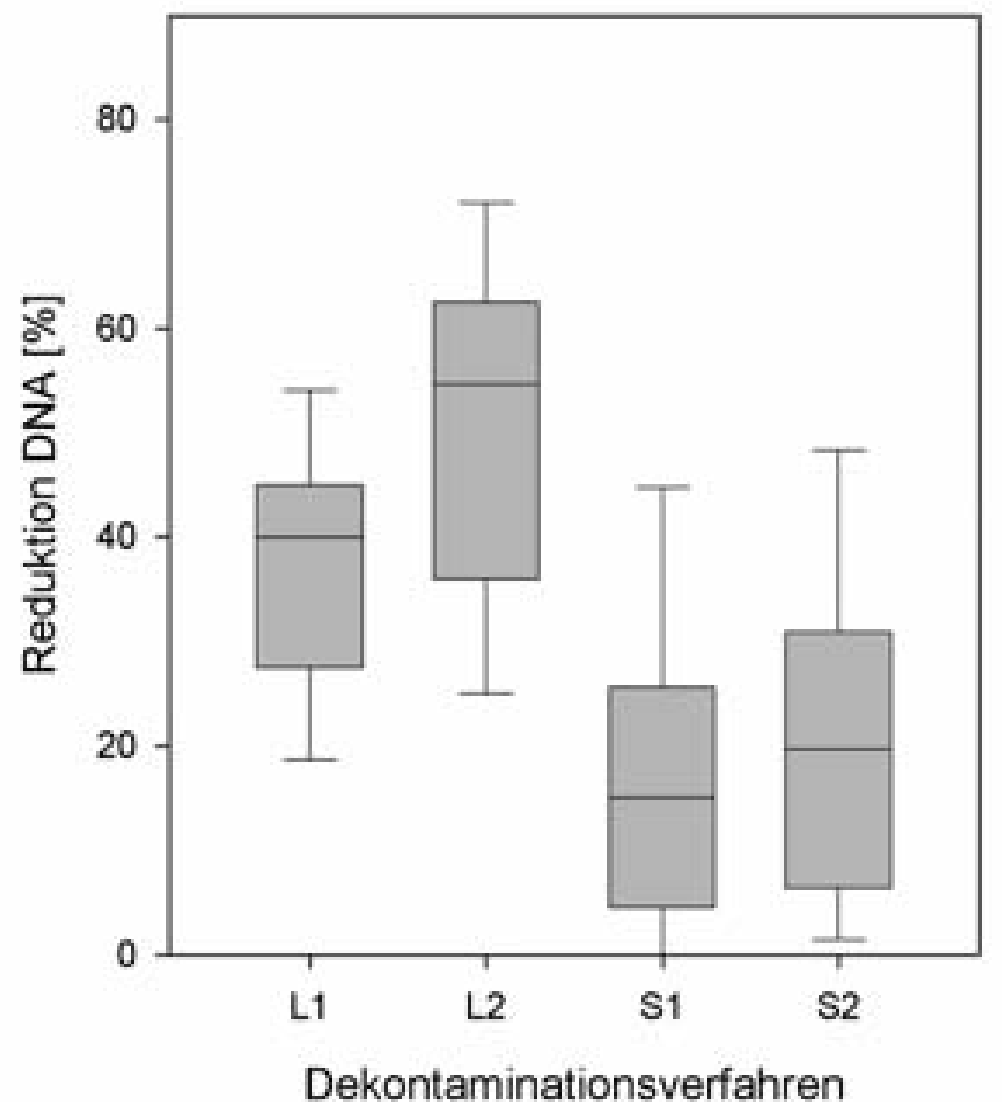

Abb. 16: Zusammengefasste Reduktion der DNA aller drei Bakterienarten nach Behandlung mit den Dekontaminationsverfahren Diodenlaser (L1), Er:YAG-Laser (L2), Chlorhexidindigluconat (S1) sowie Octenidindihydrochlorid/2-Phenoxyethanol (S2) in der Box-Plot-Darstellung

Die Bewertung zeigte, dass die genannten Unterschiede in der Dekontaminationseffizienz unter den Laserverfahren statistisch signifikant sind. Der Er:YAG Laser ist statistisch signifikant wirksamer. Beide Laser waren signifikant wirksamer als die Spüllösungen, allerdings ergaben sich unter den chemischen Desinfektionsmitteln keine signifikanten Unterschiede (Tab. 18). 
Tab. 18: Multiple Vergleiche zur Bestimmung der Unterschiede der Dekontaminationsmethoden auf Signifikanz auf der Basis der DNA aller drei Bakterienspezies

\begin{tabular}{|l|l|l|l|l|}
\hline Vergleich & Mittelwertsdifferenz & $p$-Wert & $\begin{array}{l}\text { Adjustierter } \\
\text { p-Wert } \\
\text { (Tukey) }\end{array}$ & Interpretation \\
\hline L1 vs. L2 & $-14,3306$ & $<, 0001$ & $<0,0001$ & Signifikant \\
\hline L1 vs. S1 & 20,0600 & $<, 0001$ & $\mathbf{0 , 0 0 0 4}$ & Signifikant \\
\hline L1 vs. S2 & 15,8656 & $<, 0008$ & $\mathbf{0 , 0 0 3 8}$ & Signifikant \\
\hline L2 vs. S1 & 34,3906 & $<, 0001$ & $<0,0001$ & Signifikant \\
\hline L2 vs. S2 & 30,1962 & $<, 0001$ & $<0,0001$ & Signifikant \\
\hline S2 vs. S1 & $-4,1944$ & 0,1288 & 0,4039 & $\begin{array}{l}\text { Nicht } \\
\text { signifikant }\end{array}$ \\
\hline
\end{tabular}




\section{Diskussion}

Gemeinschaften oraler Bakterien können Biofilme auf allen Oberflächen der Mundhöhle bilden. Das gilt besonders auch für iatrogen eingesetztes Fremdmaterial wie z.B. die raue Oberfläche von Implantaten aus Titan (Groessner-Schreiber et al. 2009, Krekeler et al. 1988, Bollen et al. 1996, Groessner-Schreiber et al. 2004, Sennhenn-Kirchner et al. 2007b). Die Bildung eines Biofilms erfolgt als Antwort auf extrazelluläre Signale, die aus der umgebenden Umwelt und von den Mikroorganismen selbst stammen (Kolter und Greenberg 2006, Spoering und Gilmore 2006). Die Zusammensetzung des Biofilms ist außerordentlich heterogen und multifaktoriell bedingt. Allen Biofilmen gemeinsam ist jedoch, dass die beteiligten Bakterien durch eine extrazelluläre Matrix zusammengehalten werden, deren wesentliche Bestandteile Exopolysaccharide, Proteine und Nukleinsäuren sind (Whitchurch et al. 2002, Branda et al. 2005). Die genetischen Regulationsmechanismen der Bakterien innerhalb des Verbundes sind noch weitgehend unverstanden. Über die Bedeutung des Biofilms für die Bakterien gibt es übereinstimmende Erkenntnisse. Er bietet den Mikroorganismen einen Schutz vor schädigenden Einflüssen wie z.B. vor Antibiotika oder vor dem humanen Immunsystem (Singh et al. 2000, Mah und O'Toole 2001, Leid et al. 2005, Zhang und Mah 2008). Dass persistierende Biofilme auf oralen Implantaten eine Periimplantitis verursachen können, ist wissenschaftlich belegt (Hultin et al. 2002, Shibli et al. 2003, Klinge et al. 2005). Die entzündliche Reaktion kann so stark ausgeprägt sein, dass sie gegebenenfalls zum Implantatverlust führt (Piattelli et al. 1998, Leonhardt et al. 2002, Leonhardt et al. 2003). Die einfache Anwesenheit von Bakterien in niedriger Anzahl im Bereich eines Implantats induziert nicht zwangsläufig eine Entzündung (Heydenrijk et al. 2002). Erst eine steigende Bakterienmenge und weitere Co-Faktoren wie eine lokale Abwehrschwäche Iösen den schädlichen inflammatorischen Prozess aus. Deswegen ist es sinnvoll, die bakterielle Besiedlung im Bereich von Implantaten zumindest möglichst gering zu halten, um eine Progression der Erkrankung zu verhindern (Heydenrijk et al. 2002).

Mit der Etablierung neuer molekularbiologischer Methoden wie zum Beispiel der DNAHybridisierung und der Polymerase-Kettenreaktion konnten weitere Erkenntnisse über die Bildungsmechanismen oraler Biofilme gewonnen werden (Kolenbrander 2000, Kolenbrander et al. 2010). Das gilt auch für den zeitlichen Ablauf. Demnach gehören Streptokokken und Aktinomyzeten zu den frühen Besiedlern oraler Oberflächen und bilden mit ihren Wechselwirkungen untereinander einen initialen Biofilm. Eine folgende Besiedlung mit Fusobakterien fördert die Koaggregation weiterer Bakterien, die u.a. 
Sauerstoff durch Stoffwechselvorgänge verbrauchen. Damit wird eine lokale anaerobe Atmosphäre geschaffen, die auch anaeroben Bakterien eine Etablierung in der Gemeinschaft der Mikroorganismen im Biofilm ermöglicht. Besonders Fusobacterium nucleatum, das in der vorliegenden Arbeit bei allen Probanden nachgewiesen werden konnte, gilt als Vermittler zwischen aeroben und anaeroben Bakterien und dient zur Erklärung des steigenden Anteils von Anaerobiern im älteren Biofilm. Eng mit Biofilmassoziierten Entzündungsreaktionen verbunden sind u.a. anaerobe Bakterien wie Treponema denticola, Porphyromonas gingivalis, aber auch Fusobacterium nucleatum, Prevotella intermedia und Eikenella corrodens (Socransky et al. 1998). Prevotella intermedia und Eikenella corrodens gehörten neben Fusobacterium nucleatum zu den Bakterienarten, die bei allen Probandenproben kulturell und mit der spezifischen PCR identifiziert wurden. Deswegen wurden diese drei für den Aufbau des oralen Biofilms und für die Entstehung der Periimplantitis relevanten Bakterienspezies ausgewählt, um den Effekt der Dekontaminationsverfahren zu untersuchen.

Die Besonderheit des Ansatzes der vorliegenden Arbeit ist, dass ein zehn Tage alter in vivo hergestellter Biofilm als Grundlage diente und die Versuche mit dem Material des jeweils gleichen Probanden zur besseren Vergleichbarkeit durchgeführt wurden. In den meisten bisher publizierten Untersuchungen wird der Biofilm entweder in vitro erzeugt oder er ist nur ein bis wenige Tage alt (van der Mei et al. 2006, Gosau et al. 2010). Die Etablierung der für die Periimplantitis verantwortlichen anaeroben Bakterien im Biofilm erfolgt erst nach einigen Tagen. Außerdem liegen die Bakterien in einem über mehrere Tage gereiften Biofilm geschützter und verhalten sich anders als im planktonischen Zustand. Allein schon die zeitliche Reifung von neun oder 72 Stunden zeigte einen deutlichen Unterschied der Ergebnisse der Überlebensrate von Bakterien nach der Behandlung mit Chlorhexidindigluconat untereinander und im Vergleich zu planktonisch lebenden Bakterien (van der Mei et al. 2006). Deswegen wurde hier, im Gegensatz zu anderen Arbeiten, eine Biofilmentwicklung über zehn Tage abgewartet. Weiterhin wurde stark auf die Vergleichbarkeit mit der klinischen Situation einer Periimplantitisbehandlung geachtet. Anders als in Studien von Romanos und Schwarz wurden keine Titanplättchen, sondern Titanbohrhülsen verwendet, die durch ihr Design den Biofilm vor mechanischer Beeinflussung von oralen Weichteilen etc. schützen und ihn ungehindert wachsen lassen, wie es für Nischen periimplantärer Defekte typisch ist (Romanos et al. 2000; Schwarz et al. 2006). Der erschwerte Zugang zu den Hülsen bei der Behandlung durch die Gesichtsmaske und die erschwerte Sicht auf den Biofilm durch den kleinen Innendurchmesser der Hülsen imitierten die klinische Situation zusätzlich. 
Die Beurteilung des bakteriziden Effekts erfolgte durch kulturelle Verfahren. Da der überwiegende Anteil der Mundflora aus anaeroben Bakterien besteht und der überwiegende Anteil aerober Bakterien auch in der Lage ist, fakultativ anaerob zu wachsen, wurde die Kultivierung unter anaeroben Bedingungen vorgenommen (Costerton et al. 1995, Norowski und Bumgardner 2009). Die nicht dekontaminierten, aber sonst identisch aufgearbeiteten Proben des jeweils gleichen Probanden, dienten als Kontrollen. Mit einer intensiven Spülung mit physiologischer Kochsalzlösung wurden oberflächliche, planktonische Bakterien entfernt, um möglichst ausschließlich Mikroorganismen des Biofilms zu erfassen und, um gleiche Voraussetzungen zu schaffen, den Spüleffekt des Kühlwassers der Saphirspitze des Er:YAG-Lasers zu imitieren.

Darüber hinaus wurden in dieser Arbeit durch den Einsatz der PolymeraseKettenreaktion auch noch anhaftende, aber nicht mehr vermehrungsfähige Bakterien nach den Behandlungen nachgewiesen. Die Bedeutung von abgetöteten Bakterien im verbleibenden Biofilm ist Gegenstand aktueller Diskussionen (Gosau et al. 2010).

Zur Dekontamination besiedelter Implantatoberflächen bieten sich verschiedene Verfahren an, zu denen auch der Einsatz von oralen Desinfektionslösungen gehört. Die Anwendung von Lasern wird zunehmend diskutiert (Sennhenn-Kirchner et al. 2007b, Sennhenn-Kirchner et al. 2009b). Um die Wirkung zu ermitteln, werden meist artifizielle, d.h. in vitro hergestellte Biofilme verwendet. Da die Bildung und damit die Eigenschaften der untersuchten Biofilme sehr unterschiedlich sind und die Behandlungsmethoden in ihrer Anwendung viele Variable aufweisen, ist eine Vergleichbarkeit der Wirkung nicht gegeben. Es sollte hier die Frage geklärt werden, mit welcher der Maßnahmen der beste Dekontaminationseffekt erzielt werden kann. In der vorliegenden Arbeit wurden deshalb vier unterschiedliche Dekontaminationsverfahren miteinander verglichen. Besonderes Augenmerk wurde auf die Durchführung der Untersuchungen unter praxisnahen Bedingungen gelegt. Dazu gehörte die in-vivo-Erzeugung des Biofilms auf einer Titanoberfläche, die in Implantaten Verwendung findet. Für die Dekontamination wurden ein Dioden- (L1) und ein Er:YAG-Laser (L2), sowie als Spüllösungen Chlorhexidindigluconat (S1) und Octenidindihydrochlorid/Phenoxyethanol verwendet und Einwirkungsbedingungen gewählt, die im Wesentlichen der Literatur entnommen und als praktikabel angesehen wurden (Aufenanger 2001, SennhennKirchner et al. 2004, Sennhenn-Kirchner et al. 2007b, Sennhenn-Kirchner et al. 2009a). 
Bei allen der in dieser Arbeit untersuchten 16 Probanden wurden die vier Verfahren zur bakteriellen Dekontamination des Biofilms durchgeführt und die Ergebnisse miteinander verglichen.

Laserstrahlung kommt als Methode zur Dekontamination von Implantatoberflächen in Betracht, da sie antimikrobielle Eigenschaften besitzt (Coluzzi 2002, Sennhenn-Kirchner et al. 2007b, Schwarz et al. 2008a, Sennhenn-Kirchner et al. 2009b). Besonders in der Parodontitis- und zunehmend auch bei der Periimplantitistherapie gibt es dafür Erfahrungen mit Lasern (Sennhenn-Kirchner et al. 2007b, Schwarz et al. 2007c, Schwarz et al. 2008a).

In der vorliegenden Arbeit fand ein Diodenlaser und ein Er:YAG-Laser Verwendung. Kriterien für die Auswahl dieser beiden Laser sind die unterschiedlichen Charakteristika in ihrem Wirkbereich. Damit sollten Aussagen über die antibakterielle Effizienz der differierenden Wirkprinzipien ermöglicht werden. Die wesentlichen Unterschiede werden hier kurz skizziert. Ein entscheidender Parameter der Laserwirkung ist die Wellenlänge der Emission. Dabei spielt die Absorption in Wasser die bedeutsamste Rolle. Die meisten Gewebe haben einen Wasseranteil von 60-80\% mit der Konsequenz unterschiedlicher Eintrittstiefen der Laserstrahlung mit differierenden Wellenlängen (Walsh et al. 1989, Walsh und Cummings 1994, Romanos et al. 2009)

Zu den Lasern, deren Strahlung tiefer in Gewebe $(0,5-3 \mathrm{~mm})$ eindringen, gehört der hier verwendete Diodenlaser. Als Nachteil werden die entstehenden höheren Temperaturen und damit eine mögliche Schädigung von gesundem Gewebe und Implantatoberflächen angesehen (Hale und Querry 1973, Schwarz et al. 2007c). Die Einstellungen und das Ablaufprogramm des Diodenlasers zur Bearbeitung des Biofilms erfolgten nach vorbeschriebenen experimentellen Bedingungen (Sennhenn-Kirchner et al. 2007b).

Ein Laser mit geringerer Eindringtiefe der Strahlung $(0,2-2 \mathrm{~mm})$ ist der in den vorliegenden Versuchen verwendete Erbium:YAG-Laser. Ein Charakteristikum ist die besonders ausgeprägte Absorption in Wasser (Walsh et al. 1989, Schwarz et al. 2007b,). Die Wirkung auf biologisches Gewebe beruht in erster Linie auf den sprunghaften Übergang von wasserhaltigen Strukturen vom flüssigen in den gasförmigen Zustand. Der dabei resultierende Druck führt zur gezielten Zellzerstörung bzw. zur Abtragung von Gewebesubstanz (Hibst und Keller 1989, Keller et al. 1998, Schwarz et al. 2007b). Die freigesetzte Energie wird durch die Verdampfungswärme des Wassers bestimmt und nicht durch die der höherschmelzenden Gewebesubstanz und ist damit niedriger als bei anderen Verfahren (Quirynen et al. 1996, Visuri et al. 1996, Schwarz et al. 2003). Auch die Titanoberfläche wird weniger aufgeheizt, da der Laser nicht in diesem Bereich sein 
Absorptionsmaximum hat. Eine integrierte Wasserkühlung sorgt für eine weitere Schonung des umgebenden Gewebes (Romanos et al. 2009).

Die in den vorliegenden Untersuchungen vorgenommenen Lasereinstellungen und Behandlungszeiten wurden nach Berichten von Bach (Bach et al. 2000) über den Einfluss von Laserlicht auf Bakterien im Biofilm und von Sennhenn-Kirchner (SennhennKirchner et al. 2009b) zur Eliminierung von Candida albicans auf Titanoberflächen ausgewählt.

Die hier verwendeten Laserverfahren ergaben beide im Vergleich zu den Spüllösungen eine Steigerung der Abtötung lebender anaerober Bakterien im Biofilm. Der Mittelwert nach der Behandlung mit dem Diodenlaser lag bei 92,2\%, für den Er:YAG-Laser bei höheren 93,9\%. Der Unterschied erwies sich statistisch allerdings als nicht signifikant. Während der Er:YAG-Laser im Vergleich mit beiden chemischen Lösungen eine signifikant besserer Reduktion erzielte, traf das bei dem Diodenlaser lediglich gegenüber Chlorhexidindigluconat zu.

Ebenfalls mit einem zehn Tage alten in-vivo-Biofilm als praxisnahes Modell wurde mit einem Diodenlaser eine Reduktion aerober Keime von ca. 99\% erreicht. Eine genauere Untersuchung zeigte, dass Streptokokken etwas wirksamer abgetötet werden als Staphylokokken (Sennhenn-Kirchner et al. 2007b). Dieses Ergebnis überstieg die bakterizide Wirkung des Lasers im Vergleich zu den Versuchen der vorliegenden Arbeit. Der Unterschied ist allerdings als gering zu bewerten und könnte dadurch erklärt werden, dass einmal nur aerobe und in der vorliegenden Studie anaerobe Bakterien untersucht worden sind. Um diese wenig ausgeprägte Diskrepanz zu klären, müssten vergleichende Untersuchungen unter aeroben und anaeroben Bedingungen durchgeführt werden. Die Erkenntnisse von Fontana, der den guten bakteriziden Effekt des Diodenlasers beschrieben hat, konnten durch die Arbeit bestätigt werden (Fontana et al. 2004a). Über direkte Vergleiche beider Laser mit dem Fokus auf den bakteriziden Effekt lagen kaum literaturgestützte Informationen vor. In der bereits weiter oben erwähnten Veröffentlichung über die Wirkung verschiedener Dekontaminationsverfahren auf Candia albicans wurde eine Effizienz des Diodenlasers von 94\% und die des Er:YAG-Lasers von bis zu 99\% nachgewiesen (Sennhenn-Kirchner et al. 2009b). Diese Experimente bestätigen die sehr gute abtötende Wirkung der Laser, die auch hier dem Einfluss der Spüllösungen überlegen waren.

Der durch das Kulturverfahren ermittelte Reduktionseffekt lebender anaerober Bakterien erwies sich im Vergleich mit dem Diodenlaser beim Er:YAG-Laser als stärker ausgeprägt, allerdings ohne statistisch signifikant zu sein. Damit stellt sich die Frage, ob zur Auswahl 
des Lasers für die praktische klinische Anwendung noch weitere Lasereigenschaften hilfreich sein können. Aufgrund der unterschiedlichen Wellenlängen der Laser ergeben sich Differenzen bei der Eindringtiefe der Strahlen. Der Diodenlaser erreicht tiefere Schichten wie z.B. in einem Rattenmodell gezeigt (Fontana et al. 2004b). Erst ab einer Schichtdicke von 300 $\mu$ m Dentin kommt es zu einer Wirkungseinschränkung, beschrieben an einem Diodenlaser bei $980 \mathrm{~nm}$ (Franzen et al. 2005). Die Eigenschaften eines Nd:YAG-Lasers sind denen des Diodenlasers sehr ähnlich. Die Gefahr von Gewebeschäden und Beeinträchtigung der Implantatoberfläche ist besonders für Wellenlängen in diesem Bereich gegeben. Die kann allerdings beim Diodenlaser durch geeignete Einstellungen (1W, CW, $20 \mathrm{sec}$ Bestrahlung, $30 \mathrm{sec}$ Pause) ausgeschlossen werden (Bach et al. 2000, Sennhenn-Kirchner et al. 2007b).

Um das Problem dieser unerwünschten Nebenwirkungen zu reduzieren, war es wichtig, die Leistungsfähigkeit des Er:YAG-Lasers zu prüfen, der prinzipiell als weniger traumatisierend eingestuft wird.

Aufgrund des oben beschriebenen Wirkungsprinzips des Er:YAG-Lasers, der umgebendes Gewebe weitgehend schont und die Implantatoberfläche im Gegensatz zu anderen offenbar weniger beeinträchtigt, erscheint dieser Laser vorteilhaft. Die verminderte Eindringtiefe im Vergleich zum Diodenlaser macht sich hier praktisch nicht direkt bemerkbar. Eine Erklärung könnte darin bestehen, dass die Dicke des in vivo über zehn Tage erzeugten Biofilms nicht so ausgeprägt war, um den bakteriziden Effekt einzuschränken.

Während die Konkremententfernung von der Titanoberfläche mit der Wellenlänge des Diodenlasers nicht möglich ist (Bach et al. 2000, Deppe et al. 2000), wurden nach der Behandlung mit dem Er-YAG Laser der Biofilm bzw. anhaftenden Konkremente von der Titanoberfläche zumindest teilweise, aber auch nicht vollständig entfernt (Schwarz et al. 2003). Dass Dekontaminationen auch mit Er:YAG-Lasern nicht grundsätzlich zur Entfernung des Biofilms führt, in dem die Bakterien abgetötet wurden, konnte z.B. durch aufwändige rasterelektronenmikroskopische Aufnahmen bestätigt werden (Schwarz et al. 2003, Schwarz et al. 2007c).

Deswegen war auch für die vorliegende Arbeit davon auszugehen, dass nach der Dekontaminierung mit chemischen Desinfektionsmitteln oder Lasern noch abgetötete Bakterien an der Implantatoberfläche haften geblieben sind.

Als Kriterium für den Dekontaminationseffekt wurde in der Regel in den publizierten Untersuchungen die Bestimmung vermehrungsfähiger Bakterien vor und nach der Behandlung verwendet. Eine Aussage über verbliebene Konkremente und abgetötete Bakterien des Biofilms ließ sich damit nicht treffen. 
Neben der Laserstrahlung wählte man als Auswahl für chemische Desinfektionslösungen, Chlorhexidindigluconat $\left(\right.$ Paroex $\left.^{\circledR}\right)$ und Octenidindihydrochlorid/2-Phenoxyethanol $\left(\right.$ Octenisept ${ }^{\circledR}$ ) aufgrund von Literaturdaten und bestehender Vorerfahrungen in der Arbeitsgruppe (Decker et al. 2003, Sennhenn-Kirchner et al. 2004, Sennhenn-Kirchner et al. 2009a).

Chlorhexidindigluconathaltige Mundspüllösungen sind intensiv untersucht worden und gelten aufgrund ihrer klinischen Effektivität seit langem als Goldstandard für eine chemische Plaquekontrolle (Brecx et al. 1989, Eley 1999, Lang et al. 1994).

Als weitere antiseptische Spüllösung fand hier 0,1\%iges Octenidindihydrochlorid zusammen mit 2\% Phenoxyethanol Verwendung. Die dekontaminierende Wirkung von Octenidindihydrochlorid/2-Phenoxyethanol wurde bisher eher auf Bakterien in Biofilmen in zentralen Venenkathetern, Tracheotomieschläuchen und Metallimplantaten aus der Orthopädie untersucht (Tietz et al. 2005, Bartoszewicz et al. 2007, Zumtobel et al. 2009). Es existieren wenige Berichte über die Wirkung dieser Lösung auf Bakterien eines oralen Biofilms (Pitten und Kramer 1999, Shapiro et al. 2002, Sennhenn-Kirchner et al. 2004, Gosau et al. 2010). Ein direkter Vergleich des dekontaminierenden Effektes mit dem gut untersuchten Chlorhexidindigluconat ermöglichte in dieser Studie eine bessere Einordnung der Spüllösung.

Für Spülungen der Mundhöhle empfiehlt der Hersteller 20 Sekunden zu spülen und die Lösung dann noch eine Minute einwirken zu lassen. Die Bedingungen zur Einwirkung von Octenidindihydrochlorid/2-Phenoxyethanol über zwei Minuten, die hier eingesetzt wurden, wählte man auf Grund der besseren Vergleichbarkeit der Ergebnisse zu Chlorhexidindigluconat in Anlehnung der Untersuchungen von Sennhenn-Kirchner et al. (Sennhenn-Kirchner et al. 2004, Sennhenn-Kirchner 2009a) aus. Diese Wirkzeit entspricht der maximalen Einwirkzeit nach Angaben des Herstellers.

Im Vergleich der Wirksamkeit der beiden eingesetzten chemischen Desinfektionsmittel hinsichtlich der Reduktion vermehrungsfähiger Bakterien zeigen sich, unter den hier gewählten sehr praxisnahen Bedingungen, unterschiedliche Ergebnisse. Der Mittelwert des Verlusts kulturell anzüchtbarer Bakterien wurde unter der Einwirkung mit Chlorhexidindigluconat mit $77,5 \%$ bestimmt. Octenidindihydrochlorid/2-Phenoxyethanol führte zu einer deutlich stärkeren statistisch signifikanten Reduktion auf 90,5\%.

In einer Mitteilung wurde die bakterizide Wirkung von 12 verschiedenen oralen Desinfektionslösungen ebenfalls in einem erzeugten Biofilm bestimmt. Auch hier zeigte 
sich Octenidindihydrochlorid/2-Phenoxyethanol als wirksamer im Vergleich zu Chlorhexidindigluconat und anderen Substanzen (Shapiro et al. 2002).

Eine weitere Bestätigung des Ergebnisses ergab sich aus in-vitro-Untersuchungen mit definierten Bakteriensuspensionen in künstlichem Speichel auf Titanoberflächen. Dabei zeigten sich ebenfalls besserer Reduktionswerte für Octeninidindihydrochlorid/2Phenoxyethanol (Sennhenn-Kirchner 2004 et al.). Die Vergleichbarkeit dieses Ergebnisses war nicht völlig gewährleistet, da sich die Untersuchungsbedingungen deutlich unterschieden und Chlorhexidindigluconat nicht als Lösung, sondern als Gel appliziert wurde.

Auch gegen Pilze konnte eine bessere Wirksamkeit von Octenidindihydrochlorid/2Phenoxyethanol gezeigt werden. In einer Publikation konnte eine Reduktion vitaler Candida-Zellen in einem in-vitro-Biofilm von $43 \%$ für Chlorhexidindigluconat und $70 \%$ für Octenidindihydrochlorid/2-Phenoxyethanol gefunden werden (Sennhenn-Kirchner et al. 2007a) In der gleichen Arbeit wurde für Zitronensäure die beste antimykotische Wirkung mit $95 \%$ beschrieben.

In einer weiteren Veröffentlichung wurde über chemische Dekontamination von bakteriellen Biofilmen auf Titanoberflächen mit den beiden hier eingesetzten Lösungen berichtet (Sennhenn-Kirchner et al. 2009b). Dabei wurden auch in vivo gezüchtete Biofilme untersucht, allerdings erfolgte die Kultivierung unter aeroben Bedingungen, d.h. die Eliminierung von Anaerobiern wurde dabei nicht erfasst. Die Ergebnisse dieser Untersuchungen belegen Reduktionen in einem Bereich von $30 \%$ für Chlorhexidindigluconat und bis 99,8\% für Octenidindihydrochlorid/2-Phenoxyethanol bei einer Einwirkzeit von bis zu acht Minuten, die allerdings für die praktische Anwendung wenig geeignet scheint und zusätzlich vom Hersteller nicht empfohlen wird. In dieser Arbeit wird damit grundsätzlich die Überlegenheit von Octenidindihydrochlorid/2Phenoxyethanol gegenüber Chlorhexidindigluconat bestätigt. Diese Aussage lässt sich nach den Ergebnissen dieser Untersuchung auch auf die anaerobe Flora übertragen.

Als weitere Aufgabe sollte in dieser Studie nicht nur der Abtötungs-, sondern auch der Abtragungseffekt des Biofilms durch die vier dekontaminierenden Behandlungen untersucht werden. Es musste mit einer weiteren Methode, neben der kulturellen Anzüchtung, auch die Anzahl der adhärierenden toten Bakterien nach den Behandlungen bestimmt werden, um ein Maß für die Eliminierung der Bakterien des Biofilms zu erhalten. 
Eine aktuelle Untersuchungsmethode zur Unterscheidung zwischen lebenden von abgetöteten Bakterien ist mit Hilfe der Fluoreszenztechnik möglich. Durch Einlagerung spezifischer unterschiedlich absorbierender Farbstoffe und sich anschließender Fluoreszenz- oder Laserscan-Mikroskopie, können Informationen über die Vitalität der Bakterien gewonnen werden. Mit solchen Verfahren wurde bisher unter Anderem das Verhältnis zwischen der Anzahl lebender und abgetöteter Bakterien abhängig von den verschiedenen Oberflächen wie Zahnschmelz, Gold, Amalgam oder Komposit, auf denen sich die Biofilme bilden können, untersucht. Im direkten Vergleich wurde so z.B. auf Titanoxidoberflächen die doppelte Anzahl lebender Bakterien als auf Amalgamoberflächen festgestellt (Leonhardt und Dahlen 1995).

In einem unbehandelten Biofilm auf Zahnschmelz von Probanden wurde gezeigt, dass sich nur etwa 50\% der Bakterien des Biofilms als lebend einstufen ließen (van der Mei et al. 2006). Nach Behandlung mit Chlorhexidindigluconat reduzierte sich in der zitierten Untersuchung an einem neun Stunden alten Biofilm der überlebende Anteil der Bakterien auf 22\% bzw. an einem 72 Stunden alten Biofilm auf 8\% der Bakterien.

Das bedeutet, dass sich in einem Biofilm je nach Oberflächenmaterial sowieso ein erheblicher Anteil abgetöteter Bakterien befand.

Mit der gleichen Technik wurden in einer anderen aktuellen Untersuchung über die Desinfektion mit Spüllösungen von 12 Stunden alten oralen Biofilmen auf Titanoberflächen 20\% tote Bakterien in den unbehandelten Kontrollen nachgewiesen (Gosau et al. 2010). Chlorhexidindigluconat zeigte gute bakterizide Eigenschaften, Octenidindihydrochlorid/2-Phenoxyethanol war hier nicht berücksichtigt worden.

Die Autoren zogen aus ihren Ergebnissen die Schlussfolgerung, dass die Rolle der adhärierenden, aber nicht mehr vermehrungsfähigen Bakterien in Biofilmen zukünftig intensiv untersucht werden sollte. In keiner Untersuchung wurden allerdings spezifische Bakterien detektiert und auf ihre Vitalität analysiert.

Eine weitere Methode, lebende aber auch abgetötete Mikroorganismen nachzuweisen, steht mit der Polymerase-Kettenreaktion (PCR) zur Verfügung. In aktuellen Forschungsberichten wurde das Verfahren zur Identifizierung und Typisierung von Bakterien in oralen Biofilmen erfolgreich eingesetzt (Abiko et al. 2010, Wolff et al. 2010). In der vorliegenden Arbeit wurde eine spezifische PCR für drei Bakterienspezies Prevotella intermedia, Eikenella corrodens, Fusobacterium nucleatum, die repräsentativ im Biofilm aller 16 Probanden kulturell nachweisbar waren, etabliert. Durch einen eigenen in-vitro-Vorversuch mit Bakteriensuspensionen, konnte belegt werden, dass nach der Behandlung mit allen vier verwendeten Dekontaminationsverfahren die DNA 
der abgetöteten Bakterien durch die Untersuchung mit der PCR weiterhin nahezu uneingeschränkt nachweisbar war. Die im Vergleich zu unbehandelten Kontrollen etwas niedrigere aufgefundene Menge könnte durch Verluste z.B. durch Verspritzen bis außerhalb des Auffanggefäßes und Fehler beim Überführen des Glasschaleninhaltes in das Reaktionsgefäß erklärt werden. Der deutlich höhere bakterizide Effekt der Spüllösungen in diesem Vorversuch, im Vergleich zu dem Ergebnis des Hauptversuchs, lässt sich dadurch erklären, dass zu den mit Spüllösung benetzten Plättchen lediglich $13 \mathrm{ml} \mathrm{NaCl}$ dazugegeben wurde, da ein Ab- bzw. Wegspülen planktonischer Zellen nicht erwünscht war. Somit konnten die Spüllösungen im Vorversuch länger einwirken. Trotzdem war bei fast vollständiger Abtötung der Bakterien durch alle Behandlungsmethoden zu mehr als 75\% der DNA-Menge der Kontrollprobe nachweisbar.

Somit war die hier durchgeführte PCR in der Lage neben vitalen Bakterien auch den größten Anteil vermehrungsunfähiger Bakterien zu detektieren und konnte als Marker für adhärierende Erreger nach der jeweiligen Biofilm-Behandlung dienen.

Die PCR unterschied nicht zwischen lebenden und abgetöteten Bakterien, bot aber eine Aussage über die relativen Gesamtmengen der Bakterien im Vergleich zu den unbehandelten Kontrollproben, d.h. sie ergänzte damit die Aussage zur Dekontamination, die durch kulturelle Vermehrung der noch überlebenden Bakterien gewonnen wurde.

Ein prinzipielles Problem der PCR war die große Anfälligkeit gegenüber Kontaminationen. Auf Grund der hohen Sensitivität der Methode führten geringste bakterielle Verunreinigungen der benutzten Reagenzien und Geräte zum Auftreten oder Verstärken der positiven Signale. Sehr sorgfältiges Arbeiten und jeweils mitgeführte negative Kontrollen haben sich als unabdingbar herausgestellt.

Es wurden nur die PCR-Untersuchungen gewertet, bei denen sich in den negativen Kontrollen keine spezifische DNA nachweisen ließ und für alle vier Dekontaminationsverfahren reproduzierbare Ergebnisse erzielt wurden. Dadurch reduzierten sich die beurteilbaren Probanden für Fusobacterium nucleatum auf sechs und für Eikenella corrodens bzw. Prevotella intermedia auf jeweils fünf. Eine Steigerung der Probandenzahl wäre somit für Folgeuntersuchungen wünschenswert.

Die hier durchgeführten semiquantitativen PCR-Untersuchungen der gewonnenen Biofilmmaterialien der Probanden nach den Behandlungen ergaben unterschiedliche Reduktionen der Menge der nachweisbaren spezifischen bakteriellen DNA in Abhängigkeit der Dekontaminationsmethoden, jeweils im Vergleich zu den PCRUntersuchungen des unbehandelten Biofilmmaterials der Kontrollproben der Probanden. 
Der größten Effekt, mit etwa 50\% Reduktion der nachweisbaren bakteriellen DNA, konnte beim Er:YAG-Laser gemessen werden. Es folgte der Diodenlaser, dann die Spüllösung Octenidindihydrochlorid/2-Phenoxyethanol. Den geringsten Einfluss auf eine Reduktion der bakteriellen DNA zeigte die Behandlung mit Chlorhexidindigluconat. Diese Reihenfolge ergab sich unabhängig von den drei untersuchten Bakterienarten. Die Unterschiede zwischen dem Er:YAG-Laser und dem Diodenlaser waren statistisch signifikant. Das gilt auch für beide Laser im Vergleich zu den Spüllösungen, während die Spüllösungen unter sich keine signifikanten Differenzen in der eliminierten Bakterienmenge belegen konnten.

Zusammengefasst wird deutlich, dass ein großer Teil der abgetöteten Bakterien noch auf der Oberfläche des behandelten Titanröhrchens vorhanden blieb. Das galt vor allem nach der Behandlung mit Spüllösungen.

Der verbliebene Biofilm kann als Promotor für Adhäsion und Wiederbesiedlung wirken. Die initial glatte Oberfläche eines Implantats kann durch verbliebene, abgetötete Bakterien und Biofilmreste an Rauigkeit zunehmen und damit eine erneute Besiedlung abhängig auch vom Material fördern (Busscher et al. 2010). Über Lecithin, als bakterieller Wandbestandteil auch abgetöteter Bakterien, kann offenbar eine Bindung vitaler Bakterien vermittelt werden (Decker et al. 2003) und bakterielle Endotoxine aus der Wand abgetöteter Bakterien können eine destruktive Entzündungsreaktion im umgebenden Gewebe auslösen (Giannelli et al. 2009).

Es ist zu vermuten, dass die Reosseointegration des Zahnimplantates negativ beeinflusst und ein Rezidiv durch einen zurückbleibenden Biofilm wahrscheinlicher wird.

Die Anwendung der Laser ergab in dieser Studie den stärksten bakteriziden und eliminierenden Effekt für die Bakterien im Biofilm auf der Titanoberfläche. Als besonders wirksam stellte sich der Er:YAG-Laser dar, bei dessen Anwendung die obligat eingesetzte Wasserkühlung wahrscheinlich einen zusätzlichen mechanischen Effekt zu seiner sonstigen Wirkweise erzielte.

Ähnliche Erfahrungen wurden bei der Konkremententfernung auf Zahnoberflächen und Implantaten aus Titan berichtet (Schwarz et al. 2003, Krause et al. 2007). Allerdings waren auch nach dem Einsatz des Er:YAG-Lasers weiterhin noch Biofilmbestandteile nachzuweisen (Schwarz et al. 2007a). Auch in der vorliegenden Arbeit konnte lediglich eine Beseitigung von etwa 50\% der Bakterien bzw. ihrer Bestandteile gemessen werden, die mit den anderen Dekontaminationsmethoden unter den beschriebenen Bedingungen nicht erreicht werden konnte. Bestätigt wurden diese Ergebnisse durch Untersuchungen, 
die für Diodenlaser eine sehr ineffektive Konkrementbeseitigung zeigten (Tucker et al. 1996, Liu et al. 1999, Bach et al. 2000, Deppe 2000, Schwarz et al. 2003).

Die Effizienz des Er:YAG-Lasers hinsichtlich der Abtötung der anaeroben Bakterien und des Reinigungseffektes der Implantatoberfläche vom Biofilm ließen diesen Laser als besonders vorteilhaft für die Therapie einer Periimplantitis erscheinen. Eine Schädigung der Implantatoberfläche wurde in den Publikationen zwar nicht völlig ausgeschlossen, der Einsatz der integrierten Wasserkühlung in dem Lasersystem reduziert dieses geringe Risiko noch weiter (Schwarz et al. 2007b, Romanos et al. 2009). In verschiedenen Studien wurden kontaminierte Implantatoberflächen nach Behandlung mit einem Er:YAG Laser überprüft und zeigten keine Beeinträchtigung der Biokompatibilität (Kreisler et al. 2003, Schwarz und Becker 2003). Darüber hinaus wurde dem Er:YAG-Laser ein positiver Einfluss auf die Heilung und einer besseren Knochenintegration des Implantats in Tiermodellen zugeschrieben (Schwarz et al. 2007a, Schwarz et al. 2007b, Takasaki et al. 2007, Schwarz et al. 2008b).

Im Zusammenhang mit der nicht-chirurgischen Behandlung der chronischen Parodontitis existieren zahlreiche Publikationen über Erfahrungen mit der Lasertherapie. In einer Übersicht wurde dazu eine Meta-Analyse durchgeführt (Schwarz et al. 2008a). Die Autoren kamen zu den Schlussfolgerungen, dass in klinischen Studien ein mechanisches Debridement sich nicht von der Behandlung mit einem Er:YAG-Laser unterscheidet. Das galt für einen Beobachtungszeitraum von bis zu zwei Jahren. Allerdings war die Datenlage dafür noch zu unsicher, um definitive Aussagen zu machen. Für die Anwendung $\mathrm{CO}_{2^{-}}, \mathrm{Nd}$ :YAG- oder Diodenlaser sind nur unzureichende klinische Informationen zu gewinnen. Schwarz stellt bei der Zusammenstellung der Studiendaten in dieser Arbeit fest, dass die Studien insgesamt zu heterogen sind, um eine tatsächliche Meta-Analyse durchzuführen (Schwarz et al. 2006). Ähnlich stellte sich die Situation bei der Therapie der Periimplantitis dar. Auch hier gab es ebenfalls zahlreiche, aber sehr unterschiedliche Arbeiten, die noch keine eindeutige Bewertung zur Wirksamkeit der Dekontaminationsverfahren zulassen, da eine Vergleichbarkeit nicht gewährleistet war. Eine in-vitro-Studie über 12 Patienten mit Periimplantitis berichtete über signifikant bessere klinische Verhältnisse nach Er:YAG-Laserbestrahlung im Vergleich zur nichtchirurgischen Periimplantitistherapie mit Küretten und Chlorhexidindigluconat-Spülungen bis zu sechs Monate nach den Behandlungen (Schwarz et al. 2006). 


\section{Fazit}

Die Dekontamination von Biofilm-besiedelten Implantatoberflächen gilt als wesentliche Maßnahme zur Prophylaxe und/oder Behandlung einer Periimplantitis. Die Ergebnisse vorangegangener Studien zu dieser Problematik ließen bisher offen, welches Dekontaminationsverfahren am besten geeignet ist. Die wesentliche Ursache dafür war, dass die Studien in der Regel lediglich in vitro durchgeführt wurden, die Methoden nicht vergleichbar waren und die praktische Anwendung in der zahnärztlichen Routine unberücksichtigt blieb.

Die Originalität der vorliegenden Arbeit liegt darin, unter Beachtung praxisnaher Behandlungsbedingungen vier verschiedene Methoden jeweils an einem oralen in vivo gebildeten zehn Tage alten Biofilm auf Titanoberflächen desselben Probanden anzuwenden und die Ergebnisse der Dekontaminationen direkt miteinander zu vergleichen. Ziel war dabei, das wirksamste unter den vier Verfahren zu ermitteln. Die beiden dafür eingesetzten mikrobiologischen Nachweisverfahren wurden in dieser Kombination erstmals in einer derartigen Studie eingesetzt.

Das Kulturverfahren erlaubte die Ermittlung der bakteriziden Wirkung, durch die PCR konnten Aussagen über den noch verbleibenden Biofilm nach den Behandlungen getroffen werden.

Die deutlichste Dekontamination konnte, durch beide Nachweisverfahren evaluiert, übereinstimmend dem Er:YAG-Laser zugeordnet werden.

In zukünftigen Untersuchungen sollte die Relevanz von Residuen eines nicht mehr vitalen Biofilms und auch die Wiederbesiedlung der Laser-behandelten Oberflächen untersucht werden. 


\section{Zusammenfassung}

Der Einsatz dentaler Implantate zeigt eine stark zunehmende Tendenz, bedingt durch die Weiterentwicklung der eingesetzten Materialien und Techniken, sowie den steigenden Bedarf im Zuge der demographischen Entwicklung.

Besonders an die Langlebigkeit von Implantaten werden hohe Ansprüche gestellt. Wesentlich verantwortlich für Komplikationen wie Lockerungen und Verluste von Zahnimplantaten ist die Periimplantitis, eine Infektion implantatumgebender Gewebe, die in den meisten Fällen durch Bakterien im Biofilm auf dem Implantat verursacht wird. Hier kommt der anaeroben Bakterienspezies eine besondere Bedeutung zu. Die Dekontamination der mit Biofilmen besiedelten Oberflächen spielt somit eine Schlüsselrolle in der Prophylaxe und Therapie der Periimplantitis. Zur Eliminierung von Bakterien in oralen Biofilmen werden in der Literatur verschiedene Spüllösungen, mechanische Verfahren oder die Anwendung von Laserlicht beschrieben, die aufgrund unterschiedlicher Studienbedingungen in ihrer Wirksamkeit kaum miteinander vergleichbar sind.

Um das wirksamste Dekontaminationsverfahren $\mathrm{zu}$ evaluieren, wurden in der vorliegenden experimentellen Arbeit der bakterizide Effekt und das Ausmaß der Eliminierung des Biofilms durch den Einsatz von vier Dekontaminationsverfahren unter genau definierten Bedingungen ermittelt und direkt miteinander verglichen. Besonderer Wert wurde in dieser Studie auf praxisnahe Untersuchungsbedingungen gelegt.

Der untersuchte orale Biofilm entstand in vivo bei 20 freiwilligen Probanden unter klaren Randbedingungen über zehn Tage auf den inneren Oberflächen von implantologischen Bohrhülsen aus Titan an individuell angepassten Unterkieferschienen. Lediglich 16 Probanden erfüllten letztlich die strengen Einschlusskriterien. Zur Dekontamination wurden ein Diodenlaser, ein Er:YAG-Laser und die beiden chemischen Desinfektionsmittel Chlorhexidindigluconat und Octenidindihydrochlorid/2Phenoxyethanol eingesetzt. Die Einwirkung auf den Biofilm der Titanhülsen erfolgte in vitro in einem Phantomkopf unter Bedingungen, die die klinische Behandlungssituation simulierten.

Die bakterizide Wirkung der Methoden konnte durch quantitative Beurteilung der kulturellen Vermehrungsfähigkeit anaerober Bakterien im präparierten Biofilm ohne und nach der jeweiligen Behandlung bestimmt werden. Der stärkste antibakterielle Einfluss 
wurde für den Er:YAG-Laser (L2) mit 93,9\% ermittelt. Der Diodenlaser (L1) zeigte eine Reduktionsrate von 92,2\%, ohne sich signifikant vom Er:YAG-Laser zu unterscheiden. Beide Laserverfahren zeigten sich gegenüber beiden Spüllösungen statistisch signifikant besser wirksam. Octenidindihydrochlorid/2-Phenoxyethanol (S2) zeigte eine Bakterizidie von $90,5 \%$, der geringste Effekt mit 77,5\% wurde für Chlorhexidindigluconat (S1) evaluiert. Dieser Unterschied war statistisch signifikant und verdeutlichte die Überlegenheit von Octenidindihydrochlorid/2-Phenoxyethanol gegenüber Chlorhexidindigluconat.

Neben der bakteriziden Wirkung wurde weiter ermittelt in welchem Ausmaß nach den jeweiligen Behandlungen Restbestandteile des Biofilms, der auch nicht mehr vermehrungsfähige Bakterien beinhaltet, auf der Titanoberfläche verblieben waren. Als Indikator dafür bot sich die Polymerase-Kettenreaktion (PCR) an, bei der als Zielsequenzen DNA-Abschnitte der drei Arten Fusobacterium nucleatum, Eikenella corrodens und Prevotella intermedia genutzt wurden. Die drei Bakterienarten waren in Vorversuchen bei allen Probanden nachgewiesen worden. In weiteren Vorversuchen konnte gezeigt werden, dass die durch die Dekontaminationsverfahren abgetöteten Bakterien mit der PCR weiterhin identifizierbar waren, d.h. deren DNA nicht oder nur wenig geschädigt wurde.

Die Behandlung mit dem Er:YAG-Laser beseitigte den Biofilm zu 51,2\%, der Diodenlaser zu 36,9\%, Octenidindihydrochlorid/2-Phenoxyethanol zu 21,0\% und

Chlorhexidindigluconat zu 16,8\%. Diese Reihenfolge entsprach der, die bei der Beurteilung der bakteriziden Wirkung beobachtet wurde. Der Unterschied zwischen den Laserverfahren zeigte sich statistisch signifikant, ebenso der Vergleich beider Laser zu beiden Spüllösungen. Lediglich die Spüllösungen untereinander ergaben keinen signifikanten Unterschied bei der Entfernung bakterieller Biofilmbestandteile.

Den stärksten bakteriziden und Biofilm eliminierenden Effekt konnten damit die Laserverfahren, besonders der Er:YAG-Laser erzielen.

Die PCR zeigte sich hier als gut geeignet, auch nicht mehr vermehrungsfähige Bakterien auf der Titanoberfläche zu detektieren und damit den verbliebenen Biofilm semiquantitativ zu erfassen.

Die Ergebnisse der vorliegenden Arbeit geben Anlass, den Er:YAG-Laser im klinischen Einsatz über die anderen untersuchten Dekontaminationsverfahren zu stellen. 
Prospektive klinische Studien mit Fokus auf Periimplantitis und Lebensdauer der Implantate werden zeigen müssen, ob die in dieser Studie evaluierten Ergebnisse direkt auf die zahnärztliche Praxis übertragbar sind. 


\section{Literaturverzeichnis}

Abiko Y, Sato T, Mayanagi G, Takahashi N (2010): Profiling of subgingival plaque biofilm microflora from periodontally healthy subjects and from subjects with periodontitis using quantitative real-time PCR. J Periodontal Res $\underline{45}$, 389-395

Aoki A, Mizutani K, Takasaki AA, Sasaki KM, Nagai S, Schwarz F, Yoshida I, Eguro T, Zeredo JL, Izumi Y (2008): Current status of clinical laser applications in periodontal therapy. Gen Dent $\underline{56}$, 674-687; quiz 688-679, 767

Araki AT, Ibraki Y, Kawakami T, Lage-Marques JL (2006): Er:Yag laser irradiation of the microbiological apical biofilm. Braz Dent J 17, 296-299

Aufenanger J : Dekontaminationswirkung von Diodenlaserlicht auf rauhen Titanoberflächen in vitro. Eine mikrobiologische Studie. Med. Dissertation Göttingen 2001

Augthun M, Tinschert J, Huber A (1998): In vitro studies on the effect of cleaning methods on different implantat surfaces. J Periodontol $\underline{69}, 857-864$

Auschill TM, Hellwig E, Sculean A, Hein N, Arweiler NB (2004): Impact of the intraoral location on the rate of biofilm growth. Clin Oral Investig $\underline{8}, 97-101$

Azakami H, Teramura I, Matsunaga T, Akimichi H, Noiri Y, Ebisu S, Kato A (2006): Characterization of autoinducer 2 signal in Eikenella corrodens and its role in biofilm formation. J Biosci Bioeng 102, 110-117

Bach G, Gutknecht N, Schneider H : Lasertherapie in der Zahnheilkunde. Diodenlaser in der Praxis. Apollonia Verlag, Linnich 1998

Bach G, Neckel C, Mall C, Krekeler G (2000): Conventional versus laser-assisted therapy of periimplantitis: a five-year comparative study. Implant Dent $\underline{9}$, 247-251

Bailey DM, DeGrazia CG, Hoff SJ, Schulenberg PL, O'Connor JR, Paris DA, Slee AM (1984): Bispyridinamines: a new class of topical antimicrobial agents as inhibitors of dental plaque. $\mathrm{J}$ Med Chem 27, 1457-1464

Bartoszewicz M, Rygiel A, Krzeminski M, Przondo-Mordarska A (2007): Penetration of a selected antibiotic and antiseptic into a biofilm formed on orthopedic steel implants. Ortop Traumatol Rehabil $\underline{9}$, 310-318

Berglundh T, Persson L, Klinge B (2002): A systematic review of the incidence of biological and technical complications in implant dentistry reported in prospective longitudinal studies of at least 5 years. J Clin Periodontol 29 Suppl 3, 197-212; discussion 232-193.

Bollen CM, Papaioanno W, Van Eldere J, Schepers E, Quirynen M, van Steenberghe D (1996): The influence of abutment surface roughness on plaque accumulation and periimplant mucositis. Clin Oral Implants Res ㄱ, 201-211

Bradshaw DJ, Marsh PD, Allison C, Schilling KM (1996): Effect of oxygen, inoculum composition and flow rate on development of mixed-culture oral biofilms. Microbiology $\underline{142}$ (Pt 3), 623-629 
Bradshaw DJ, Marsh PD, Watson GK, Allison C (1998): Role of Fusobacterium nucleatum and coaggregation in anaerobe survival in planktonic and biofilm oral microbial communities during aeration. Infect Immun $\underline{66}, 4729-4732$

Branda SS, Vik S, Friedman L, Kolter R (2005): Biofilms: the matrix revisited. Trends Microbiol $\underline{13}, 20-26$

Brecx MC, Liechti T, Widmer J, Gehr P, Lang NP (1989): Histological and clinical parameters of human gingiva following 3 weeks of chemical (chlorhexidine) or mechanical plaque control. J Clin Periodontol $\underline{16}, 150-155$

Buehlmann M, Frei R, Fenner L, Dangel M, Fluckiger U, Widmer AF (2008): Highly effective regimen for decolonization of methicillin-resistant Staphylococcus aureus carriers. Infect Control Hosp Epidemiol 29, 510-516

Busscher HJ, Rinastiti M, Siswomihardjo W, van der Mei HC (2010): Biofilm formation on dental restorative and implant materials. J Dent Res $\underline{89}$, 657-665

Coluzzi DJ (2002): Lasers and soft tissue curettage: an update. Compend Contin Educ Dent $23,1104-1111$

Costerton JW, Lewandowski Z, Caldwell DE, Korber DR, Lappin-Scott HM (1995):

Microbial biofilms. Annu Rev Microbiol $\underline{49}$, 711-745

De Boever AL, De Boever JA (2006): Early colonization of non-submerged dental implants in patients with a history of advanced aggressive periodontitis. Clin Oral Implants Res $\underline{17}$, 817

Decker EM, Weiger R, Wiech I, Heide PE, Brecx M (2003): Comparison of antiadhesive and antibacterial effects of antiseptics on Streptococcus sanguinis. Eur J Oral Sci 111, 144-148

Deppe H, Horch HH (2007): Laser applications in oral surgery and implant dentistry. Lasers Med Sci 22, 217-221

Deppe H, Horch H, Donath K, Hiermer T, Henke J (2000): Experimentelle Untersuchungen zur Laser-assistierten Periimplantitistherapie. Z Zahnärztl Impl 15, 97-108

Deppe H, Horch HH, Henke J, Donath K (2001): Per-implant care of ailing implants with the carbon dioxide laser. Int J Oral Maxillofac Implants $\underline{16}, 659-667$

Dettenkofer M, Wilson C, Gratwohl A, Schmoor C, Bertz H, Frei R, Heim D, Luft D, Schulz S, Widmer AF (2010): Skin disinfection with octenidine dihydrochloride for central venous catheter site care: a double-blind, randomized, controlled trial. Clin Microbiol Infect $\underline{16}, 600$ 606

Dortbudak O, Haas R, Bernhart T, Mailath-Pokorny G (2001): Lethal photosensitization for decontamination of implant surfaces in the treatment of peri-implantitis. Clin Oral Implants Res 12, 104-108

Eigenbrod L, Frosch PJ (2010): Octenidin nicht unter Druck in Hautgewebe injizieren. Der deutsche Dermatologe 10, 641-643

Eley BM (1999): Antibacterial agents in the control of supragingival plaque--a review. Br Dent J $\underline{186}, 286-296$ 
Fontana CR, Kurachi C, Mendonca CR, Bagnato VS (2004a): Microbial reduction in periodontal pockets under exposition of a medium power diode laser: an experimental study in rats. Lasers Surg Med $\underline{35}, 263-268$

Fontana CR, Kurachi C, Mendonca CR, Bagnato VS (2004b): Temperature variation at soft periodontal and rat bone tissues during a medium-power diode laser exposure. Photomed Laser Surg 22, 519-522

Franzen R, Meister J, Schippers M, Gutknecht N (2005): Die bakterizide Wirkung eines 980 nm-Dioden-Lasers im Wurzelkanalwanddentin boviner Zähne - Eine In-vitro-Studie. LaserZahnheilkunde $\underline{3}, 143-148$

Genco RJ, Ho AW, Kopman J, Grossi SG, Dunford RG, Tedesco LA (1998): Models to evaluate the role of stress in periodontal disease. Ann Periodontol $\underline{3}, 288-302$

Giannelli M, Bani D, Tani A, Pini A, Margheri M, Zecchi-Orlandini S, Tonelli P, Formigli L (2009): In vitro evaluation of the effects of low-intensity Nd:YAG laser irradiation on the inflammatory reaction elicited by bacterial lipopolysaccharide adherent to titanium dental implants. J Periodontol $\underline{\text { 80, }}$ 977-984

Gilbert P, Das J, Foley I (1997): Biofilm susceptibility to antimicrobials. Adv Dent Res $\underline{11}$, 160-167

Gosau M, Hahnel S, Schwarz F, Gerlach T, Reichert TE, Burgers R (2010): Effect of six different peri-implantitis disinfection methods on in vivo human oral biofilm. Clin Oral Implants Res 21, 866-872

Groessner-Schreiber B, Hannig M, Duck A, Griepentrog M, Wenderoth DF (2004): Do different implant surfaces exposed in the oral cavity of humans show different biofilm compositions and activities? Eur J Oral Sci 112, 516-522

Groessner-Schreiber B, Teichmann J, Hannig M, Dorfer C, Wenderoth DF, Ott SJ (2009): Modified implant surfaces show different biofilm compositions under in vivo conditions. Clin Oral Implants Res $\underline{20}$, 817-826

Gustafsson A, Asman B (1996): Increased release of free oxygen radicals from peripheral neutrophils in adult periodontitis after Fc delta-receptor stimulation. J Clin Periodontol $\underline{23}$, 3844

Hale GM, Querry MR (1973): Optical Constants of Water in the 200-nm to 200-microm Wavelength Region. Appl Opt 12, 555-563

Harke HP (1989): Octenidine dihydrochloride, properties of a new antimicrobial agent. Zentralbl Hyg Umweltmed $\underline{188}$, 188-193

Hellwig E, Klimek J, Attin T: Einführung in die Zahnerhaltung: 2. Aufl., Urban \& Fischer, München 1999

Heydenrijk K, Meijer HJ, van der Reijden WA, Raghoebar GM, Vissink A, Stegenga B (2002): Microbiota around root-form endosseous implants: a review of the literature. Int $\mathrm{J}$ Oral Maxillofac Implants 17, 829-838

Hibst R, Keller U (1989): Experimental studies of the application of the Er:YAG laser on dental hard substances: I. Measurement of the ablation rate. Lasers Surg Med $\underline{9}$, 338-344 
Hübner NO, Siebert J, Kramer A (2010): Octenidine dihydrochloride, a modern antiseptic for skin, mucous membranes and wounds. Skin Pharmacol Physiol $\underline{23}$, 244-258

Hultin M, Gustafsson A, Hallstrom H, Johansson LA, Ekfeldt A, Klinge B (2002):

Microbiological findings and host response in patients with peri-implantitis. Clin Oral Implants $\operatorname{Res} \underline{13}, 349-358$

Josephson KL, Gerba CP, Pepper IL (1993): Polymerase chain reaction detection of nonviable bacterial pathogens. Appl Environ Microbiol $\underline{59}$, 3513-3515

Keller U, Hibst R (1989): Ablative effect of an Er:YAG laser on enamel and dentin. Dtsch Zahnarztl Z 44, 600-602.

Keller U, Hibst R, Geurtsen W, Schilke R, Heidemann D, Klaiber B, Raab WH (1998): Erbium:YAG laser application in caries therapy. Evaluation of patient perception and acceptance. J Dent $\underline{26}, 649-656$

Kite P, Dobbins BM, Wilcox MH, Fawley WN, Kindon AJ, Thomas D, Tighe MJ, McMahon MJ (1997): Evaluation of a novel endoluminal brush method for in situ diagnosis of catheter related sepsis. J Clin Pathol $\underline{50}, 278-282$

Klinge B, Hultin M, Berglundh T (2005): Peri-implantitis. Dent Clin North Am 49, 661-676, viiviii

Kolenbrander PE (2000): Oral microbial communities: biofilms, interactions, and genetic systems. Annu Rev Microbiol 54, 413-437

Kolenbrander PE, Palmer RJ, Jr., Periasamy S, Jakubovics NS (2010): Oral multispecies biofilm development and the key role of cell-cell distance. Nat Rev Microbiol $\underline{8}, 471-480$

Kolter R, Greenberg EP (2006): Microbial sciences: the superficial life of microbes. Nature $\underline{441}, 300-302$

Krause F, Braun A, Brede O, Eberhard J, Frentzen M, Jepsen S (2007): Evaluation of selective calculus removal by a fluorescence feedback-controlled Er:YAG laser in vitro. J Clin Periodontol $\underline{34}$, 66-71

Kreisler M, Kohnen W, Marinello C, Schoof J, Langnau E, Jansen B, d'Hoedt B (2003):

Antimicrobial efficacy of semiconductor laser irradiation on implant surfaces. Int $\mathrm{J}$ Oral Maxillofac Implants $\underline{18}, 706-711$

Kreisler M, Kohnen W, Christoffers AB, Gotz H, Jansen B, Duschner H, d'Hoedt B (2005): In vitro evaluation of the biocompatibility of contaminated implant surfaces treated with an $\mathrm{Er}$ : YAG laser and an air powder system. Clin Oral Implants Res $\underline{16}, 36-43$

Krekeler G, Pelz K, Schopferer W (1988): Colonisation of diseased periodontal and endodontic tissues by microorganisms and their pathogenic potential. Z Stomatol $\underline{85}, 313-$ 317

Kuboniwa M, Amano A, Kimura KR, Sekine S, Kato S, Yamamoto Y, Okahashi N, lida T, Shizukuishi S (2004): Quantitative detection of periodontal pathogens using real-time polymerase chain reaction with TaqMan probes. Oral Microbiol Immunol $\underline{19}$, 168-176

Lang NP, Schild U, Bragger U (1994): Effect of chlorhexidine (0.12\%) rinses on periodontal tissue healing after tooth extraction. (I). Clinical parameters. J Clin Periodontol $\underline{21}$, 415-421 
Lang NP, Wilson TG, Corbet EF (2000): Biological complications with dental implants: their prevention, diagnosis and treatment. Clin Oral Implants Res 11 Suppl 1, 146-155

Leid JG, Willson CJ, Shirtliff ME, Hassett DJ, Parsek MR, Jeffers AK (2005): The exopolysaccharide alginate protects Pseudomonas aeruginosa biofilm bacteria from IFNgamma-mediated macrophage killing. J Immunol $\underline{175}$, 7512-7518

Leonhardt A, Dahlen G (1995): Effect of titanium on selected oral bacterial species in vitro. Eur J Oral Sci 103, 382-387

Leonhardt A, Renvert S, Dahlen G (1999): Microbial findings at failing implants. Clin Oral Implants Res 10, 339-345

Leonhardt A, Grondahl K, Bergstrom C, Lekholm U (2002): Long-term follow-up of osseointegrated titanium implants using clinical, radiographic and microbiological parameters. Clin Oral Implants Res $\underline{13}, 127-132$

Leonhardt A, Bergstrom C, Lekholm U (2003): Microbiologic diagnostics at titanium implants. Clin Implant Dent Relat Res $\underline{5}$, 226-232

Li J, Helmerhorst EJ, Leone CW, Troxler RF, Yaskell T, Haffajee LD, Socransky RF, Oppenheim FG (2004): Identification of early microbial colonizers in human dental biofilm. J Appl Microbiol 97, 1311-1318

Lindquist LW, Carlsson GE, Jemt T (1996): A prospective 15-year follow-up study of mandibular fixed prostheses supported by osseointegrated implants. Clinical results and marginal bone loss. Clin Oral Implants Res $\underline{7}, 329-336$

Liu CM, Hou LT, Wong MY, Lan WH (1999): Comparison of Nd:YAG laser versus scaling and root planing in periodontal therapy. J Periodontol $\underline{70}, 1276-1282$

Mah TF, O'Toole GA (2001): Mechanisms of biofilm resistance to antimicrobial agents. Trends Microbiol $\underline{9}$, 34-39

Marsh PD (2004): Dental plaque as a microbial biofilm. Caries Res $\underline{38}, 204-211$

Matsuyama T, Aoki A, Oda S, Yoneyama T, Ishikawa I (2003): Effects of the Er:YAG laser irradiation on titanium implant materials and contaminated implant abutment surfaces. J Clin Laser Med Surg 21, 7-17

McBain AJ, Bartolo RG, Catrenich CE, Charbonneau D, Ledder RG, Gilbert P (2003): Effects of a chlorhexidine gluconate-containing mouthwash on the vitality and antimicrobial susceptibility of in vitro oral bacterial ecosystems. Appl Environ Microbiol $\underline{69}$, 4770-4776

Millward TA, Wilson M (1989): The effect of chlorhexidine on Streptococcus sanguis biofilms. Microbios $\underline{58}, 155-164$

Mombelli A (2002): Microbiology and antimicrobial therapy of peri-implantitis. Periodontol $2000 \underline{28}, 177-189$

Mombelli A, Lang NP (1998): The diagnosis and treatment of peri-implantitis. Periodontol $2000 \underline{17}, 63-76$ 
Mombelli A, Decaillet F (2011): The characteristics of biofilms in peri-implant disease.J Clin Periodontol 38 Suppl 11, 203-213

Moore LE, Ledder RG, Gilbert P, McBain AJ (2008): In vitro study of the effect of cationic biocides on bacterial population dynamics and susceptibility. Appl Environ Microbiol $\underline{74}$, 4825-4834

Norowski PA Jr, Bumgardner JD (2009): Biomaterial and antibiotic strategies for periimplantitis: a review. J Biomed Mater Res B Appl Biomater 88, 530-543

Papapanou PN, Behle JH, Kebschull M, Celenti R, Wolf DL, Handfield M, Pavlidis P, Demmer RT (2009): Subgingival bacterial colonization profiles correlate with gingival tissue gene expression. BMC Microbiol $\underline{9}, 221$

Park CY, Kim SG, Kim MD, Eom TG, Yoon JH, Ahn SG (2005): Surface properties of endosseous dental implants after NdYAG and $\mathrm{CO} 2$ laser treatment at various energies. J Oral Maxillofac Surg $\underline{63}, 1522-1527$

Piattelli A, Scarano A, Piattelli M (1998): Histologic observations on 230 retrieved dental implants: 8 years' experience (1989-1996). J Periodontol $\underline{69}$, 178-184

Pitten FA, Kramer A (1999): Antimicrobial efficacy of antiseptic mouthrinse solutions. Eur J Clin Pharmacol 55,95-100

Quirynen M, Bollen CM, Papaioannou W, Van Eldere J, van Steenberghe D (1996): The influence of titanium abutment surface roughness on plaque accumulation and gingivitis: short-term observations. Int J Oral Maxillofac Implants $\underline{11}$, 169-178

Quirynen M, De Soete M, van Steenberghe D (2002a): Infectious risks for oral implants: a review of the literature. Clin Oral Implants Res $\underline{13}, 1-19$

Quirynen M, Zhao H, van Steenberghe D (2002b): Review of the treatment strategies of oral malodour. Clin Oral Investig $\underline{6}, 1-10$

Renvert S, Roos-Jansaker AM, Lindahl C, Renvert H, Rutger Persson G (2007): Infection at titanium implants with or without a clinical diagnosis of inflammation. Clin Oral Implants Res $\underline{18}, 509-516$

Riley DJ, Bavastrello V, Covani U, Barone A, Nicolini C (2005): An in-vitro study of the sterilization of titanium dental implants using low intensity UV-radiation. Dent Mater $\underline{21}, 756-$ 760

Romanos GE, Everts H, Nentwig GH (2000): Effects of diode and Nd:YAG laser irradiation on titanium discs: a scanning electron microscope examination. J Periodontol $\underline{71}$, 810-815

Romanos GE, Gutknecht N, Dieter S, Schwarz F, Crespi R, Sculean A (2009): Laser wavelengths and oral implantology. Lasers Med Sci $\underline{24}$, 961-970

Roos-Jansaker AM, Renvert H, Lindahl C, Renvert S (2006): Nine- to fourteen-year follow-up of implant treatment. Part III: factors associated with peri-implant lesions. J Clin Periodontol $\underline{33}, 296-301$

Rutar A, Lang NP, Buser D, Burgin W, Mombelli A (2001): Retrospective assessment of clinical and microbiological factors affecting periimplant tissue conditions. Clin Oral Implants Res 12, 189-195 
Sachse K.: PCR Detection of microbial pathogens. Sachse KuJF, editor. Humana Press, Totowa, New Jersey 2003

Sanchez-Garces MA, Gay-Escoda C (2004): Periimplantitis. Med Oral Patol Oral Cir Bucal $\underline{9}$ Suppl, 69-74; 63-69

Sbordone L, Bortolaia C (2003): Oral microbial biofilms and plaque-related diseases: microbial communities and their role in the shift from oral health to disease. Clin Oral Investig $\underline{7}, 181-188$

Schwarz F, Becker J (2003): Einfluss eines Er:YAG-Lasers auf die Oberflächenstruktur von Titanimplantaten. Schweiz Monatsschr Zahnmed 113, 661-668

Schwarz F, Sculean A, Berakdar M, Szathmari L, Georg T, Becker J (2003): In vivo and in vitro effects of an Er:YAG laser, a GaAlAs diode laser, and scaling and root planing on periodontally diseased root surfaces: a comparative histologic study. Lasers Surg Med $\underline{32}$, 359-366

Schwarz F, Bieling K, Sculean A, Herten M, Becker J (2004): [Treatment of periimplantitis with laser or ultrasound. A review of the literature]. Schweiz Monatsschr Zahnmed 114, 1228-1235

Schwarz F, Sculean A, Romanos G, Herten M, Horn N, Scherbaum W, Becker J (2005): Influence of different treatment approaches on the removal of early plaque biofilms and the viability of SAOS2 osteoblasts grown on titanium implants. Clin Oral Investig $\underline{9}, 111-117$

Schwarz F, Bieling K, Nuesry E, Sculean A, Becker J (2006): Clinical and histological healing pattern of peri-implantitis lesions following non-surgical treatment with an Er:YAG laser. Lasers Surg Med 으, 663-671

Schwarz F, Jepsen S, Herten M, Aoki A, Sculean A, Becker J (2007a): Immunohistochemical characterization of periodontal wound healing following nonsurgical treatment with fluorescence controlled Er:YAG laser radiation in dogs. Lasers Surg Med 39, 428-440

Schwarz F, Olivier W, Herten M, Sager M, Chaker A, Becker J (2007b): Influence of implant bed preparation using an Er:YAG laser on the osseointegration of titanium implants: a histomorphometrical study in dogs. J Oral Rehabil $\underline{34}$, 273-281

Schwarz F, Ferrari D, Popovski C, Becker J (2007c): Entfernung bakterieller Plaque-Biofilme von strukturierten Titanimplantaten unter Verwendung von Laserwellenlängen im Bereich von $3 \mu \mathrm{m}$. LaserZahnheilkunde $\underline{4}$, 231-238.

Schwarz F, Aoki A, Becker J, Sculean A (2008a): Laser application in non-surgical periodontal therapy: a systematic review. J Clin Periodontol 35, 29-44

Schwarz F, Rothamel D, Herten M, Wustefeld M, Sager M, Ferrari D, Becker J (2008b): Immunohistochemical characterization of guided bone regeneration at a dehiscence-type defect using different barrier membranes: an experimental study in dogs. Clin Oral Implants Res $\underline{19}, 402-415$

Sennhenn-Kirchner S, Aufenanger J, Jacobs HG (2002): Decontamination effects of diode laser irradiation on rough implant surfaces - microbiological results of an in-vitro-study. J Dent Implantol $\underline{18}$, 23-28 
Sennhenn-Kirchner S, Schliesing J, Jacobs HG, Mergeryan H (2004): Antimikrobielle Wirkung verschiedener chemischer Agenzien of rauen Titanoberflächen. Z Zahnärztl Impl $\underline{20}$, 152-157

Sennhenn-Kirchner S, Cevik G, Ahlborn S, Jacobs HG, Schwarz P, Borg von Zepelin M (2007a): Decontamination efficacy of antiseptical agents on various Candida albicans isolates of a five day in-vitro biofilm model. Z Zahnärztl Impl 23, 188-200

Sennhenn-Kirchner S, Klaue S, Wolff N, Mergeryan H, Borg von Zepelin M, Jacobs HG (2007b): Decontamination of rough titanium surfaces with diode lasers: microbiological findings on in vivo grown biofilms. Clin Oral Implants Res $\underline{18}, 126-132$

Sennhenn-Kirchner S, Wolff N, Klaue S, Mergeryan H, Borg-von Zepelin M (2009a): Decontamination effiacy of antiseptic agents on in vivo grown biofilms on rough titanium surfaces. Quintessenz Int $\underline{40}, 80-88$

Sennhenn-Kirchner S, Schwarz P, Schliephake H, Konietschke F, Brunner E, Borg-von Zepelin M (2009b): Decontamination efficacy of erbium:yttrium-aluminium-garnet and diode laser light on oral Candida albicans isolates of a 5-day in vitro biofilm model. Lasers Med Sci $\underline{24}, 313-320$

Shapiro S, Giertsen E, Guggenheim B (2002): An in vitro oral biofilm model for comparing the efficacy of antimicrobial mouthrinses. Caries Res $\underline{36}$, 93-100

Shetty K (2006): The role of salivary cytokines in the etiology and progression of periodontal disease. Gen Dent 54, 140-143; quiz 144

Shibli JA, Martins MC, Lotufo RF, Marcantonio E Jr (2003): Microbiologic and radiographic analysis of ligature-induced peri-implantitis with different dental implant surfaces. Int J Oral Maxillofac Implants $\underline{18}$, 383-390

Singh PK, Schaefer AL, Parsek MR, Moninger TO, Welsh MJ, Greenberg EP (2000): Quorum-sensing signals indicate that cystic fibrosis lungs are infected with bacterial biofilms. Nature $\underline{407}, 762-764$

Socransky SS, Haffajee AD (2002): Dental biofilms: difficult therapeutic targets. Periodontol $200028,12-55$

Socransky SS, Haffajee AD, Cugini MA, Smith C, Kent RL Jr (1998): Microbial complexes in subgingival plaque. J Clin Periodontol $\underline{25}$, 134-144

Spoering AL, Gilmore MS (2006): Quorum sensing and DNA release in bacterial biofilms. Curr Opin Microbiol $\underline{9}$, 133-137

Stewart PS (2002): Mechanisms of antibiotic resistance in bacterial biofilms. Int J Med Microbiol 292, 107-113

Sulewski JG (2000): Historical survey of laser dentistry. Dent Clin North Am 444, 717-752.

Süßmuth R, Eberspächer J, Haag R, Springer W: Biochemical-microbiological practice. Thieme Verlag, New York 1999

Suzuki N, Yoshida A, Saito T, Kawada M, Nakano Y (2004): Quantitative microbiological study of subgingival plaque by real-time PCR shows correlation between levels of Tannerella forsythensis and Fusobacterium spp. J Clin Microbiol 42, 2255-2257 
Syed SA, Loesche WJ (1972): Survival of human dental plaque flora in various transport media. Appl Microbiol 24, 638-644

Takasaki AA, Aoki A, Mizutani K, Kikuchi S, Oda S, Ishikawa I (2007): Er:YAG laser therapy for peri-implant infection: a histological study. Lasers Med Sci $\underline{22}, 143-157$

Tietz A, Frei R, Dangel M, Bolliger D, Passweg JR, Gratwohl A, Widmer AE (2005): Octenidine hydrochloride for the care of central venous catheter insertion sites in severely immunocompromised patients. Infect Control Hosp Epidemiol 26, 703-707

Tucker D, Cobb CM, Rapley JW, Killoy WJ (1996): Morphologic changes following in vitro CO2 laser treatment of calculus-ladened root surfaces. Lasers Surg Med $\underline{18}, 150-156$

van der Mei HC, White DJ, Atema-Smit J, van de Belt-Gritter E, Busscher HJ (2006): A method to study sustained antimicrobial activity of rinse and dentifrice components on biofilm viability in vivo. J Clin Periodontol $\underline{33}, 14-20$

Visuri SR, Walsh JT Jr, Wigdor HA (1996): Erbium laser ablation of dental hard tissue:

effect of water cooling. Lasers Surg Med $\underline{18}$, 294-300

Walsh JT Jr, Flotte TJ, Deutsch TF (1989): Er:YAG laser ablation of tissue: effect of pulse duration and tissue type on thermal damage. Lasers Surg Med $\underline{9}$, 314-326

Walsh JT Jr, Cummings JP (1994): Effect of the dynamic optical properties of water on midinfrared laser ablation. Lasers Surg Med 15, 295-305

Whitchurch CB, Tolker-Nielsen T, Ragas PC, Mattick JS (2002): Extracellular DNA required for bacterial biofilm formation. Science $\underline{295}, 1487$

Wilson M (1996): Susceptibility of oral bacterial biofilms to antimicrobial agents. J Med Microbiol 44 , 79-87

Wolff D, Staehle HJ, Wolff B (2010): Amplification of minute amounts of oral bacterial DNA for real-time quantitative PCR analysis. Caries Res $\underline{44}$, 498-504

Zhang L, Mah TF (2008): Involvement of a novel efflux system in biofilm-specific resistance to antibiotics. J Bacteriol 190, 4447-4452

Zumtobel M, Assadian O, Leonhard M, Stadler M, Schneider B (2009): The antimicrobial effect of Octenidine-dihydrochloride coated polymer tracheotomy tubes on Staphylococcus aureus and Pseudomonas aeruginosa colonisation. BMC Microbiol $\underline{9}, 150$ 